IGOR Ž. ŽAGAR

Four critical essays on argumentation 
digitalna knjižnica - digital library uredniški odbor • editorial board igor ž. žagar jonatan vinkler janja žmavc alenka gril marcello potocco 



\section{Four Critical Essays on Argumentation}

Igor Ž. Žagar 



\section{Contents}

9 Preface

11 Argumentation in critical discourse analysis

13 Topoi in critical discourse analysis

14 Argumentation and CDA

15 How topoi are found ...

19 ... And how topoi are used

24 Back to the foundations: Aristotle and Cicero

31 Topoi, 2000 years later

33 Toulmin: topoi as warrants

36 In place of conclusion

37 Fallacies: do we 'use' them or 'commit' them? Or: is all our life just a collection of fallacies?

37 J. L. Austin as rhetorician

41 C. L. Hamblin's pragmatic perspective

44 Troubles with fallacies

50 Superabundance and redundance of fallacies

54 Replacing analysis with fixed lists of fallacies: the case of CDA

65 Conclusion: back to Austin and Hamblin 


\section{Question and doubts about visual argumentation}

69 Is there anything like visual argumentation?

A short exercise in methodical doubt

70 Twenty years in a short overview

74 Framing in visual argumentation

82 Rhizome and superdiversity in visual argumentation - a commentary

85 The reasoning is the seeing. Is it?

95 Thousands of words and a single picture

98 In place of conclusion

101 Perception, inference, and understanding in visual argumentation (and beyond)

102 'Pure' and 'infected' visuals, eye tracking and pilot questionnaire

107 Calibrating the questionnaire: not too much and not too little

109 About the smoking fish

112 About UVA for women

115 About Marat'a death

121 In place of conclusion: A perceptual-cognitive grid

126 Subjective (synchronic) view

127 Enchronic view

\section{Summary}

143 References

147 Index 


\section{Preface}

This book is divided into two thematic parts: the first one, Argumentation in critical discourse analysis, is dedicated to the use of topoi and fallacies in the Critical Discourse Analysis (more precisely in its Discourse Historical Approach branch), while the second part, Questions and doubts about visual argumentation, tackles some important methodological problems pertinent to the field of visual argumentation.

Argumentation in critical discourse analysis combines two thematically connected papers (modified and revised): 'Topoi in critical discourse analysis' was first presented as a key-note address at the 2009 conference on Political Linguistics in Lodz, Poland, while the second one, 'Fallacies: Do we "use" them or "commit" them?', was a follow-up of the Lodz paper, presented at the Ontario Society for the Study of Argumentation conference at the University of Windsor, Canada, in 2011.

Second part, Questions and doubts about visual argumentation, consists of two narrowly connected papers (modified and revised): 'Is there anything like visual argumentation? A short exercise in methodical doubt', first presented at the $1^{\text {st }}$ European Conference on Argumentation in Lisbon in 2015, while the second one, 'Perception, inference and understanding in visual argumentation (and beyond)' is its follow-up, presented at the $2^{\text {nd }}$ European Conference on Argumentation in Fribourg, Switzerland, in 2017. 



\section{Argumentation in critical discourse analysis}





\section{Topoi in critical discourse analysis ${ }^{1}$}

The Discourse-Historical Approach (DHA), pioneered by Ruth Wodak (see Wodak, de Cillia, Reisigl, Liebhart 1999; Wodak, van Dijk 2000; Wodak, Chilton 2005; Wodak, Meyer 2006; Wodak 2009), is one of the major branches of critical discourse analysis (CDA). In its own (programmatic) view, it embraces at least three interconnected aspects:

1. 'Text or discourse immanent critique' aims at discovering internal or discourse-internal structures.

2. The 'socio-diagnostic critique' is concerned with the demystifying exposure of the possibly persuasive or 'manipulative' character of discursive practices.

3. Prognostic critique contributes to the transformation and improvement of communication. (Wodak 2006: 65)

CDA, in Wodak's view,

is not concerned with evaluating what is 'right' or 'wrong'. CDA [...] should try to make choices at each point in the research itself, and should make these choices transparent. ${ }^{2}$ It should also justify theoretically why certain interpretations of discursive events seem more valid than others.

1 First version of this chapter was published in Igor Ž. Žagar, 'Topoi in Critical Discourse Analysis,' Lodz Papers in Pragmatics 6, no. 1 (2010): 3-27.

2 All emphases (italics) in the chapter are mine (IŽŽ). 
One of the methodical ways for critical discourse analysts to minimize the risk of being biased is to follow the principle of triangulation. Thus one of the most salient distinguishing features of the DHA is its endeavour to work with different approaches, multimethodically and on the basis of a variety of empirical data as well as background information. (Wodak ibid.)

One of the approaches DHA is using in its principle of triangulation is argumentation theory, more specifically the theory of topoi. In this article, I will be concerned with the following questions: how and in what way are topoi and, consequentially, argumentation theory, used in DHA as one of the most influential schools of CDA? Other approaches (e.g. Fairclough $(1995,2000,2003)$ or van Leeuwen (2004, 2008; van Leeuwen, Kress 2006)) do not use topoi at all. Does such a use actually minimize the risk of being biased, and, consequentually, does such a use of topoi in fact implement the principle of triangulation?

\section{Argumentation and CDA}

Within argumentation theory, Wodak continues (ibid.: 74),

'topoi' or 'loci' can be described as parts of argumentation which belong to the obligatory, either explicit or inferable premises. They are the content-related warrants or 'conclusion rules' which connect the argument or arguments with the conclusion, the claim. As such, they justify the transition from the argument or arguments to the conclusion. (Kienpointner, 1992: 194)

We can find the very same definition ${ }^{3}$ in The Discursive Construction of National Identity (Wodak, de Cillia, Reisigl, Liebhart 1999: 34), in Discourse and Discrimination (Reisigl, Wodak 2001: 75), in The Discourse of Politics in Action (Wodak 2009: 42), in Michal Krzyzanowski's chapter 'On the 'Europeanisation' of Identity Constructions in Polish Political Discourse after 1989', published in Discourse and Transformation in Central and Eastern Europe (Galasinska and Krzyzanowski 2009: 102), and in John E. Richardson's paper (co-authored with R. Wodak) 'The Impact of Visual Racism: Visual arguments in political leaflets of Austrian and British farright parties' (manuscript: 3), presented at the 2008 Venice Argumentation 
Conference. ${ }^{4}$ In addition to the above definition, Richardson (2004: 230) talks of topoi 'as reservoirs of generalised key ideas from which specific statements or arguments can be generated'.

Surprisingly, both definitions take the concept of topos/topoi as something self-evident, generally known and widely used, as, for example, bread, table, engine, to write, to clean up, and many other everyday obviousnesses. Nevertheless, topos/topoi is one of the most controversial, even unclear, concepts in the history of rhetoric and argumentation as I will illustrate below..

Also, one could wonder about the purpose and the (ontological) status of the two definitions: are topo $i$ 'content-related warrants' or are they 'generalised key ideas'? Because warrants are much more than just 'key ideas'; they demand much more to be able to secure the transition from an argument to a conclusion than just being 'generalised ideas', namely, a certain structure, or mechanism, in the form of an instruction or a rule. While ideas, or generalised ideas, lack at least a kind of mechanism the warrants are supposed to possess in order to be able to connect the argument to the conclusion.

Let us proceed step by step.

\section{How topoi are found ...}

In the above-mentioned publications, we get to see the lists of the(se) topoi. In the chapter 'The Discourse-Historical Approach' (Wodak 2006: 74), we read that 'the analyses of typical content-related argument schemes can be carried out against the background of the list of topoi though incomplete and not always disjunctive', as given in the following table:

1. Usefulness, advantage

2. Uselessness, disadvantage

3. Definition, name-interpretation

4. Danger and threat

5. Humanitarianism

6. Justice

4 The paper was published in Critical Discourse Studies 6, no. 4 (2009), under the title 'Recontextualising fascist ideologies of the past: right-wing discourses on employment and nativism in Austria and the United Kingdom'. In this paper, I am referring to the manuscript version. 
7. Responsibility

8. Burdening, weighting

9. Finances

10. Reality

11. Numbers

12. Law and right

13. History

14. Culture

15. Abuse

In Richardson (2008, p. 4), we have exactly the same list of topoi, but this time they are characterised as 'the most common topoi which are used when writing or talking about 'others', specifically about migrants.

In The Discourse of Politics in Action (Wodak 2009: 44), we get the following list of 'the most common topoi which are used when negotiating specific agenda in meetings, or trying to convince an audience of one's interests, visions or positions'. They include:

1. Topos of Burdening

2. Topos of Reality

3. Topos of Numbers

4. Topos of History

5. Topos of Authority

6. Topos of Threat

7. Topos of Definition

8. Topos of Justice

9. Topos of Urgency

In The Discourse of Politics in Action, we can also find additional topoi: topos of challenge, topos of the actual costs of enlargement of the EU, topos of belonging, and topos of 'constructing a hero'. Here the analyses of typical content-related argument schemes as found in discourse are not just carried out 'against the background of the list of topoi', but some parts of discourse 'gain the status of topoi' (topos of the actual costs ...). Thus, as far as the status of topoi is concerned, we seem to have got a bit further: there is not just a list of topoi that can serve as the background for the analysis; 
more topoi can be added to the list. And, presumably, if topoi can be added to the list, they can probably also be deleted from the list. Unfortunately, in the publications I have listed, we get no epistemological or methodological criteria as to how this is done, i.e. why, when, and how certain topoi can be added to the list, or why, when, and how they can be taken off the list.' It also remains a mistery how some parts of discourse (can) gain the status of topoi, or what exactly is meant by some parts of discourse gaining the status of topoi.

The most puzzling list of topoi can be found in Krzyzanowski (2009: 103). In this article we get the 'list of the topoi identified in the respective corpora' (the national and the European ones-IŽŽ). They are: ${ }^{6}$

Topoi in the national corpus

1. Topos of national uniqueness

2. Topos of definition of the national role

3. Topos of national history

4. Topos of East and West

5. Topos of past and future

6. Modernisation topos

7. Topos of the EU as a national necessity

8. Topos of the EU as a national test

9. Topos of the organic work

10. Topos of Polish pragmatism and Euro-realism.

Topoi in the European corpus

Topos of diversity in Europe

Topos of European history and heritage

Topos of European values

Topos of European unity

Topos of Europe of various speeds

5 Let alone the fact that there is no theoretical explanation why there should be lists at all, or how we should proceed when checking the possible argument schemes 'against the background of the list of topoi'.

6 These lists may look like recipes, as Wodak once commented, but this is the way the authors present them. 
Topos of core and periphery

Topos of European and national identity

Topos of Europe as a Future Orientation

Modernatisation topos

Topos of the Polish national mission in the European Union

Topos of joining the EU at any cost

Topos of preferential treatment.

How these topoi were 'identified', and what makes them 'the topoi'and not just simply 'topoi'-, we do not get to know; Krzyzanowski just lists them as such. Is there another list that helped them to be identified? If so, it must be very different from the lists we have just mentioned. Maybe there are several different lists? If so, who constructs them? When, where, and, especially, for what purpose and how? Is there a kind of a grid, conceptual or in some other way epistemological and/or methodological, that helps us/ them to do that? If so, where can we find this grid? How was it conceptually constructed? And if there is no such grid, how do we get all these different lists of topoi? By casuistry, intuition, rule of thumb? Are they universal, just general, or maybe only contingent?

Judging from the lists we have just seen, there are no rules or criteria; the only methodological precept seems to be: 'anything goes'! If so, why do they (i.e. CDA) need triangulation? And what happened to the principle stipulating that CDA 'should try to make choices at each point in the research itself, and should make these choices transparent?'

We have seen identical and similar bundles of topoi for different purposes or occasions; we have seen different bundles of topoi for identical and similar purposes or occasions; we have seen different bundles of topoi for different occasion; and we have seen pretty exotic bundles of topoi for pretty particular and singular purposes. This leads us to a key question: can

7 It is interesting to observe that in his plenary talk at the CADAAD 2008 conference (University of Hertfordshire), Teun van Dijk emphasized: 'CDA is not a method, CDA is not a theory ... CDA is like a movement, a movement of critical scholars.' But then he added: 'And they will use all the methods we know in various domains and schools of discourse analysis (see: http://www.viddler.com/explore/cadaad/videos/4/; 5th and 6th minute).' 'Anything goes' should therefore be interpreted and understood in a much more narrow sense, namely, as 'any method goes'. In other words, if a particular scholar or a particular school is using a certain method, the rules and principles of this chosen method should be followed. 
anything be or become a topos (at least within DHA)? And, consequentially, what actually (i.e. historically) is a topos?

Before we try to answer these questions, let us have a look at how the above-mentioned topoi are used in the respective works, listed at the beginning of the book.

\section{... And how topoi are used}

In Discourse and Discrimination (Reisigl, Wodak 2001: 75), as well as in 'The Discourse-Historical Approach' (Wodak 2006: 74), we can find, among others, the following identical definition of the topos of advantage:

The topos of advantage or usefulness can be paraphrased by means of the following conditional: if an action under a specific relevant point of view will be useful, then one should perform it [...] To this topos belong different subtypes, for example the topos of 'pro bono publico' ('to the advantage of all'), the topos of 'pro bono nobis' ('to the advantage of us'), and the topos of 'pro bono eorum' ('to the advantage of them').

And then the definition is illustrated by the following example:

In a decision of the Viennese municipal authorities [...], the refusal of a residence permit is set out as follows:

Because of the private and family situation of the claimant, the refusal of the application at issue represents quite an intrusion into her private and family life. The public interest, which is against the residence permit, is to be valued more strongly than the contrasting private and family interests of the claimant. Thus, it had to be decided according to the judgement.

If a topos is supposed to connect an argument with a conclusion, as all the relevant DHA publications claim, one would expect that at least a minimal reconstruction would follow, namely, what is the argument in the quoted fragment? What is the conclusion in the quoted fragment? How is the above-mentioned topos connecting the two, and what is the argumentative analysis of the quoted fragment? Unfortunately, all these elements are missing; the definition and the quoted fragment are all that there is of the supposed argumentative analysis.

And this is the basic pattern of functioning for most of these works. At the beginning, there would be a list of topoi and a short description for 
each of them (some of the quoted works would avoid even this step): first, a conditional paraphrase of a particular topos would be given, followed by a short discourse fragment (usually from the media) illustrating this conditional paraphrase (in Discourse and Discrimination, pp. 75-80), but without any explicit reconstruction of possible arguments, conclusions, or topoi connecting the two in the chosen fragment. After this short theorethical (or 'theorethical') introduction, different topoi would just be referred to by names throughout the book, as if everything has already been explained in these few introductory pages.

It is interesting to observe how the functioning of these topoi is described (especially in Discourse \& Discrimination, which is the most thorough in this respect): topoi are mostly 'employed' (p. 75), or 'found' (p. 76), when speaking about their supposed application in different texts, but also 'traced back (to the conclusion rule)' (p. 76) or 'based on (conditionals)' (p. 77), when speaking about their possible frames of definitions. How topoi are 'based on (conditionals)', or 'traced back (to the conclusion rule)', and how these operations relate to argument(s) and conclusion(s) that topoi are supposed to connect is not explained.

Consider another interesting example, this time from Discourse of Politics in Action (Wodak 2009: 97). In subsection 4.1, Wodak examines the discursive construction of MEP's identities, especially whether they view themselves as Europeans or not. At the end of the subsection, she summarizes:

Among MEPs ${ }^{8}$ no one cluster characteristics is particularly prominent; however, most MEPs mention that member states share a certain cultural, historical and linguistic richness that binds them together, despite differences in specifics; this topos of diversity occurs in most official speeches (Weiss, 2002). Among the predicational strategies employed by the interviewees, we see repeated reference to a common culture and past (topos of history, i.e. shared cultural, historical and linguistic traditions; similar social models) and a common present and future (i.e. European social model; 'added value' of being united; a way for the future). Morover, if identity is to some extent 'based on the formation of sameness and difference' (topos of difference; strategy of establishing uniqueness; Wodak et al., 1993: 36-42), we see this in the 
frequent referral to Europe, especially in terms of its social mod$\mathrm{el}(\mathrm{s})$, as not the US or Asia (most prominently Japan).

In trying to reconstruct the 'topological' part of this analysis, three topoi are mentioned: topos of diversity, topos of history, and topos of difference. Surprisingly, only the topos of history is listed and (sparingly) explained in the list of topoi on p. 44: 'Topos of History-because history teaches that specific actions have specific consequences, one should perform or omit a specific action in a specific situation.' The absence of the other two should probably be accounted for with the following explanation on pages $42-43$ :

These topoi have so far been investigated in a number of studies on election campaigns (Pelinka, Wodak 2002), on parliamentary debates (Wodak, van Dijk 200o), on policy papers (Reisigl, Wodak 2000), on 'voices of migrants' (Krzyzanowski, Wodak 2008), on visual argumentation in election posters and slogans (Richardson, Wodak, forthcoming ${ }^{[9]}$ ), and on media reporting (Baker et al. 2008).

But in the study 'on visual argumentation in election posters and slogans', for example, the(se) topoi are not discussed at all; they are presented as a fixed list of names of topoi, without any explanation of their functioning, while the authors (Richardson and Wodak) make occasional reference to their names - not to the mechanism of their functioning! - just as Wodak does in the above example from The Discourse of Politics in Action.

Therefore, if a topos is to serve the purpose of connecting an argument with a conclusion, as the respective works emphatically repeat, one would expect at least a minimal reconstruction - but there is none. What we have could be described as referring to topoi or evoking them or simply mentioning them, which mostly seems to serve the purpose of legitimating the (already) existing discourse and/or text analysis, but gives little analyticalor theorethical-added value in terms of argumentation analysis.

When I speak of reconstruction, what I have in mind is at least a minimal syllogistic or enthymemetic structure of the following type (as an example, I am using another topic from The Discourse of Politics in Action

9 A version of this paper later appeared under the title 'The Impact of Visual Racism: Visual Arguments in Political Leaflets of Austrian and British Far-Right Parties' (Richardson, Wodak 2009). 
(Wodak 2009: 132-142), namely the problem of EU enlargement, as discussed among MEPs):

(1) If a specific action costs too much money, one should perform actions that diminish the costs. (Topos connecting argument with conclusion $)^{10}$

(2) EU enlargement costs too much money. (Argument)

(3) EU enlargment should be stopped/slowed down ... (Conclusion)

A real case in point of such an obsessive hunt for topoi is the analysis we find in Krzyzanowski (2009: 104). First, he gives an example from one of his corpora, then he provides an analysis:

Example:

As General de Gaulle said, 'one's geography cannot be changed and one can only change one's geopolitics'. Two dictators, Hitler and Stalin, changed our geography. Yet, with help of democratic institutions of the West and also thanks to a democratic rebirth in the East, we have been changing our geopolitics on our own in the recent years. Our current endeavours to join NATO and the European Union, our efforts to create new shapes of the regional politics, shall be seen as crucial, yet only as fragments of construction of a new, just and solid-based European order (PS-13: 2).

Analysis:

The fact that it is the national and not any other form of history which is eventually invoked in discourse constitutes an attempt typical of the constructions of national identities and identifications. In turn, the topos of East and West emphasises another strictly national aspect of the first corpus in question. It includes a set of elements of pre-1989 political language which very strongly emphasised the differences that existed between Europe's East and West and which reinforced the divisions introduced by the post-Second World War geopolitical order. Accordingly, this topos seeks [!] a unique placement of Poland above the divisions of East and West, and thus (heading back [!] into the topos of national uniqueness) reinforces Poland's attractiveness vis-a-vis the 
European Union: it argues [!] that Poland has a unique role as a 'bridge' between Europe's East and West. Then, the topos of past and future also constructs [!] Polish national identifications, yet within the dichotomy between collective 'scope of experience' and 'horizon of expectations' (Koselleck, 1989). While this topos is used to emphasize that the Polish past might have been troubled and negative [...], it insists [!] that the Polish 'European' future will be almost entirely positive and peaceful.

Unlike the previously elaborated [sic!] topoi, the topos of modernisation clearly stands out and reaches beyond [!] the constructions of national identification. It focuses [!] mostly on presenting the European Union as carrying some unique modernising force which would help reform Polish state and society. The topos of modernisation is therefore frequently tied to the topos of the $E U$ as a national necessity and to the topos of the EU as a national test of which both construct the 'power' of the Union over Poland in a similar way. By implying that the Union is characterised by some unique principles and standards of social and political organisation [...], the topos of modernisation, contrary to the previous ones, constructs a very positive image of the Union to the detriment of Poland, which is portrayed in a negative way.

Surprisingly, we learn that topoi in this rather long excerpt are 'elaborated', while Krzyzanowski does not even touch on them, let alone define them or give a possible pattern of their functionning (as Reisigl and Wodak do in the first part of Discourse and Discrimination). In his analysis, the words and phrases that are labeled topoi not only do not serve to connect the arguments and the conclusions, but act on their own: they can be arguments and/or conclusions, sometimes even both. Actually, it is rather difficult to identify what arguments and conclusions could be in this text. Even more, they are clearly and openly antropomorphized, since they 'seek', 'head back', 'argue', 'construct', 'insist', 'reach beyond' and 'focus' (if we stay with the quoted part of the article), but they hardly connect anything.

In their seminal work Traité de l'argumentation: La nouvelle rhétorique (1958/1983: 112-113) Chaim Perelman and Lucie Olbrechts-Tyteca bitterly comment on the degeneration of rhetoric in the course of history, but what we see in the above quote goes a step further: it is not just degeneration, it is pure vulgarisation and abuse of one of the most important and 
fruitful rhetorical concepts. It is therefore probably high time that we answer the crucial question: what are topoi?

\section{Back to the foundations: Aristotle and Cicero}

It is quite surprising that none of the quoted works even mention the origins of topoi, their extensive treatment in many works and the main authors of these works, namely Aristotle and Cicero. As mentioned earlier, the definition, borrowed from Kienpointner (mostly on a copy-paste basis), does not stem from their work either: it is a hybrid product, with strong input from Stephen Toulmin's work The Uses of Argument, published in 1958. All this is even more surprising because today it is almost a commonplace (a topos of its own, if I may say so) that for Aristotle a topos is a place to look for arguments (which is true), a heading or department where a number of rhetoric arguments can be easily found (which is true as well), and that those arguments are ready for use-which is a rather big misunderstanding. According to Aristotle, topoi are supposed to be of two kinds: general or common topoi, appropriate for use everywhere and anywhere, regardless of situation, and specific topoi, in their applicability limited mostly to the three genres of oratory (judicial, deliberative, and epideictic). Or, as Aristotle (Rh. 1358a31-32, 1.2.22) puts it: 'By specific topics I mean the propositions peculiar to each class of things, by universal those common to all alike.'

The Aristotelian topos (literally: 'place', 'location') is an argumentative scheme, which enables a dialectician or rhetorician to construe an argument for a given conclusion. The majority of Aristotle's interpreters see topoi as the (basic) elements for enthymemes, the rhetorical syllogisms. "The use of topoi, or loci, as the Romans have called them, can be traced back to early rhetoricians (mostly referred to as sophists) such as Protagoras or Gorgias. But while in early rhetoric topos was indeed understood as a complete pattern or formula, a ready-made argument that can be mentioned at a certain stage of speech (to produce a certain effect, or, even more important, to justify a certain conclusion) - an understanding that largely prevailed with the Renaissance as well-most of the Aristotelian topoi are general instructions allowing a conclusion of a certain form (not content), to be derived from premises of a certain form (not content).

11 An important and more than credible exception in this respect is Sara Rubinelli with her excellent and most thorough monograph on topoi, Ars Topica. The Classical Technique of Constructing Arguments from Aristotle to Cicero, Argumentation Library, Springer, 2009. 
Consider the list of common topoi, usually attributed to Aristotle: ${ }^{\mathrm{I2}}$

\begin{tabular}{lc} 
Common Topoi & Special Topoi \\
\hline Definition & Judicial \\
Genus/Species & Justice (right) \\
Division & Injustice (wrong) \\
Whole/Parts & Deliberative \\
Subject/Adjuncts & The good \\
Comparison & The unworthy \\
Similarity/Difference & The advantageous \\
Degree & The disadvantageous \\
Relationship & Ceremonial \\
Cause/Effect & Virtue (the noble) \\
Antecedent/Consequence & Vice (the base) \\
Contraries & \\
Contradictions & \\
Circumstances & \\
Possible/Impossible & \\
Past Fact/Future Fact & \\
Testimony & \\
Authorities & \\
Witnesses & \\
Maxims or Proverbs & \\
Rumors & \\
Oaths & \\
Documents & \\
Law & \\
Precedent & \\
The supernatural & \\
Notation and Conjugates & \\
\hline
\end{tabular}

If we compare them with the list of his categories from Metaphysics:

Substance

Quantity

Quality

Relation

Place

Time

Position

State

Action

Affection

12 This table is an extrapolated and reworked version of the topoi listed in Aristotle's Rhetoric B 23. It was taken from an excellent website on rhetoric, Silva Rhetoricae (http://humanities.byu.edu/rhetoric/Silva.htm). 
it becomes pretty obvious that Aristotle derived his common topics from his categories. While categories represent the most general, and basic, relations between different entities in the world, and are, therefore, metaphysical in nature, the common topics (i.e. topoi) represent the most general, and basic, relations between concepts, notions, or words representing or denoting these different entities in the world. That is why Aristotle could present them as a 'list' (though it really was not a list in the sense DHA is using the term): because they were so very general, so very basic, that they could have been used in every act of speech or writing. This is not the case with the DHA lists of topo $i$ we have been discussing above: their topoi cannot be used in just any situation, but in rather particular situations, especially the topoi 'identified' by Krzyzanowski. They could be classified not as common topoi, but more likely as specific topoi, something Aristotle called idia, which could be roughly translated as 'what is proper to...', 'what belongs to.... Also, this 'list' of Aristotle's common topoi was not there for possible or prospective authors 'to check their arguments against it'. This 'list' was there for general use, offering a stock of possible and potential common topoi for possible and potential future arguments and speeches.

\section{Some basic definitions}

Here is a short schematic and simplified overview of how Aristotle defines the mechanics and the functioning of topoi and their parts in his Topics, a work that preceded Rhetoric. We have to start with a few definitions.

Problems-what is at stake, what is being discussed-are expressed by propositions. Every proposition consists of a subject and predicate(s) that belong(s) to the subject. These predicates, usually referred to as predicables, are of four kinds: definition, genus, property and accident:

Definition is a phrase indicating the essence of something. (T. I. v. 39-40)

A genus is that which is predicated in the category of essence of several things which differ in kind. (T. I. v. 32-33)

A property is something which does not show the essence of a thing but belongs to it alone and is predicated convertibly of it. (T. I. v. 19-21)

An accident is that which is none of these things ... but still belongs to the thing. (T. I. v. 4-6) 
These are the theorethical and methodological preliminaries that lead us to topoi, not yet the topo $i$ themselves! To be able to select subject appropriate claims, premises for concrete context-dependent reasonings from the pool of potential propositions, we need organa or tools. Aristotle distinguishes four:

The means by which we shall obtain an abundance of reasonings are four in number: (1) the provision of propositions, (2) the ability to distinguish in how many senses a particular expression is used,

(3) the discovery of differences and (4) the investigation of similarities. (T. I xiii. 21-26)

Strictly speaking, we are not yet dealing with topoi here as well, though very often and in many interpretation $\mathrm{s}^{\mathrm{13}}$ the four organa, as well as the four predicables, are considered to be topoi (and in the case of predicables, maybe even the topoi).

Another complicating moment in this respect may be that Aristotle described topoi as 'empty places' where concrete arguments, for different purposes, can be found. And even if this sounds paradoxical, it is quite logical: if those places were not empty, allowing for each concrete matter to be moulded in them, but already filled up, they just would not be common anymore, and we would not be able to use them for each and every subject matter, but just in that one described and defined with the concrete content of a particular premise.

Aristotle had ambiguous characterisations of topos-and he used many, not always very consistent with one another. Consider the following (Rhet. 1403a17-18, 2.26.1): 'I call the same thing element and topos; for an element or topos is a heading under which many enthymemes fall.' It is important to emphasize that by 'element' Aristotle does not mean a proper part of the enthymeme, but a general form under which many concrete enthymemes of the same type can be subsumed. According to this definition, topos is a general argumentative form or pattern, and concrete arguments are instantiations of this general form. Or as Auctor ad Herennium puts it (3-29.15ss): loci are the background and concrete arguments are imagines (images) on that background.

In the Topics, Aristotle actually established a very complex typology of topoi with hundreds of particular topoi: about 300 in the Topics, but just

13 See Rubinelli 2009: 8-14. 
29 in the Rhetoric. ${ }^{14}$ Two of the most important sub-types of his typology, sub-types that were widely used throughout history, are:

(a) topoi concerning opposites, and

(b) topoi concerning semantic relationships of 'more and less'.

For an understanding of how topoi are supposed to function, here are two notorious examples:

Ad $a$

If action $Y$ is desirable in relation to object $X$, the contrary action $Y^{\prime}$ should be disapproved of in relation to the same object $X$.

This is a topos, as Aristotle would have formulated it. And what follows is its application to a concrete subject matter that can serve as a general premise in an enthymeme (topos cannot):

'If it is desirable to act in favor of one's friends, it should be disapproved of to act against one's friends.'

Ad $b$

If a predicate can be ascribed to an object $X$ more likely than to an object $Y$, and the predicate is truly ascribed to $Y$, then the predicate can even more likely be ascribed to $X$.

Once more, this is a topos. And what follows is its application to a concrete subject matter that can serve as a general premise in an enthymeme (topos cannot):

'Whoever beats his father, even more likely beats his neighbour.'

We should now be able to distinguish two ways in which Aristotle frames topoi in his Topics. Even more, topoi in the Topics would usually be twofold; they would consist of an instruction, and on the basis of this instruction, a rule would be formulated. For example:

(1) Instructions (precepts): 'Check whether C is D.'

(2) Rules (laws): 'If C is D, then B will be A.'

Instructions would usually check the relations between the four predicables (definition, genus, property, accident), and, subsequently, a kind of

14 The 29 topoi in the Rhetoric cannot all be found among the 300 topoi from the Topics. There is a long-standing debate about where these 29 topoi come from, and how the list was composed. Rubinelli (2009: 71-73) suggests that their more or less 'universal applicability' may be the criterion. 
rule would be formulated that could-applied to a certain subject matterserve as a general premise of an enthymeme.

What is especially important for our discussion here-that is, the use of topoi in critical discourse analysis-is that though they were primarily meant to be tools for finding arguments, topoi can also be used for testing given arguments. This seems to be a much more critical and productive procedure than testing hypothetical arguments 'against the background of the list of topoi'. But in order to do that, DHA analysts should:

(1) clearly and unequivocally identify arguments and conclusions in a given discourse fragment,

(2) show how possible topoi might relate to these arguments.

In the DHA works quoted in the first part of this article, neither of the two steps was taken.

We have seen how topoi were treated in the Topics. But when we turn from the Topics to the later Rhetoric, we are faced with the problem that the use and meaning of topos in Aristotle's Rhetoric is much more heterogeneous than in the Topics. Beside the topoi complying perfectly with the description(s) given in the Topics, there is an important group of topoi in the Rhetoric, which contain instructions for arguments not of a certain form, but with a certain concrete predicate, for example, that something is good, honorable, just, etc.

In Rhetoric I.2, 1358a2-35, Aristotle distinguishes between general/ common topoi on the one hand and specific topoi on the other. In that same chapter, he explains the sense of 'specific' by saying that some things are specific to physics, others to ethics, etc. But from chapter I.3 on, he makes us think that 'specific' refers to the different species of rhetoric, so that some topo $i$ are specific to deliberative, others to epideictic, and still others to judicial speech. While he is inclined to call the general or common topoi simply topoi, he uses several names for the specific topoi-idiai protaseis, eidê, idioi topoi. Therefore, it may be tempting to call the specific topoi 'material' and the common topoi 'formal', as it happened several times in the history of rhetoric. But in doing so, we may overlook that some of the common topoi (in chapters II.23-24) are not all based on those formal categories on which the topoi of the Topics rely (the four predicables). Most of them are 'common' only in the sense that they are not specific to one single species of speech, but to all of them. Aristotle calls those koina, 'what is general, 
common'. Some of them offer strategic advice, for example, to turn what has been said against oneself upon the one who said it.

With the Romans, topoi became loci, and Cicero literally defines them as 'the home of all proofs' (De or. 2.166.2), 'pigeonholes in which arguments are stored' (Part. Or. 5.7-10), or simply 'storehouses of arguments' (Part. Or. 109.5-6). Also, their number was reduced from 300 in Topics or 29 in Rhetoric to up to 19 (depending on how we count them).

Although Cicero's list correlates pretty much, though not completely, with Aristotle's list from the Rhetoric B 23, there is a difference in use: Cicero's list is considered to be a list of concepts that may trigger an associative process rather than a collection of implicit rules and precepts reducible to rules, as the topoi in Aristotle's Topics are. In other words, Cicero's loci mostly function as subject matter indicators and loci communes. ${ }^{15} \mathrm{Or}$, in Rubinelli's words (2009: 107):

A locus communis is a ready-made argument that, as Cicero correctly remarks, may be transferable [...] to several similar cases. Thus, the adjective communis refers precisely to the extensive applicability of these kind of arguments; however, it is not to be equated to the extensive applicability of the Aristotelian topoi [...]. The latter are 'subjectless', while the former work on a much more specific level: they are effective mainly in juridical, deliberative and epideictic contexts.

But being ready-made, does not mean that they prove anything specific about particular cases that are being examined, or that they add any factual information to it. As Rubinelli puts it (2009: 148):

[...] a locus communis is a ready-made argument. It does not guide the construction of an argument, but it can be transferable to several similar cases and has the main function of putting the audience in a favourable frame of mind.

15 This is probably due to the fact that Cicero was selecting and using loci in conjunction with the so-called stasis theory, or issue theory. What is stasis theory? Briefly and to put it simply, the orator has to decide what is at stake (why he has to talk and what he has to talk about): (1) whether something happened or not; (2) what is it that happened; (3) what is the nature/quality of what happened; (4) what is the appropriate place/authority to discuss what has happened. And Cicero's loci 'followed' this repartition. 
Which brings us a bit closer to how topoi might be used in DHA. In the works quoted in this paper, the authors never construct or reconstruct arguments from the discourse fragments they analyse-despite the fact that they are repeatedly defining topoi as warrants connecting arguments with conclusions; they just hint at them with short glosses. And since there is no reconstruction of arguments from concrete discourse fragments under analysis, hinting at certain topoi, referring to them or simply just mentioning them, can only serve the purpose described by Rubinelli as 'putting the audience in a favourable frame of mind.' 'Favourable frame of mind' in our case - the use of topoi in DHA - would mean directing a reader's attention to a 'commonly known or discussed' topic, without explicitly phrasing or reconstructing possible arguments and conclusions. Thus, the reader can never really know what exactly the author had in mind and what exactly he/she wanted to say (in terms of (possible) arguments and (possible) conclusions).

\section{Topoi, 2000 years later}

Let us jump from the 'old' rhetoric to the 'new' rhetoric now, skipping more than 2000 years of 'degeneration of rhetoric', as Chaim Perelman puts it in his (and L Olbrechts-Tyteca's) influential work Traité de l'argumentation: La nouvelle rhétorique.

Topoi are characterised by their extreme generality, says Perelman (1958/1983: 112-113), which makes them usable in every situation. It is the degeneration of rhetoric and the lack of interest for the study of places that has led to these unexpected consequences where 'oratory developments', as he ironically calls them, against fortune, sensuality, laziness, etc., which school exercises were repeating ad nauseam, became qualified as commonplaces (loci, topoi), despite their extremely particular character. By commonplaces we more and more understand, Perelman continues, what Giambattista Vico called 'oratory places', in order to distinguish them from the places treated in Aristotle's Topics. Nowadays, commonplaces are characterised by banality which does not exclude extreme specificity and particularity. These places are nothing more than Aristotelian commonplaces applied to particular subjects, concludes Perelman. That is why there is a tendency to forget that commonplaces form an indispensable arsenal in which everybody who wants to persuade others should find what he is looking for.

And this is exactly what seems to be happening to the DHA approach to topoi as well. Even more, the works quoted in the first part of the chapter 
give the impression that DHA is not using the Aristotelian or Ciceronian topoi, but the so-called 'literary topoi', conceptualized by Ernst Robert Curtius in his Europaeische Literatur und Lateinisches Mittelalter (1990: 62-105, English translation). What is a literary topos? In a nutshell, already oral histories passed down from pre-historic societies contain literary aspects, characters, or settings which appear again and again in stories from ancient civilisations, religious texts, art, and even more modern stories. These recurrent and repetetive motifs or leitmotifs would be labeled literary topoi. 'They are intelectual themes, suitable for development and modification at the orator's pleasure', argues Curtius (1990: 70). And topoi is one of the expressions Wodak is using as synonyms for leitmotifs (2009: 119):

In the analysis of text examples which were recorded and transcribed I will first focus on the leitmotifs, which manifest themselves in various ways: as topoi, as justification and legitimation strategies, as rules which structure conversation and talk, or as recurring lexical items ...

This description and definition may well be dismissed as very general or superficial, but in The Discursive Construction of National identi$t y$, where 49 topoi are listed (without any pattern of functioning ${ }^{16}$ ), we can also find (p. 38-39) locus amoenus (topos of idyllic place) and locus terribilis (topos of terrible place) typical of literary topoi as described by Curtius.

For the New Rhetoric (Perelman, Olbrechts-Tyteca 1958/1983: 113) topoi are not defined as places that hide arguments, but as very general premises that help us build values and hierarchies, something Perelman, whose background was jurisprudence, was especially concerned about. But, in the opinion of some argumentation theorists, The New Rhetoric has three main deficiencies:

(1) Perelman and Olbrechts-Tyteca do not develop sufficient criteria for the distinction between sound and fallacious arguments.

(2) They rarely provide explicit reconstructions of arguments, despite their clearly expressed intention to reconstruct their internal structure.

16 Instead, we can read (p. 34): 'In place of a more detailed discussion, we have provided a condensed overview in the form of tables, which list the macro-strategies and the argumentative topoi, or formulae, and several related (but not disjunctively related) forms of realization with which they correlate in data.' 
(3) They do not develop systematic criteria for the demarcation of argument schemes.

In other words, Perelman left topoi on a somewhat descriptive level, and exactly the same objections could be raised for the Discourse-Historical Approach within CDA. ${ }^{17}$ But, in contrast to DHA, which is using topoi superficially, Perelman has made some very interesting and important observations regarding the role and the use of topoi in contemporary societies. He argued that (Perelman, Olbrechts-Tyteca ibid.: 114) even if it is the general places that mostly attract our attention, there is an undeniable interest in examining the most particular places that are dominant in different societies and allow us to characterize them. On the other hand, even when we are dealing with very general places, it is remarkable that for every place we can find an opposite place: to the superiority of lasting, for example, which is a classic place, we could oppose the place of precarious, of something that only lasts a moment, which is a romantic place.

And this repartition gives us the possibility to characterize societies, not only in relation to their preference of certain values, but also according to the intensity of adherence to one or another member of the antithetic couple.

This sounds like a good research agenda for DHA, as far as its interest in argumentation is concerned: to find out what views and values are dominant in different societies, and characterize these societies by reconstructing the topoi that underlie their discourses. But in order to be able to implement such an agenda-an agenda that is actually very close to DHA's own agenda-DHA should dismiss the list of prefabricated topoi that facilitates and legitimizes its argumentative endeavor somehow beforehand (i.e. the topoi are already listed, we just have to check our findings against the background of this list of topoi), and start digging for the topoi in concrete texts and discourses. How can DHA achieve that?

\section{Toulmin: topoi as warrants}

Curiously enough, the same year that Perelman and Olbrechts-Tyteca published their New Rhetoric, Stephen Toulmin published his Uses of Argument, probably the most detailed study of how topoi work. I say 'curiously enough' because he does not use the terms topos or topoi, but the somewhat judicial term 'warrant'. The reason for that seems obvious: he is trying to cover

17 It should be emphasized, of course, that DHA is not an argumentation theory per se, it is just using argumentation (or some parts of it). 
different 'fields of argument', and not all fields of argument, according to him, use topoi as their argumentative principles or bases of their argumentation. According to Toulmin (1958/1995: 94-107), if we have an utterance of the form, 'If D then C'-where D stands for data or evidence, and C for claim or conclusion - such a warrant would act as a bridge and authorize the step from D to C, which also explains in more detail where Manfred Kienpointner's definition of topos draws from: mostly from Toulmin. But then a warrant may have a limited applicability, so Toulmin introduces qualifiers $\mathrm{Q}$, indicating the strength conferred by the warrant, and conditions of rebuttal (or Reservation) $\mathrm{R}$, indicating circumstances in which the general authority of the warrant would have to be set aside. And finally, in case the warrant is challenged in any way, we need some backing as well. His diagram of argumentation looks like this:

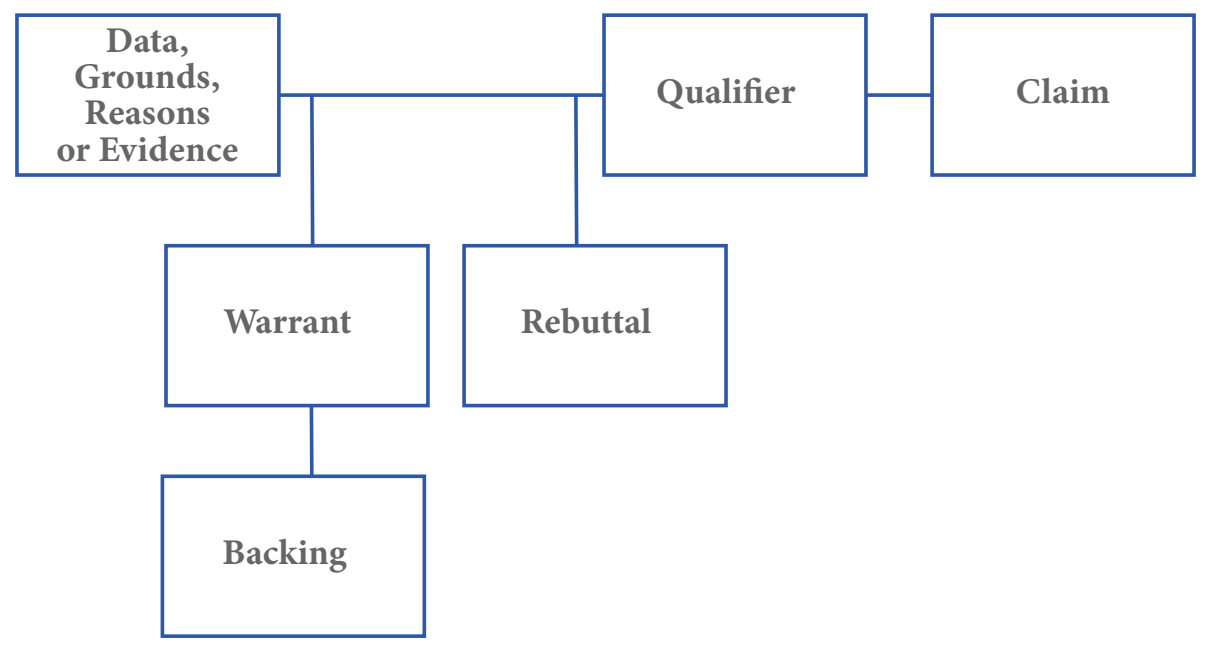

It is worth noting that in Toulmin's diagram, we are dealing with a kind of 'surface' and 'deep' structure: while data and claim stay 'on the surface', as they do in everyday communication, the warrant is-presumably because of its generality-'under the surface' (like the topos in enthymemes), and usually comes 'above the surface' only when we try to reconstruct it. And how do we do that, how do we reconstruct a warrant?

What is attractive and useful about Toulmin's theory is the fact that he is offering a kind of a guided tour to the center of topoi in six steps, not just in three (as in enthymemes). All he asks is that you identify the claim or the standpoint of the text or discourse you are researching, and then he provides a set of five questions that lead you through the process. 
If we revisit our semi-hypothetical example with the topos of actual costs of enlargement:

(1) If a specific action costs too much money, one should perform actions that diminish the costs.

(2) EU enlargement costs too much money.

(3) EU enlargment should be stopped/slowed down ... (Wodak 2009: 132-142)

and expand it into the Toulmin model, we could get the following:

Claim: EU enlargement should be stopped/slowed down ...

What have you got to go on?

Datum: EU enlargement costs too much money.

How do you get there?

Warrant: If a specific action costs too much money, one should perform actions that diminish the costs.

Is that always the case?

Rebuttal: No, but it generally/usually/very often is. Unless there are other reasons/arguments that are stronger/ more important ... In that case the warrant does not apply.

Then you cannot be so definite in your claim?

Qualifier: True: it is only usually... so.

$$
\begin{array}{r}
\text { But then, what makes } \\
\text { you think at all that if } \\
\text { a specific action costs } \\
\text { too much money one } \\
\text { should perform } \\
\text { actions... }
\end{array}
$$

Backing: The history of the EU shows...

If the analysis (text analysis, discourse analysis) would proceed in this way $^{18}$ - applying the above scheme to concrete pieces of discourse each time 
it wants to find the underlying topoi-the lists of topoi in the background would become unimportant, useless, and obsolete. As they, actually, already are. Text mining, to borrow an expression from computational linguistics, would bring the text's or discourse's own topoi to the surface, not the prefabricated ones. Even more, Toulmin's scheme allows for possible exceptions, or rebuttals, indicating where, when, and why a certain topos does not apply. Such a reconstruction can offer a much more complex account of a discourse fragment under investigation than enthymemes or static and rigid lists of topoi.

\section{In place of conclusion}

If DHA really wants to follow the principle of triangulation, as described in the beginning of the article, to make choices at each point in the research itself, and at the same time make these choices transparent, taking all these steps in finding the topoi in concrete texts would be the only legitimate thing a credible and competent analysis should do. If DHA wants to incorporate argumentation analysis in its agenda, that is, not just references to the names of concepts within argumentation analysis. 


\section{Fallacies:}

\section{do we 'use' them or 'commit' them? Or: is all our life just a collection of fallacies?'}

In this chapter, I am looking at how fallacies are used in Discourse-Historical Approach (DHA), a branch of Critical Discourse Analysis (CDA) that uses argumentation as one of its analytical tools. In view of this goal, I propose a rhetorical reading of Austin, an Austinian interpretation of Hamblin, and a hybrid Austino-Hamblinian perspective on fallacies (or what is considered to be fallacies).

I'll be asking four questions: what are fallacies? Are there obvious and unambiguous fallacies in natural languages? Aren't we forced to commit and live (in) fallacies? And, is it methodologically acceptable to use prefabricated lists of fallacies as an analytical tool in such a dynamical enterprise as (critical) discourse analysis?

\section{J. L. Austin as rhetorician}

J. L. Austin is usually considered to be the 'father' of speech act theory, and the 'inventor' of performativity. In a very general framework this is both true, but historically and epistemologically speaking there is a narrow and intricate correlation, as well as a deep rupture between the two theories.

Performativity came about as a result of Austin's deep dissatisfaction with classical philosophical(logical) division between statements/utterances

1 First version of this chapter was published in Frank Zenker, ed., Argumentation: cognition \& community: OSSA, May 18-21, 2011 (Ontario: Ontario Society for the Study of Argumentation, University of Windsor, 2011), CD-ROM. 
that can be (and should be) either true or false (with no gradation in between), and only serve to describe the extra-linguistic reality (a division that implies another opposition between saying and doing in language and with language).

Speech acts, on the other hand, came about as a result of Austin's dissatisfaction with his own performative/constative distinction, a distinction that placed on the one side the utterances with which we can do (perform) something (and are neither true nor false) and the utterances with which we can only describe what is already there (and can be either true or false). After a careful consideration of what could be the criteria of performativity in the first part of his lectures (that later became a book), in the second part Austin comes to a conclusion that not only performatives do something (with words), but that every utterance does something (with words). 'Something' implying: not just describing reality. But between the two poles of the lectures, the performative one and the speech acts one, there is an important (I'll call it rhetorical) transitional passage that is usually overlooked, and I would like to start my humble examination of fallacies here, with this passage.

Can we be sure that stating truly is a different class of assessment from arguing soundly, advising well, judging fairly, and blaming justifiably? Do these not have something to do in complicated way with facts? [...] Facts come in as well as our knowledge or opinion about facts. (Austin 1962/1980: 142)

There are two important epistemological innovations in this paragraph:

(1) Statements (stating truly) are given the same status as all other utterances we may produce;

(2) Facts are given the same status as (our, your, their ...) knowledge of facts.

And here is Austin's rationale for this:

[...] consider also for a moment whether the question of truth or falsity is so very objective. We ask: 'Is it a fair statement?', and are the good reasons and good evidence for stating and saying so very different from the good reasons and evidence for performative acts like arguing, warning, and judging? Is the constative, then, always true or false? When a constative is confronted with the facts, we in fact appraise it in ways involving the employment 
of a vast array of terms, which overlap with those that we use in the appraisal of performatives. In real life, as opposed to the simple situations envisaged in logical theory, one cannot always answer in a simple manner whether it is true or false. (Austin ibid.: 142-43)

\section{What is true and what is false?}

Truth and falsity therefore don't have objective criteria, but depend on 'good reasons and good evidence' we have for stating something. And even then, we assess constatives employing 'a vast array of terms', which should be understood as 'not just whether they correspond to facts or not'. And Austin's conclusion concurs with Hamblin's (as we will see later): it is easy to say what is true or false in logic, it is much more complicated and less evident in everyday life and everyday language use.

Here are Austin' arguments for this 'relativization':

Suppose that we confront 'France is hexagonal' with the facts, in this case, I suppose, with France, is it true or false? Well, if you like, up to a point; of course I can see what you mean by saying that it is true for certain intents and purposes. It is good enough for a top-ranking general, perhaps, but not for a geographer. 'Naturally it is pretty rough', we should say, 'and pretty good as a pretty rough statement'. But then someone says: 'But is it true or is it false? I don't mind whether it is rough or not; of course it's rough, but it has to be true or false, it's a statement, isn't it?' How can one answer this question, whether it is true or false that France is hexagonal? It is just rough, and that is the right and final answer to the question of the relation of 'France is hexagonal' to France. It is a rough description; it is not a true or a false one. (Austin ibid.: 143)

\section{True, false or (just) rough}

Statements/utterances can therefore not just be either true or false, there is (or at least should be) a gradation between what is false and what is true, between $o$ and 1 . What we say can be more or less true, true up to a (certain) point, or more precisely: true for certain intents and purposes. As 'France is hexagonal' is a rough description, so are 'France is a country of good wines', or 'France is a cheese country', for example. But these utterances are not 
true (or false) in any logical (or absolute) sense of the term: One must have good (specific) reasons and specific (appropriately oriented) intentions for uttering them.

Which brings us to an important part of this discussion, the question of framing.

What is judged true in a schoolbook may not be so judged in a work of historical research. Consider the constative, 'Lord Raglan won the battle of Alma', remembering that Alma was a soldier's battle if ever there was one, and that Lord Raglan's orders were never transmitted to some of his subordinates. Did Lord Raglan then win the battle of Alma or did he not? Of course in some contexts, perhaps in a schoolbook, it is perfectly justifiable to say so- it is something of an exaggeration, maybe, and there would be no question of giving Raglan a medal for it. As 'France is hexagonal' is rough, so 'Lord Raglan won the battle of Alma' is exaggerated and suitable to some contexts and not to others; it would be pointless to insist on its truth or falsity. (Austin ibid.: 143-44)

\section{Truth, falsity and the context}

What we say can therefore not only be more or less true, true up to a point, or true for certain intents and purposes, it can also be true only in some contexts, but not in others. And that is not all, Austin's relativization continues:

Thirdly, let us consider the question whether it is true that all snow geese migrate to Labrador, given that perhaps one maimed one sometimes fails when migrating to get quite the whole way. Faced with such problems, many have claimed, with much justice, that utterances such as those beginning 'All...' are prescriptive definitions or advice to adopt a rule. But what rule? This idea arises partly through not understanding the reference of such statements, which is limited to the known; we cannot quite make the simple statement that the truth of statements depends on facts as distinct from knowledge of facts. Suppose that before Australia is discovered X says 'All swans are white'. If you later find a black swan in Australia, is X refuted? Is his statement false now? Not necessarily: he will take it back but he could say 'I wasn't talking about swans absolutely everywhere; for example, I was not making a statement about possible swans on Mars'. Reference depends on knowledge at the time of utterance. (Austin ibid.: 144)

If we sum up all these Austin's hedgings, we get the following: 
(1) What we say can only be more or less true (i.e. true up to a point);

(3) it can only be true for certain intents and purposes;

(4) it can only be true in some contexts, and

(5) its truth (or falsity) depends on knowledge at the time of utterance.

\section{Circumstances, audiences, purposes and intentions — not truth or falsity}

This is a real rhetorical perspective on communication (truth, logic, and philosophy) that was very often overlooked, mostly at the expense of classificatory madness that started with J. R. Searle. What Austin is proposing is that-outside logic, in the real world, in everyday communication, where we don't go around with propositions in our pockets and truth tables in our hands-the truth or falsity of what we say be replaced by right or proper things to say, in these circumstances, to this audience, for these purposes and with these intentions. Such a proposal is very Protagorean in nature and does justice to the first three canons of rhetoric, or more appropriately to the officia oratoris, placing emphasis on inventio and elocutio.

I will claim that Hamblin followed the same enterprise 15 years later with his Fallacies. These two ground breaking works follow the same pattern, run parallel, and I will (hopefully) show why.

\section{L. Hamblin's pragmatic perspective \\ Formal language vs. natural language}

(1) In real life, as opposed to the simple situations envisaged in logical theory, one cannot always answer in a simple manner whether something is true or false.

Within a formal language it is generally clear enough which arguments are formally valid; but an ordinary-language argument cannot be declared 'formally valid' or 'formally fallacious' until the language within which it is expressed is brought into relation with that of some logical system. (Hamblin 1970/2004: 193)

The message of this passage is very clear: we can speak of formal validity (which includes truth and falsity, and, consequently, fallacies) only in formal systems (but Hamblin relativizes even that by saying 'it is generally clear enough'), but not in 'natural languages'. If we want any kind of formal 
validity in natural languages, which wouldn't involve only la langue (language) in de Saussure's conceptualization, but also his la parole (speech, (everyday) communication) - we need to bring it into relation with a formal language of a formal (logical) system. This 'bringing into relation' usually means: translating the very vast vocabulary (lexicon) of ordinary language, with its extremely ramified semantics and pragmatics, into a very limited vocabulary of logic with its even more limited semantics.

And we can do so, Hamblin argues, 'only at the expense of features essential to natural language'. (Hamblin ibid.: 213)

\section{Arguments are meant to interpret, not describe 'reality'}

(2) Reference depending on knowledge at the time of utterance.

If the arguments we are discussing are arguments that John Smith produces within his own head and for his own edification, the appraisal-criteria will refer exclusively to what is known to John Smith, in doubt to John Smith, and so on. However, the paradigm case of an argument is that in which it is produced by one person to convince another.' (Hamblin ibid.: 239)

My interpretation of the above passage would be that there is no perennial and universal truth, and consequently, no perennial and universal truth-conditions or criteria. The truth is relative, but we shouldn't understand 'relative' as a trivial stereotype that everything changes and everything can be different. 'Relative' should be understood more in its etymological sense (relativus $=$ having reference or relation to; from relatus = to refer (perf. pass. part.)), as a thing (concept, thought) having a relation to or being in a relation to another thing (concept, thought). In this particular relation, the truth is seen as such and such; in some other relation, the truth may be seen differently.

\section{Arguments and acceptance: the role of the audience}

(3) Right or proper things to say in these circumstances, to this audience, for these purposes and with these intentions.

What good reasons various people may have for accepting various statements and procedures are, no doubt, themselves sometimes relevant to the worth of argument erected on them; but, if we are to draw the line anywhere, acceptance by person the argument is 
aimed at - the person for whom the argument is an argument-is the appropriate basis of a set of criteria. (Hamblin ibid.: 242)

There are no universal arguments or universal criteria for what an argument should look like to be (seen as) an argument. An argument should be adopted and/or constructed relative to the (particular) circumstances and the (particular) audience, as well as to the purposes and intentions we, as arguers, have. Consequently, there can be no universal fallacies or universal criteria for what is a fallacy in everyday communication (persuasion and argumentation).

\section{Arguments and truth-conditions? Whose truth conditions?}

(4) Argumentation/persuasion has no necessary link with truth or falsity.

We must distinguish the different possible purposes a practical argument may have. Let us suppose, first, that $A$ wishes to convince $B$ of $T$, and discovers that $B$ already accepts $S$ : $A$ can argue ' $S$, therefore $T$ ' independently of whether $S$ and $T$ are really true. Judged by B's standards, this is a good argument and, if $A$ is arguing with $B$ and has any notion at all of winning, he will have to start from something $B$ will accept. The same point applies to the inference-procedure. One of the purposes of argument, whether we like it or not, is to convince, and our criteria would be less than adequate if they had nothing to say about how well an argument may meet this purpose. (Hamblin ibid.: 241)

This is a kind of a corollary to the previous point (point 3): not only do we have to rely on arguments that are acceptable by the person the argument is aimed at, we have to use these arguments (at least as our starting points), even if we are not sure whether they are true or false, good or bad.

\section{Rational arguments or/and rational choice of arguments?}

This quote also openly exposes and emphasizes one of the facets of arguments that is too often timidly held in the shade by (some) argumentation theorists: one of the purposes of argument is to convince, not just to present a good, solid, valid 'evidence'. And in his plea for conviction, Hamblin even goes a step further, for some argumentation theorists maybe even over the edge: 
(5) Conviction, of course, may be secured by threat, water torture or hypnotism instead of by argument, and it is possible that Logic should have nothing to say about these means; but we can hardly claim that an argument is not an argument because it proceeds ex concesso, or that such arguments have no rational criteria of worth. (Hamblin ibid.: 241)

Threat, water torture or hypnotism (we could add more) would be, no doubt, judged as fallacious means of securing conviction by standard, mainstream theories of argumentation (if there is any such thing). But Hamblin's point is worth some consideration: these means of 'conviction' are nevertheless arguments, they may not be rational arguments, but there may be rational criteria for using them (in particular circumstances).

\section{Troubles with fallacies}

In this light, Hamblin's claim from the beginning of his book that there has never yet been a book on fallacies becomes more understandable: Arthur Schopenhauer's Art of Controversy is, in his opinion, too short, Jeremy Bentham's Book of Fallacies is too specialized, the medieval treatises are mostly commentaries on Aristotle, and Aristotle's Sophistical Refutations are, in Hamblin's view, 'just the ninth book of his Topics' (Hamblin ibid.: 11).

So the state of the art would be that nobody is particularly satisfied with this corner of logic, concludes Hamblin.

\section{Impossibility to classify fallacies}

And, there may be a reason for that. Even if in almost every account from Aristotle onwards we can read that a fallacious argument is one that seems to be valid, but it is not, it is rather often argued that it is impossible to classify fallacies at all (and I have just presented Hamblin's own contribution(s) to this impossibility). Hamblin himself quotes De Morgan (1847/1926: 276, in Hamblin ibid.: 13): 'There is no such thing as a classification of the ways in which men may arrive at an error: it is much to be doubted whether there ever can be.' And Joseph (1906/1916: 569, in Hamblin ibid.: 13): 'Truth may have its norms, but error is infinite in its aberrations, and cannot be digested in any classification.' And Cohen and Nagel (1934: 382, in Hamblin ibid.: 13): 'It would be impossible to enumerate all the abuses of logical principles occurring in the diverse matters in which men are interested.' 


\section{Impossibility to avoid fallacies}

On the other hand, it seems that certain fallacies are unavoidable, which raises the question whether they are fallacies at all (and even much more important ones: how to classify fallacies? Are there any stable criteria for detecting fallacies? All the way to the obvious one: do fallacies exist at all?).

Port Royal Logic warns:

Finally, we reason sophistically when we draw a general conclusion from an incomplete induction. When from the examination of many particular instances we conclude to a general statement, we have made an induction. After the waters of many seas have been found salty and the waters of many rivers found fresh, we can conclude that sea water is salty but river water is fresh ... It is enough to say here that imperfect inductions-that is inductions based on examination of fewer than all instances - often lead us to error. (Arnauld and Nicole 1662/1964: 264, in Hamblin ibid.: 46)

While David Hume (1748/1963, in Hamblin ibid.: 29) is quite unambiguous: every argument from particular cases to a general rule must be fallacious.

\section{Are all fallacies fallacious?}

Hamblin, 200 years later, opens a new perspective on this problem: if some fallacies seem to be omnipresent and unavoidable, maybe we shouldn't treat them as fallacies: 'Fallacy of Secundum Quid [hasty generalization] is an ever-present and unavoidable possibility in practical situations, and any formal system that avoids it can do so only at the expense of features essential to natural language.' (Hamblin ibid.: 213) Ignoratio Elenchi [ignoring the issue, irrelevant conclusion] is another fallacy of this unavoidable kind. Hamblin argues:

This category can be stretched to cover virtually every kind of fallacy. If an arguer argues for a certain conclusion while falsely believing or suggesting that a different conclusion is established, one for which the first conclusion is irrelevant, then the arguer commits the fallacy of irrelevant conclusion. The premises miss the point. (Hamblin ibid.: 31)

Secundum Quid, for example, could thus be interpreted just as an instance of Ignoratio Elenchi. 
Begging the question [Petitio Principii, circular reasoning] fits in the same category; already J. S. Mill (in his System of Logic, 1843) claims that all valid reasoning commits this fallacy. While Cohen and Nagel affirm:

There is a sense in which all science is circular, for all proof rests upon assumptions which are not derived from others but are justified by the set of consequences which are deduced from them ... But there is a difference between a circle consisting of a small number of propositions, from which we can escape by denying them all, or setting up their contradictories, and the circle of theoretical science and human observation, which is so wide that we cannot set up any alternative to it. (Cohen, Nagel 1934: 379, in Hamblin ibid.: 35)

A possible conclusion we could draw from this observation: on the micro level, we can fuss about small things, everyday conversation and everyday reasoning, and pass our time in inventing numerous fallacies, but when it comes to the macro level, to big things (the big picture), fallacies are not objectionable any more-because there is no alternative. A problem that is very similar to Gödel's incompleteness theorem:

Any effectively generated theory capable of expressing elementary arithmetic cannot be both consistent and complete. In particular, for any consistent, effectively generated formal theory that proves certain basic arithmetic truths, there is an arithmetical statement that is true, but not provable in the theory. (Kleene 1967: 250)

This theorem was designed to prove inherent limitations (incompleteness) for axiomatic systems for mathematics, but what Cohen and Nagel are claiming is, mutatis mutandis, an application of Gödel's (first) incompleteness theorem to possible theories of fallacies. Graphically, we could represent this dialectical dynamics between macro and micro level like this: 


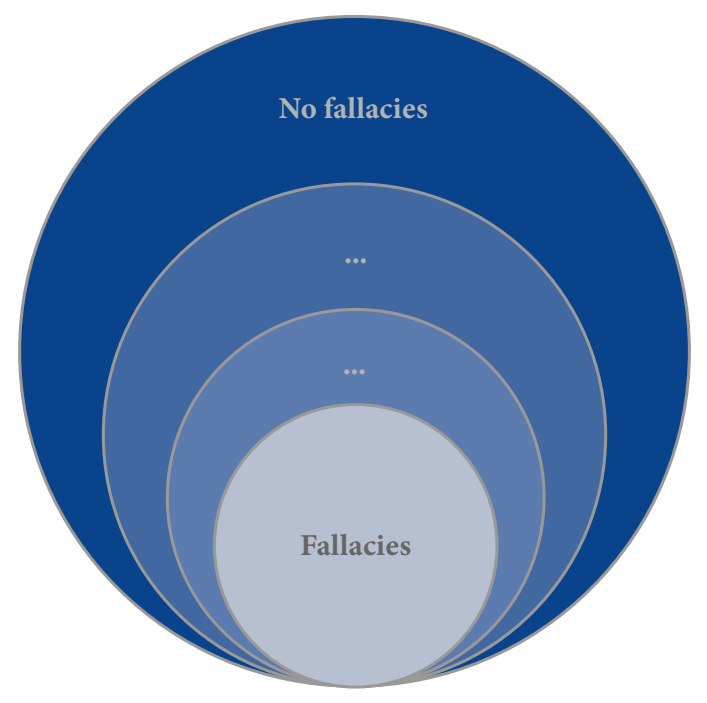

And a verbal explanation of this superposing of circles could read like this: smaller the systems or frameworks (of interest and work), with specific and unambiguous rules, easier it is to detect and declare something a fallacy. Bigger the systems or frameworks ('naturally' comprising many small(er) ones), with less specific and more loose rules, harder and less relevant it is to detect and declare something a fallacy. We could thus represent the relationship between social relations (practical reasoning in everyday life/society) and 'formal' relations (logical reasoning) as follows:

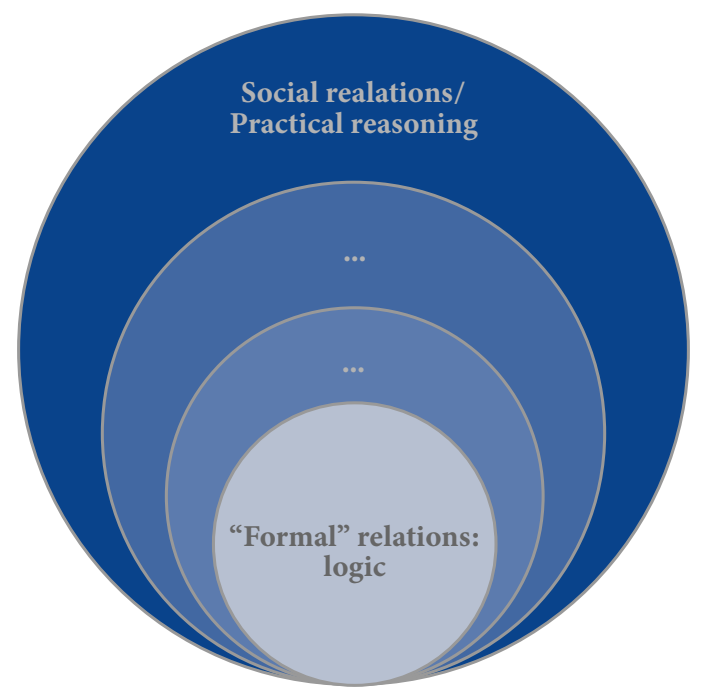


Or put differently: from a small circle perspective (micro-level), what is going on within the biggest circle (macro-level) could easily be described as fallacious (according to micro-level standards and criteria). And what is going on within the biggest circle might be described as absolutely correct, valid and/or sound (according to macro-level standards and criteria), while the standards and criteria of the small(est) circle might easily be described as fallacious (according to macro-level standards and criteria). What is a bit surprising, even strange about this micro-macro relationship, is that both levels (micro and macro) could and would use the same 'conceptual' grounds for declaring something as fallacy.

Here is an illustration from well developed fields within humanities and social sciences, the difference between macrohistory and microhistory:

A macrohistory takes a long view of history, looking at multiple societies and nations over the course of centuries to reach broad-ranging conclusions about the march of history. Using vast amounts of data-some verified but much of it estimated - the macrohistorian makes conjectures based on averages. This approach might appear to have the most interest on a general level, but often loses sight of local and individual differences.

When writing microhistory, the author concentrates upon a single individual or community and through study and analysis, attempts to reach understanding of wider issues at play. Very tightly limited both spatially and temporally, a microhistory might appear of rather limited importance to a reader whose interests lie beyond that particular point in time and space but, in fact, the approach does have certain advantages. The author of such a history is usually an expert in their field, knowing not just the generalities but also the minutae of their study. This allows a level of depth not usually found in more broadly based works. In addition, they may avoid the natural biases that come in macrohistories from the area of specialization of the author. (Steele 2006) 
If we sum up: when a macrohistorian 'takes a long view of history, looking at multiple societies and nations over the course of centuries to reach broad-ranging conclusions about the march of history', making 'conjectures based on averages', for a microhistorian he may be committing a Straw-man fallacy, namely taking facts and data from a particular context and projecting them on a much larger screen. Such a generalization necessary implies 'conjectures based on averages', while conjectures based on averages usually qualify as yet another (very general) fallacy, namely 'hasty generalization' or Secundum Quid.

On the other hand, when microhistorian 'concentrates upon a single individual or community', 'very tightly limited both spatially and temporally', he may be-again, but from the opposite direction-taking facts and data out of the context and restricting them to a much narrower screen. Thus microhistorian may be committing a Straw-man fallacy for a macrohistorian, as well as a hasty generalization or Secundum Quid, because he is not taking into account all the elements of a larger picture. We could, once more, represent this relationship as follows:

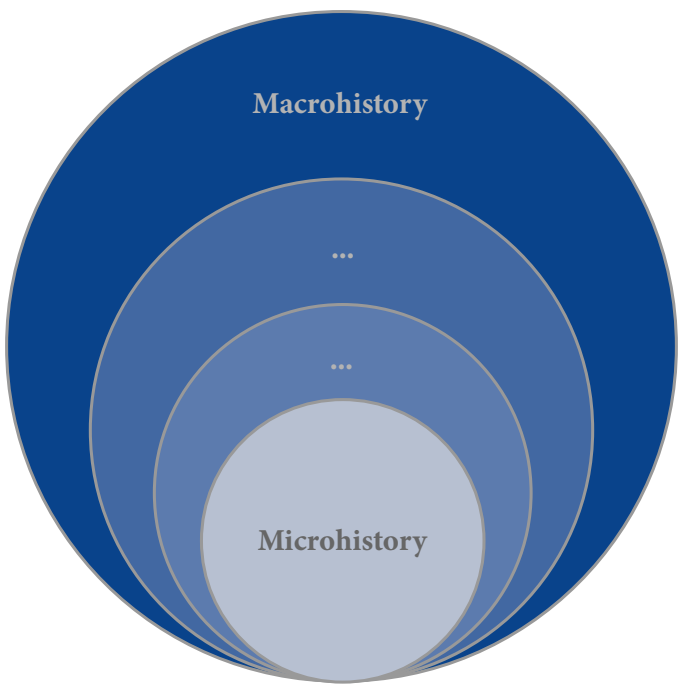

From a historical perspective, macrohistory, no doubt, embraces microhistory. But from a perspective of historiography, what counts as the basic operating principle (even basic epistemological and methodological precept) of macrohistory could easily be seen as a fallacy by microhistory, and vice versa. 


\section{Superabundance and redundance of fallacies}

If we take a look at a situation 40 years after Hamblin, which is today, what we see is an enormous interest in fallacies: there are many, even too many writings on fallacies, and many, even too many definitions of what fallacies are. But the reason for this inflation of writings on fallacies (and even production of ever new ones) may be the same as the one Hamblin mentioned for the shortage of accounts on fallacies: the impossibility to unequivocally and unambiguously classify fallacies at all.

Here is a sample of definitions we can find online; I emphasized the most ambiguous and vague parts of these definitions, and provided short glosses between square brackets:

\section{Vagueness and ambiguity of definitions}

(1) A fallacy is, very generally, [not specific enough, no informative value] an error in reasoning. This differs from a factual error, which is simply being wrong about the facts. To be more specific, a fallacy is an 'argument' in which the premises given for the conclusion do not provide the needed degree of support [what kind of support? to what degree? where are the limits of the 'needed support' and how is it defined?] (Labossiere, The Nizkor Project (http://www.nizkor.org/features/fallacies/))

(2) In logic and rhetoric [logic and rhetoric have very different principles of functioning] a fallacy is incorrect reasoning in argumentation [unclear; what is 'reasoning in argumentation'? isn't every reasoning based on arguments?] resulting in a misconception [misconception of what?]. By accident or design, fallacies may exploit emotional triggers in the listener or interlocutor (e.g., appeal to emotion), or take advantage of social relationships between people (e.g., argument from authority) [unclear and vague descriptions, not even definitions; no clear criteria to recognize the mentioned fallacies]. (Wikipedia (http://en.wikipedia.org/wiki/ Fallacy)).

(3) A fallacy is a kind of error [unclear; what does 'a kind of ...' mean?] in reasoning. ... Fallacies should not be persuasive, but they often are. Fallacies may be created unintentionally, or they may be created intentionally in order to deceive other people. (Internet Encyclopedia of Philosophy (http://www.iep.utm.edu/fallacy/)) 
(4) Fallacies are defects [what kind of defects?] that weaken [does 'weaken' mean that these arguments are still arguments, but with less argumentative force?] arguments. [...] It is important to realise two things about fallacies: First, fallacious arguments are very, very common and can be quite persuasive, at least to the casual reader or listener ... Second, it is sometimes hard to evaluate whether an argument is fallacious [is it, therefore, at all possible to detect such 'defects'? what purposes can such a 'definition' serve at all?]. (Handout and links (http://www.unc.edu/depts/ wcweb/handouts/fallacies.html))

(5) A 'fallacy' is a mistake [any kind of mistake?], and a 'logical' fallacy is a mistake in reasoning [is every mistake in reasoning-incidentally, what does count as a mistake in reasoning?-a 'logical' fallacy? there are many 'fallacies' that seem to be contextual or circumstantial]. There are, of course, other types of mistake than mistakes in reasoning. For instance, factual mistakes are sometimes referred to as 'fallacies' [repetitive, even circular, but not explicative enough]. (Fallacy files, http://www.fallacyfiles.org/introtof.html)

\section{Inventing the fallacies}

Obviously, there is quite a confusion about what fallacies are nowadays. And this confusion, this inability (impossibility?) to propose clear-cut criteria, boundaries and definitions, generates new fallacies. Actually, there is quite an inflation of (new) fallacies nowadays as well avalanche. Here are a few of my favourite ones:

\section{(a) Poisoning the Well Fallacy}

(Nizkor project: http://www.nizkor.org/features/fallacies/poisoning-thewell.html) This sort of 'reasoning' involves trying to discredit what a person might later claim by presenting unfavorable information (be it true or false) about the person. This 'argument' has the following form:

(1) Unfavorable information (be it true or false) about person A is presented.

(2) Therefore any claims person A makes will be false. 
Example

Before Class:

Bill: 'Boy, that professor is a real jerk. I think he is some sort of eurocentric fascist.'

Jill: 'Yeah.'

During Class:

Prof. Jones: '...and so we see that there was never any "Golden Age of Matriarchy" in 1895 in America.'

After Class:

Bill: 'See what I mean?'

Jill: 'Yeah. There must have been a Golden Age of Matriarchy, since that jerk said there wasn't.'

First, it is not quite evident that this is a fallacy; fallacy is a fallacious argument and a fallacy is yet to be extracted from the above dialogue (if there is any).

Secondly, if we apply a kind of a principle of charity on this artificially constructed dialogue, and concede there is an argument in the above dialogue, we don't need any new fallacy, it could easily be analysed as Ignoratio Elenchi, Secundum Quid or even Petitio Principii (if we stay with the all embracing fallacies (or 'fallacies'). But it could easily be a version of $A d$ Hominem, ${ }^{4}$ Straw-man, ${ }^{5}$ even AdPopulum. ${ }^{6}$ So, why create a new fallacy? Maybe because it is hard to choose between the existing ones, since the criteria are so unclear?

(b) Nirvana fallacy

(Wikipedia: http://en.wikipedia.org/wiki/Nirvana_fallacy) The Nirvana fallacy is the logical error of comparing actual things with unrealistic,

3 Please, see the definitions on the previous pages.

4 'An Ad Hominem is a general category of fallacies in which a claim or arguments is rejected on the basis of some irrelevant fact about the author of or the person presenting the claim or argument.' The Nizkor Project: http://nizkor.com/features/fallacies/ad-hominem.html

5 'The Straw Man fallacy is committed when a person simply ignores a person's actual position and substitutes a distorted, exaggerated or misrepresented version of that position.' http://nizkor.com/features/fallacies/straw-man.html

6 'The basic idea is that a claim is accepted as being true simply because most people are favorably inclined towards the claim.' http://nizkor.com/features/fallacies/ appeal-to-popularity.html 
idealized alternatives. It can also refer to the tendency to assume that there is a perfect solution to a particular problem.

Example: 'If we go on the Highway 95 at four in the morning we will get to our destination exactly on time because there will be NO traffic whatsoever.'

First, there is no reason or justification to label this 'fallacy' a 'logical error', it is purely circumstantial. Secondly, even if criteria for detecting fallacies are not very clear, it is rather obvious that 'Nirvana fallacy' could be analysed as Ad Consequentiam ${ }^{7}$ or/and Ad Ignorantiam $^{8}$ (leaving aside at least the ubiquitous Secundum Quid or the obvious Ignoratio Elenchi).

\section{(c) Argumentum ad Hitlerum}

(Wikipedia: http://en.wikipedia.org/wiki/Reductio_ad_Hitlerum) Reductio ad Hitlerum, also argumentum ad Hitlerum, (dog Latin for 'reduction to Hitler' or 'argument to Hitler', respectively) is an ad hominem or ad misericordiam argument, and is an informal fallacy. It is a fallacy of irrelevance where a conclusion is suggested based solely on something or someone's origin rather than its current meaning or context. This overlooks any difference to be found in the present situation, typically transferring the positive or negative esteem from the earlier context. Hence this fallacy fails to examine the claim on its merit.

Example: Hitler was a vegetarian, so vegetarianism is wrong.

As, surprisingly, already mentioned in the 'definition' this is an Ad Hominem argument (or an Ad Misericordiam one), so why create a new one? Maybe because it could also be interpreted as Ignoratio Elenchi and Secundum Quid, even as Ad Populum or/and Ad Baculum.' And in order to avoid ambiguity, another fallacy is created, which paradoxically

7 Ad Consequentiam 'is an argument that concludes a hypothesis (typically a belief) to be either true or false based on whether the premise leads to desirable or undesirable consequences'. https://en.wikipedia.org/wiki/Appeal_to_consequences Ad Consequentiam can, of course, be a logical fallacy as well, just the case in question is not.

8 Ad Ignorantiam, 'also known as appeal to ignorance (in which ignorance represents 'a lack of contrary evidence') is a fallacy in informal logic. It asserts that a proposition is true because it has not yet been proven false or proposition is false because it has not yet been proven true'. https://en.wikipedia.org/wiki/Argument_from_ignorance

9 Ad Baculum 'is the fallacy committed when one makes appeal to force or threat of force to bring about the acceptance of the conclusion. One participates in argumentum ad baculum when one points out the negative consequences of holding the contrary position'. https://en.wikipedia.org/wiki/Argumentum_ad_baculum. 
increases the (possibility of) ambiguity as far as criteria and definitions are concerned.

\section{Replacing analysis with fixed lists of fallacies: the case of CDA}

All the epistemological and methodological objections, ambiguities and caveats on one side, as well as the practical, empirical multiplications of fallacies and their overlapping on the other, make the study of fallacies a thriving enterprise, a field of its own and in its own right. But, can we use such a shaky ground as an analytical tool (as one of the analytical tools) in another theoretical enterprise, within another theory?

Let us have another look at one of these theories, a Critical Discourse Analysis (CDA from now on), more precisely at Ruth Wodak's DiscourseHistorical Approach (other branches of CDA don't use fallacies as one of their analytical tool), a theory we were critically examining in the first chapter, regarding their use of topoi.

\section{What is critical discourse analysis?}

Here is some more historical background. In short, CDA is usually associated with names such as Norman Fairclough, Ruth Wodak, Teun van Dijk, Paul Chilton, Guenther Kress, Michael Billig and Theo van Leuween, to name just a few. Their work is based on 'critical linguistics' that started mostly at the University of East Anglia in the 1970s (and was associated with the names of Robert Hodge, Roger Fowler and Guenther Kress), while the work of these critical linguists was based on the systemic-functional and social-semiotic linguistics of Michael Halliday whose approach is still crucial to CDA.

In Ruth Wodak's words, CDA

studies real, and often extended, instances of social interaction, which take (partially) linguistic form. The critical approach is distinctive in its view of (a) the relationship between language and society, and (b) the relationship between analysis and the practices analysed. (Wodak 1997: 173)

Or with the words of Jan Blommaert, CDA's sympathizer, but also a harsh critic:

CDA focuses its critique on the intersection of language/discourse/speech and social structure. It is uncovering ways in which 
social structure relates to discourse patterns (in the form of power relations, ideological effects, and so forth), and in treating these relations as problematic, that researchers in CDA situate the critical dimension of their work. It is not enough to uncover the social dimension of language use. These dimensions are the object of moral and political evaluation, and analysing them should have effects in society: empowering the powerless, giving voices to the voiceless, exposing power abuse, and mobilising people to remedy social wrong. (Blommaert 2005: 25)

\section{The discourse-historical approach and the (mis)use of argumentation}

Ruth Wodak initialised her own 'school' of CDA, called DiscourseHistorical Approach. Its programmatic view and its shortcomings, especially when using argumentation (topoi) in their analyses, can be found in the first chapter of this book (see also Žagar 2010, 2011). And it was these analyses of how DHA uses and misuses topoi that made me interested in how they use (and mostly misuse) fallacies.

The work of reference for DHA is the book Discourse and Discrimination ( $D \& D$ from now on) by Martin Reisigl and Ruth Wodak, published in 2001 (Routledge). I say the work of reference, because it is the only book in the DHA tradition that gives any substantial overview of the theoretical approaches and concepts DHA is using. All the subsequent works would just quote Discourse and Discrimination, these quotes would get shorter and shorter, and in one of the Wodak's last books, The Discourse of Politics in Action: Politics as Usual (2009), even some authors of theoretical approaches and concepts DHA is using would be lost and replaced-with the names of Wodak and collaborators ...

\section{Fallacies as seen by DHA}

Here is the passage that introduces fallacies in $D \& D$ :

If one wants to analyse the persuasive, manipulative, discursive legitimation of racist, ethnicist, nationalist, sexist and other forms of discrimination and the pseudo-argumentative backing and strengthening of negative, discriminatory prejudices, one encounters many violations of these ten rules. In rhetoric and argumentation theory, these violations are called 'fallacies' (among 
many others see Kienpointner 1996; van Eemeren, Grootendorst, Kruiger 1987: 78-94; van Eemeren and Grootendorst 1992, Lamham 1991: 77ff.; Ulrich 1992). (Reisigl, Wodak 2001: 71)

The 'violations of these ten rules' refer to pragma-dialectical ten rules for critical discussion that Reisigl and Wodak introduce on the previous page. But these ten rules for 'rational arguing' as Reisigl and Wodak call them are not valid just for 'persuasive, manipulative, discursive legitimation of racist, ethnicist, sexist and other forms of discrimination', but for every form of discussion that aims at resolving the difference of opinion in a rational way by means of critical discussion. Racist, ethnicist, sexist and other forms of discrimination usually don't aim at resolving the difference of opinion in a rational way.

Besides that, 'violations of these ten rules' is the way fallacies are defined in pragma-dialectics, not in rhetoric and argumentation theory in general. In rhetoric and argumentation theory there are many different approaches to fallacies that don't even mention those ten rules of critical discussion, even theories that are unfamiliar with those ten rules or refuse to use them.

Another problem for this hasty DHA definition arises if we confront it with a definition from pragma-dialectics itself:

In the pragma-dialectical approach, a fallacy is defined as a speech act that counts as a violation of one or more of the rules for critical discussion, which impedes the resolution of a difference of opinion. Fallacies are conceived and analysed from the same view as Aristotle originally approached them: The dialectical perspective [my emphases]. They are incorrect, unreasonable moves in a debate or in discussion in which (at least) two parties participate. (van Eemeren, Garssen, Meuffels 2009: 20)

In pragma-dialectics, fallacies are conceived and analysed from the dialectical perspective: they are incorrect, unreasonable moves in a debate or in a discussion. In DHA, on the contrary, a list of 14 fallacies is constructed (at least in D\&D: 71-74), with a short description and an even shorter example of each one of them. On the following 200 pages occasional references would be made to this list, without any analysis or justification why the examples on these 200 pages (mostly taken from the press) would represent any of the 14 fallacies listed (on pages 71-74), and the ten rules for 
critical discussion are never mentioned again. This is the very same way DHA deals with topoi (see previous chapter).

Eight years after the Discourse and Discrimination was published, in Wodak's The Discourse of Politics in Action, we get the following definition of fallacies:

Reisigl and Wodak (2001) also draw on van Eemeren and Grootendorst (1992) and Kienpointner (1996) when providing the list of general common fallacies, which includes the following very frequently employed argumentative devices: argumentum ad baculum, i.e. 'threatening with the stick', thus trying to intimidate instead of using plausible arguments; the argumentum ad hominem, which can be defined as a verbal attack on the antagonist's personality and character ... instead of discussing the content of an argument; the fallacy of hasty generalization, when making generalizations about characteristics attributed to a group without any evidence; and finally, the argumentum ad populum or pathetic fallacy, which consists of appealing to prejudiced emotions, opinions and convictions of a specific social group or to the voxpopu$l i$ instead of employing rational arguments. (Wodak 2009: 43-45)

An attentive reader has no doubt noticed that the list of references got shorter, that the list of 14 fallacies from D\&D got a new denomination: 'general common fallacies' (without any explanation how 'general common' is defined, or what constitutes 'general common' fallacies in relation to less 'general common' fallacies), and that within these 'general common fallacies' an even narrower list for 'very frequently employed' fallacies was constructed. It is just these four fallacies that are used in the analyses that follow. Let us have a look how.

\section{Detecting fallacies in the Discourse of politics in action}

The Discourse of Politics in Action: Politics as Usual is a book about European politics, more precisely, about how politics is done-in all possible detailsin the European parliament. In her own words, Wodak wanted to

find out 'how politics is done', 'what politicians actually do', and 'what the media convey about how politics is done'. Moreover, I also wanted to probe the implications of the public's lack of knowledge about the behind-the scenes reality of 'politics as usual' in an era of politics that many characterize in terms of an increasing 
and widespread disenchantment with politics, depoliticization and the so-called 'democratic deficit'. (Wodak ibid.: xii)

In chapter 4, 'On being European', Wodak examines the discursive construction of MEP's identities ${ }^{10}$ by analysing the responses of MEPs to questions about whether they see themselves as European or not.

Here is one of her conclusions about these interviews:

In contrast to the European Commission officials who tended to speak of themselves in terms of 'we', referring to the Commission, and equating this with the European Union, the MEP's constructed and performed numerous identities, both professional and personal (Wodak, 2004b). [Different identities are enumerated] Many of these 'presentations of self' manifest themselves in brief personal anecdotes or longer narratives, used as argumentum ad exemplum, i.e. one generalizable incident; this could also be analysed as employing the fallacy of hasty generalization. (Wodak ibid.: 99)

Wodak doesn't present any concrete data, not even an example on which the above claims would be based. But if there is no data, no analysis can be performed. And if data as well as the analysis of these hypothetical data are missing, it is impossible to judge whether we are dealing with fallacies or not. In this respect, it is crucial to remember what Hamblin keeps emphasizing:

A fallacy is a fallacious argument. Someone who merely makes false statement, however absurd, is innocent of fallacy unless the statements constitute or express an argument. (Hamblin ibid.: 224)

What Wodak does offer is a short summary that many of these " entations of self" manifest themselves in brief personal anecdotes or longer narratives, used as argumentum ad exemplum, i.e. one generalizable incident'.

Is there any other way of presenting oneself in an interview than brief personal anecdotes or longer narratives? I can't think of any. It is quite a mystery why Wodak labels these presentations of self, be it personal anecdotes or longer narratives, as argumentum ad exemplum; a classical definition of argumentum ad exemplum would be 'arguing against a particular 10 MEP is an acronym for a Member of European Parliament. 
example cited rather than the question itself', but in this case, we don't even have an example and there is certainly no question (except the one Wodak asked). She goes on by paraphrasing(?)/explaining(?) argumentum ad exemplum as 'one generalizable incident'. If we set aside that she is using wrong definition and classification, and that she is obviously not familiar with the standard terminology in rhetoric and argumentation (fallacy research included), one could wonder why a presentation of self would be described as a 'generalizable event'? If somebody is presenting herself, why should that personal presentation be generalizable to others? Wodak doesn't say (she doesn't even present any of the self-presentations she is referring to), but she does claim that this argumentum ad exemplum (which is not an argumentum ad exemplum), i.e. one generalizable incident (which, again, is not generalizable), 'could also be analysed as employing the fallacy of hasty generalization'.

We are encountering two problems here: (1) Wodak claims that this non-existing argumentum ad exemplum could be analysed as the fallacy of hasty generalization; (2) she further claims that this non-existing argumentum ad exemplum could be analysed as employing the fallacy of hasty generalization.

\section{Setting up fallacies as analytical procedure}

A few critical remarks are in order here:

Ad 1

Once more, I would like to quote Hamblin here: 'Fallacy of Secundum Quid is an ever-present and unavoidable possibility in practical situations, and any formal system that avoids it can do so only at the expense of features essential to natural language.' (Hamblin ibid.: 213)

But let alone Hamblin's caveat, Wodak would first have to show that these individual self-presentations were not presented as presentations of self, but as events (she refers to them as 'incidents') that could be generalized, that usually are generalized, that were meant to be generalized, i.e. as instances of a more general pattern. But she doesn't, she doesn't even present the 'examples' she is talking about.

Ad 2

Wodak then claims that these un-existing argumenta ad exempla could be analysed as 'employing the fallacy of hasty generalization'. 'Employing' clearly implies that something was done intentionally, with a purpose of 
achieving a certain goal. In our case (i.e. Wodak's case), this goal seems to be to deliberately create (later on, Wodak even uses a much stronger term, i.e. 'setting up') a fallacy. Which raises an important epistemological as well as methodological question: do we commit fallacies (with a technical meaning: producing/coming up with/perpetrating a fallacy without knowing that it was a fallacy; I am not claiming here that the English verb 'to commit' is restricted to this meaning, I am just using it in order to point to a dichotomy and construct an opposition), or do we employ them, even set them up (i.e., we are conscious of the fact that we have used a fallacy)?

The answer is easy with witless examples like 'Everything that runs has feet; the river runs: therefore, the river has feet': it is obvious that these examples were set up with a certain goal or intention. But what about the ever-present 'fallacies' like hasty generalizations? As Hamblin pointed out, they are unavoidable, that is the way we reason all the time, because in everyday life we have no alternative: when reporting somebody's words or actions, we simply can't take into consideration all the instances of a particular case, it would be practically impossible. In everyday life, we usually make our decisions on a limited number of analogies and examples, even on examples or experiences we don't have direct access to (we were just told about them). Does that mean that we are talking and living (in) fallacies?

But let us proceed with Wodak's book. What follows is the analysis of excerpts of different interviews:

Just before this excerpt begins, MEP 3 and the interviewer have been talking about the kind of contact MEPs have (or believe they should have) with their constituencies. In this context, MEP 3 contrasts her own behaviour with that of what she considers to be typical of (male) politician, thus providing a stereotypical generalization and setting up a straw-man fallacy. (Wodak ibid.: 105)

Again, there is no example (excerpt), and no analysis that would follow. We are told that MEP 3 contrasts her own behaviour with that of what she considers to be typical of (male) politician. We don't get to know what and how that is. But, if somebody is comparing her own behaviour with the behaviour of some other group she is witnessing in her professional life, this is her own personal experience, not (necessarily) a 'stereotypical generalization'. It may sound stereotypical, if there are similar descriptions of a certain professional group circulating in a certain public sphere (though we would first have to answer the question, why do we find them stereotypical, 
and what stereotypical really means (how it is defined)). But what MEP 3 might have said could in no way be described as generalization: she was simply comparing her own behaviour with what she sees (herself, not 'public opinion' or 'vox populi') to be typical of male politicians. She is therefore expressing her own opinion, not in any way a general one.

But Wodak goes even further in her analysis (or 'analysis'): MEP 3 isn't just guilty of 'stereotypical generalization', she is also 'setting up a strawman fallacy', in other words, MEP 3 has deliberately, intentionally constructed a fallacy.

I have already touched the difference between intentionally and unintentionally 'producing' fallacies in the previous section. A few words now about the Straw-man fallacy for which-in my opinion-we could use almost the same caveat Hamblin used for Secundum Quid: Straw-man fallacy is an ever-present and unavoidable possibility in practical situations. Why? Let us have a look at few 'popular' definitions that are available online:

(Nizkor Project: http://www.nizkor.org/features/fallacies/strawman.html) The Straw Man fallacy is committed when a person simply ignores a person's actual position and substitutes a distorted, exaggerated or misrepresented version of that position.

And here is a more detailed definition:

(Wikipedia: http://en.wikipedia.org/wiki/Straw_man) The straw man fallacy occurs in the following pattern of argument:

(1) Person A has position X.

(2) Person $B$ disregards certain key points of $X$ and instead presents the superficially similar position $Y$. Thus, $\mathrm{Y}$ is a resulting distorted version of $\mathrm{X}$ and can be set up in several ways, including:

(2.1) Presenting a misrepresentation of the opponent's position and then refuting it, thus giving the appearance that the opponent's actual position has been refuted.

(2.2) Quoting an opponent's words out of context-that is, choosing quotations that misrepresent the opponent's actual intentions.

(2.3) Presenting someone who defends a position poorly as the defender, then refuting that person's arguments-thus 
giving the appearance that every upholder of that position (and thus the position itself) has been defeated.

(2.4) Inventing a fictitious persona with actions or beliefs, which are then criticized, implying that the person represents a group of whom the speaker is critical.

(2.5) Oversimplifying an opponent's argument, then attacking this oversimplified version.

(3) Person B attacks position $Y$, concluding that $X$ is false/incorrect/ flawed.

How are we to understand and interpret this? That every time we don't take in consideration all the facts, or all the data available on a certain topic, everything a person we are talking about has said (and we hardly ever can, because not only human capabilities are limited, so is the time we have at our disposal), we can be accused of committing a Straw-man fallacy? Quoting an opponent's words out of context is a ubiquitous example we can hardly avoid we simply can't repeat everything that person has said. When writing reviews, for example, concentrating on what seemed important from our point of view, and pointing to possible weak points, is easily (and rather often) described (by the author under review) as misrepresenting author's views, oversimplifying or even inventing a fictitious persona. Accusations that somebody has committed a Straw-man fallacy are therefore (or at least can be) a handy rhetorical technique when we don't like someone's arguments (or don't agree with them). And there is always something that we leave out (that, for different reasons, we have to leave out), and we can never include everything a particular author has said or written.

Let us turn to more detailed analysis now. This is how Wodak continues:

In lines 1-3 she casts the typical politician as preferring to meet with citizens indirectly, through the media. Alternatively, the typical politician might 'drop in' on his constituency only briefly, in a condescending, patronizing $[\ldots]$ and elitist $[. .$.$] manner.$

[9 lines of summing up the interview dropped]

Several topoi, strategies and fallacies are employed here: the topos of history, which refers to her experience as evidence for a more general claim, combined with the fallacy of hasty generalization; the topos of urgency, which stereotypically characterizes 
politicians' lives, and the topos of difference combined with the discursive strategy of singularization, which serves to construct herself as unique. (Wodak ibid.: 105)

And this is the excerpt Wodak's analysis refers to:

(Example 4 (Text 3.28)), 9 lines out of 22:

-1 I mean I know that - - even on / on a: national level

-2 I mean there are very many politicians all sorts in all parties

-3 that prefer to / to meet the / the - - eh / the citizens through

- media

-4 eh - - / so I know that I'm not that sort.

-5 so I prefer to meet the people. - -

-6 it / it could be hard but it's more interesting.

-7 and that's the way $I$ learn all the time - a lot.

_- 8 ... and a $(\mathrm{xx})$ of - - / I met so very many politicians - during my - - living

_-9 years (Wodak ibid.: 104-105)

When comparing the excerpt and the analysis, a few questions come to mind. First, where in the excerpt could all these topoi and fallacies mentioned in the 'analysis' be found in the first place? What constitutes them as topoi and fallacies? How do topoi 'combine' with fallacies (or discursive strategies), what exactly is meant by that? Wodak would leave all these crucial questions unanswered.

But if the reader of her book is left without these answers (if it is not clearly showed in the analysis and in the excerpt where the topoi and fallacies are, and what constitutes them as topoi and fallacies), what can we learn from such an 'analysis'? What is its added value, its explanatory force in terms of cognition and comprehension?

If we try to find answers in the text itself, we can easily see that MEP 3 is saying I know that [...] there are very many politicians [...] that prefer to meet the citizens through media (lines 1-3), I prefer to meet people (line 5). And what I, as a reader, can conclude from this is that MEP 3 is expressing a purely personal experience, with no intention of generalization. (She is saying: $I$ know - - very many politicians (not all). In her own view, she knows the situation, and that is all that she is saying.) So, where is the fallacy of Hasty Generalization? The analyst should point to it, show how 
it is constructed, and that it is a fallacy at all (i.e. fallacious argument). Otherwise everything (every single utterance, not just a combination of an argument and a conclusion) could be judged a fallacy.

Here is another analysis, this time from the chapter One day in a life of an MEP. Hans, an Austrian MEP, is meeting a Slovenian delegation (at that time Slovenia was an accession country) and Wodak gives the following analysis of the conversation:

Once again, Hans emphasizes his contrary in a very explicit factual statement: 'enlargement costs a lot of money!' This time the audience for his argument is actually a delegation from an accession country, to whom he conveys in no uncertain terms the dominant-and in his view erroneous-beliefs about enlargement held by many politicians inside the EU. This topos of the actual costs of enlargement, and the corresponding representation of the EU as harbouring misguided beliefs on the subject (Hans even characterizes the Eurocrats as 'empty heads' (Hohlköpfe), in a colloquialism indicating the informal context and by employing the fallacy of hasty generalization again) might also serve as a legitimation strategy later on, should enlargement not go according to plan. (Wodak ibid.: 141-142)

And here is the conversation the above analysis refers to:

31 S1: in other words do you mean that one can now

32 that one can assume that the basic decision

33 that one will begin discussion with six countries

34 that any fundamental obstacles could still be in the way?

$35 \mathrm{H}$ : uh I would not make any strong predictions uh today

36 S1: yes

$37 \mathrm{H}$ : even if the monetary union is over

38 its side effects are not finished yet

39 politics can develop its own dynamics

40 politics develops its own dynamics when money is the issue

41 uh this is not unjustified

42 but the only thing that makes sense to the hollow European skulls (Hohlköpfe) 
$44 \mathrm{~S} 1$ : yes

$45 \mathrm{H}$ : eastern enlargement costs money

46 S1: yes yes (Wodak ibid.: 141-142)

Again, it is completely unclear where and what the fallacy of hasty generalization should be. There are (only) two possible candidates, 'the only thing (that makes sense) ...' or 'hollow skulls'. But it is hard to understand why these two should be fallacies: 'the only thing (that makes sense ...)' is (or at least could be) an amplification or hyperbole, a rather standard(ized) rhetorical device we use for emphasizing. While the 'hollow skulls' is clearly a metaphor (or a metonymy in certain interpretations), serving the same purpose as hyperbole at the beginning of the turn, but hardly a fallacyunless every trope is a potential fallacy, of course. And even if every potential trope would be a potential fallacy, the hollow European skulls would be more of a candidate for a Straw-man fallacy or even Ad Hominem, not a fallacy of Hasty Generalization.

We could go on with many more examples from Wodak's book, but they are all repeating the same pattern described. A tentative conclusion may therefore be in order.

\section{Conclusion: back to Austin and Hamblin}

I would like to conclude in the same way I started, with Austin and Hamblin. After pointing out that the reference depends on the knowledge at the time of utterance, Austin emphasizes:

It is essential to realize that 'true' and 'false', like 'free' and 'unfree', do not stand for anything simple at all; but only for a general dimension of being a right or proper thing to say as opposed to a wrong thing, in these circumstances, to this audience, for these purposes and with these intentions. In general we may say this: with both statements (and, for example, descriptions) and warnings, \&c., the question can arise, granting that you had the right to warn and did warn, did state, or did advise, whether you were right to state or warn or advise-not in the sense of whether it was opportune or expedient, but whether, on the facts and your knowledge of the facts and the purposes for which you were speaking, and so on, this was the proper thing to say. (Austin ibid.: 144-145) 
Whenever we are judging, not only whether something is true or false, free or unfree, but also whether something is a fallacy or not, we have to take into consideration the circumstances, the audience, the purposes as well as the intentions of the utterer. And when we do, we also have to bear in mind the following:

When there are two or more parties to be considered, an argument may be acceptable in different degrees to different ones or groups, and a dialectical appraisal can be conducted on a different basis according to which party or group one has in mind; but again, if we try to step outside and adjudicate, we have no basis other than our own on which to do so. Truth and validity are onlookers' concepts and presuppose a God's-eye-view of the arena. (Hamblin ibid.: 242)

The choice of arguments, criteria and acceptability of their use is always a matter that only the parties involved in the argumentative discussion can decide on. According to their knowledge at the time of the discussion, the circumstances in which the discussion takes place, the audiences that are involved in the discussion, the purposes and intentions the parties in the discussion have. And since these discussions take place in natural languages, in particular circumstances and at specific times, logic as an artificial system can't really help. 
Question and doubts about visual argumentation 



\section{Is there anything like visual argumentation? A short exercise in methodical doubt ${ }^{\mathrm{I}}$}

In 2014 journal Argumentation and Advocacy was celebrating

the groundbreaking work on visual argument that appeared in the journal's 1996 (double) issue on visual argument. Since that time, visual argument has become a central topic in argumentation theory and been featured in presented papers and published articles that explore case studies and investigate the possibility of a theory of visual argumentation (published on Argthry, $28^{\text {th }}$ August 2014).

As an interested bystander who was not a partisan of visual argumentation (VA) nor an active participant in more or less heated debates around VA, I would like to start with a very short overview of these passed twenty years. Then-extensively commenting on Leo Groarke's paper 'Six Steps to a Thick Theory'-I will concentrate on some basic concepts AV is, in my view, lacking, but should be incorporated in their conceptual framework in order to better explain the following rhetorical problems: how visuals function, that is, how they get or catch the viewers, how the viewers break down the presented visuals, and how they reconstruct their meaning.

1 First version of this chapter (titled 'Against visual argumentation: multimodality as composite meaning and composite utterances') was published in Dima Mohammed and Marcin Lewinski, eds., Argumentation and reasoned action, vol. I: Proceedings of the $1^{\text {st }}$ European conference on argumentation. Studies in Logic, vol. 62. (London: College Publications, 2016), 829-852. 
Since knowing is seeing and seeing is knowing are deeply rooted and widely used metaphors in (not just) Western culture, such a rhetorical analysis, borrowing its tools from multimodal analysis, anthropological linguistics and (critical) discourse analysis, may importantly contribute to the thriving methodological discussion on how knowledge is extracted from the visuals, and how visuals generate knowledge.

\section{Twenty years in a short overview}

The way I say these twenty years of development of visual argumentation could be expressed contrastively, almost like an antithesis. On the one hand, the introduction to this double issue of A\&A on VA, written by D. Birdsell and L. Groarke twenty years ago, is (understandably) still pretty cautious as to what visuals can do (all emphases are mine):

- $\quad[. .$.$] the first step toward a theory of visual argument must be a$ better appreciation of both the possibility [!] of visual meaning and the limits of verbal meaning' (Birdsell, Groarke 1996: 2);

- $\quad$ '...] we often clarify the latter (i.e., spoken or written words) with visual cues [...]' (Ibid.);

- 'Words can establish a context of meaning into which images can enter with a high degree of specificity while achieving a meaning different from the words alone' (Ibid.: 6);

- ' '....] diagrams can forward arguments' (Ibid.);

- 'The implicit verbal backdrop that allows us to derive arguments from images is clearly different from the immediate context created by the placement of a caption beside an image.' (Ibid.)

If we sum up: visuals may have some argumentative or persuasive potential (there is a possibility of visual meaning, visuals can forward arguments, and arguments can be derived from visuals) but they are usually (always?) still coupled with the verbal, and can achieve these argumentative effects only (?) in combination with the verbal. And the pièce de resistance Birdsell and Groarke are offering to illustrate the claims above (i.e., the possibility of visual argumentation) is an anti-smoking poster, published by the U.S. Department of Health, Education and Welfare in 1976 (I'll be commenting on it later on). Here it is: 


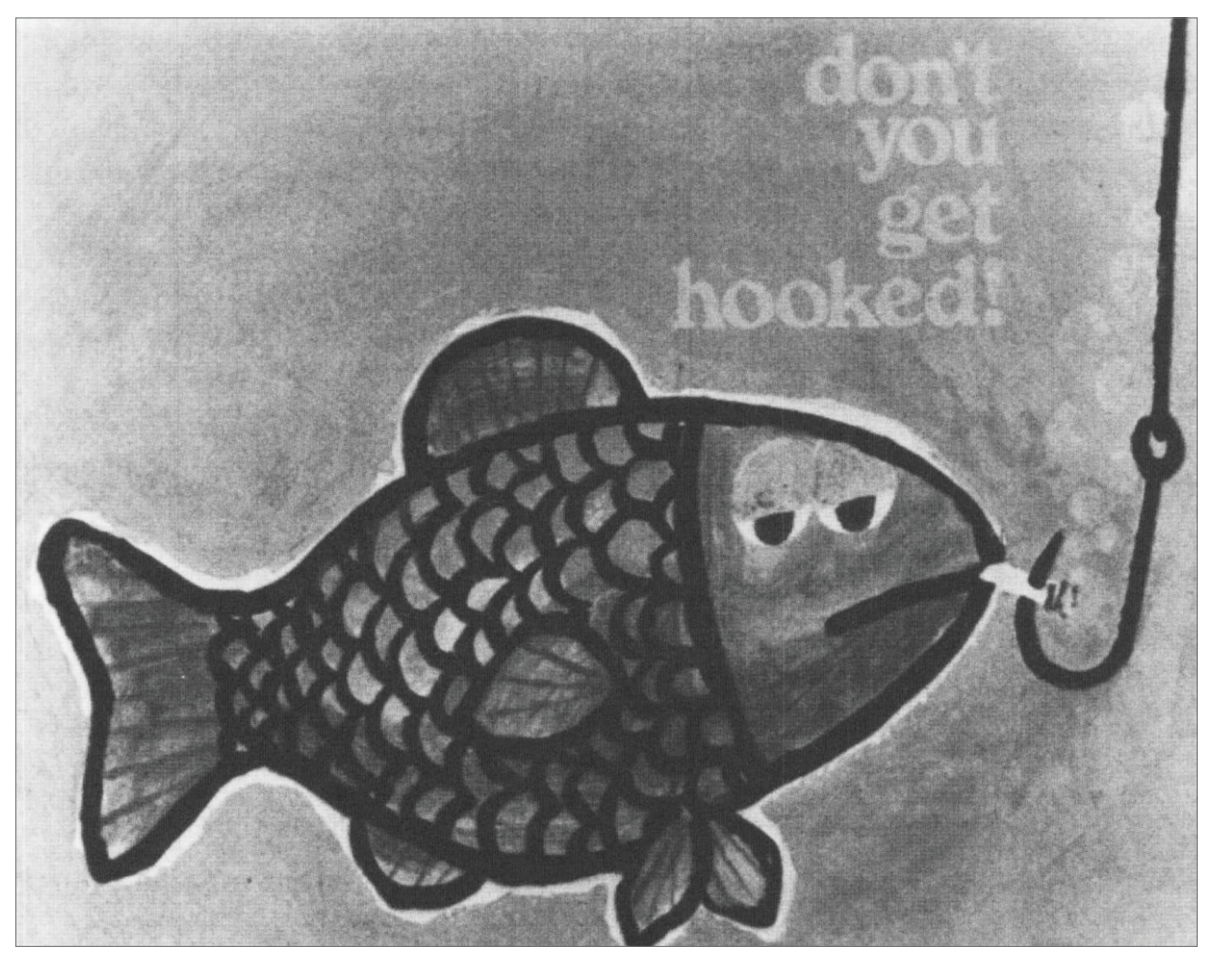

Figure I. Smoking fish.

On the other hand, in the last ten years or so, visuals are more and more often presented by the proponents of VA as directly and unambiguously offering arguments by themselves, without any intervention or help from the verbal (or any other code), and not being conditioned or in any other way dependent on the verbal at all. Here are two reconstructed examples (I say reconstructed because I was unable to get the original materials from the authors).

The first one is a square ball, used as an example by one of the presenters at the 2014 ISSA conference. It was a small drawing of a square ball (unfortunately, the presenter wouldn't send me the exact drawing) with 'China' written on it, obviously cut from some newspaper or magazine, but presented without any immediate context: it wasn't made obvious to which section of the newspaper the visual belonged to (and the presenter would not explain it), nor could we see the neighbouring articles (and the presenter wouldn't explain that either). But he was very explicit in claiming that the argument offered by the visual itself was more than obvious: 'The Chinese football sucks!' 
The counter-argument came up in the discussion. A colleague in the audience understood the square ball with the 'China' inscription on it as a metaphor of corruption in the PRC. Another colleague understood it as a metaphor of a hybrid socio-political system: turbo-capitalism under the leadership of the Central Committee of the CPC.

To sum up, the discussion showed very clearly that the argument was not evident from the drawing itself, otherwise so different interpretations could not have been possible. But, if the drawing would have been framed appropriately (so that we were able to see where in the paper the drawing was published, in which section, or what were the neighbouring articles), such an appropriate and sufficient framing would disambiguate the interpretation(s).

Here is another example of insufficient framing:

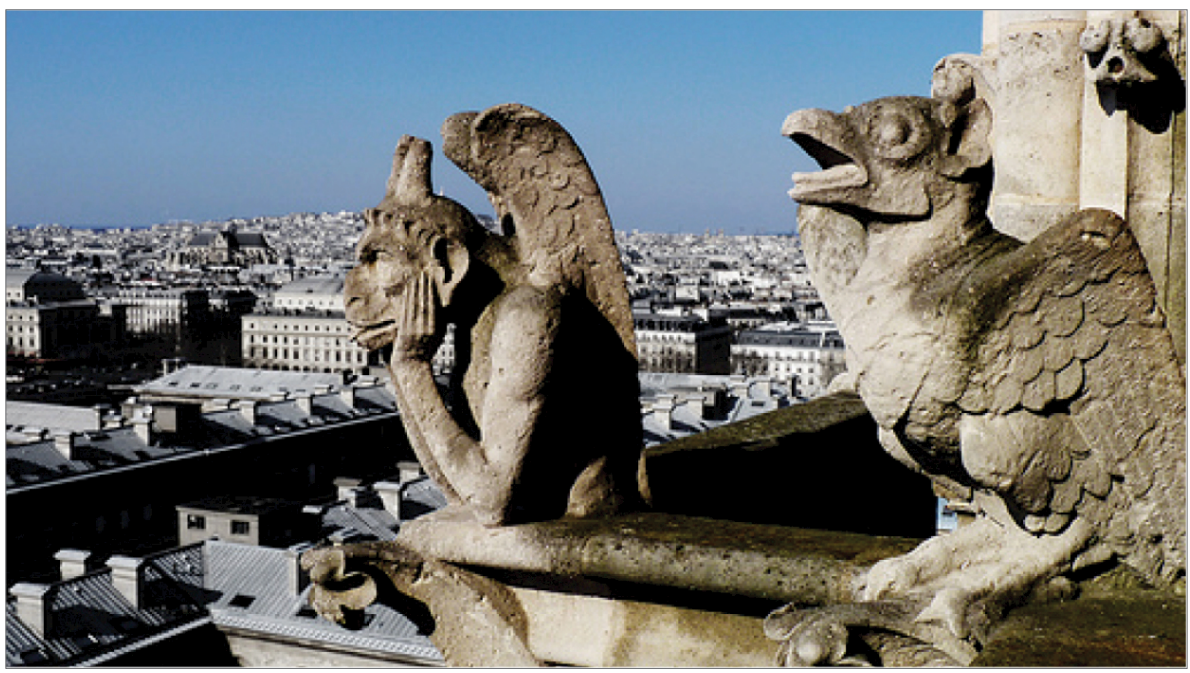

Figure 2. Notre-Dame Gargoyles I. 


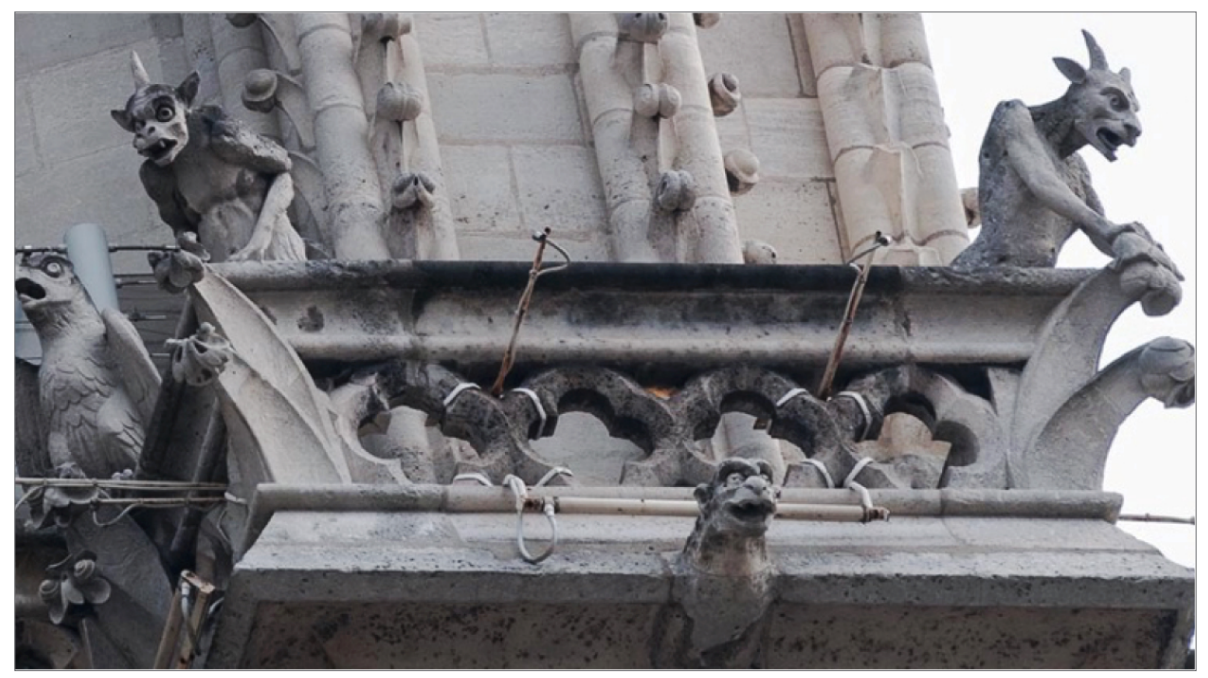

Figure 3. Notre-Dame Gargoyles II.

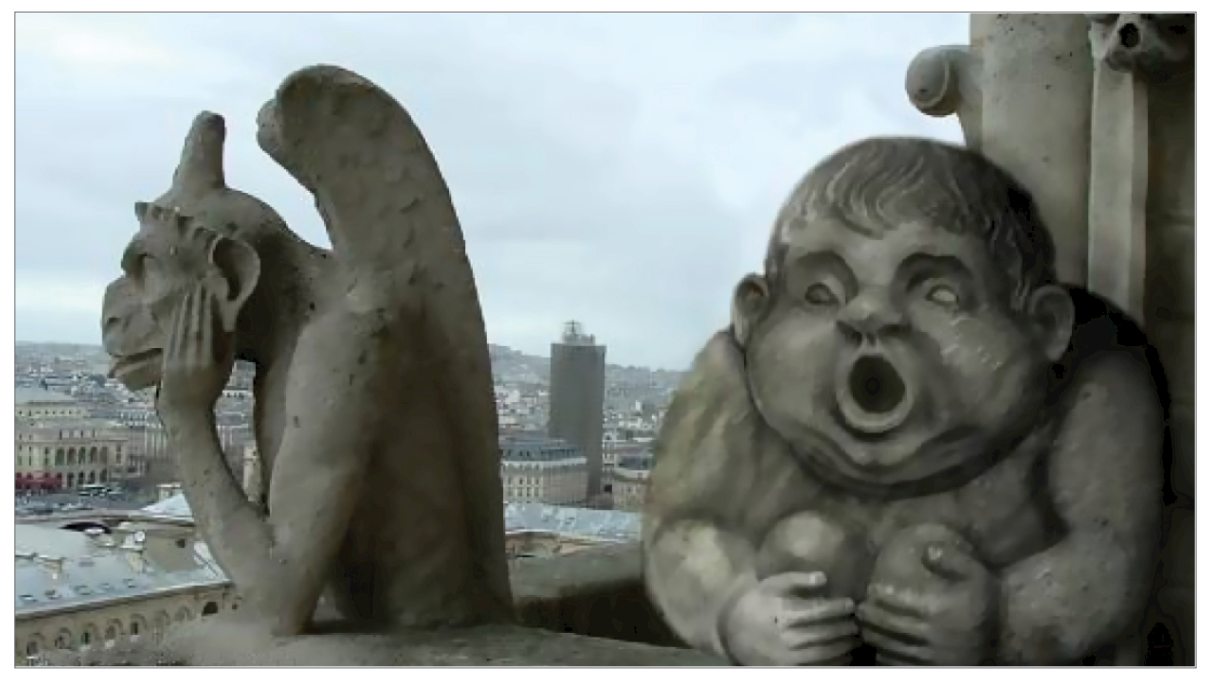

Figure 4. Notre-Dame Gargoyles III.

A photo resembling the three above (unfortunately, this presenter wouldn't send me the exact photo either) likewise was presented at the IPrA conference in New Delhi in 2013, with almost the same words as the square ball at the ISSA 2014 conference: 'What the argument is, is obvious from the photo itself.' 


\section{Framing in visual argumentation}

But, are possible or potential arguments supposedly contained in the visuals really so obvious? We should recall what already Ch. S. Peirce had pointed out more than hundred years ago (Peirce 1931-58: 2.172): 'Nothing is a sign unless it is interpreted as a sign.' In other words, nothing is interpreted as a sign (i.e., representing or referring to something else) unless there is intention to see it and to understand it as a sign.

And these signs (consider figures 2, 3, and 4) can have many different interpretations (if not framed appropriately and sufficiently):

- $\quad$ view of Paris (or one of the views of Paris);

- $\quad$ view of Paris from Notre-Dame;

- $\quad$ Notre-Dame on the background of Paris;

- Postcard greetings from Paris;

- $\quad$ some memorial photos from/of Paris;

- details of Notre-Dame architecture;

- examples of sacral architecture;

- motives from the Notre-Dame outer walls;

- mythological motives from the Notre-Dame architecture; even

- $\quad$ excerpt from a book on plumbing (these Gargoyles were often used as gutters).

What is my point in enumerating all these? Simply, that we should first know what the (immediate) context of a visual is, and only then proceed with the interpretation and meaning construction. Or, in Wittgenstein's words (Wittgenstein 1953/1986: I-\#663): 'Only when one knows the story does one know the significance of picture.' Which is, if we ponder a bit about this problem, just a corollary of a much more famous $7^{\text {th }}$ thesis from his Tractatus Logico-Philosophicus: 'Whereof one cannot speak, thereof one must be silent.' Applied to visuals, we could paraphrase it as: until we know what the visual is (all) about, we cannot talk about it.

Or put it in the terms of what I will be proposing: we have to frame the visual (or the verbal, for that matter), and perform a frame analysis first (i.e. before proceeding to any kind of meaning construction). 


\section{Goffman's frames}

Frames I will be concentrating on in this paper are not semantic frames as developed and defined by Charles Fillmore in 1977 (though even semantic frames (may) have a role in potentially argumentative interpretation of visuals as I will try to point out at least fragmentary), but frames that help us organize our everyday experience, frames as developed by sociologist Erving Goffman in his influential book Frame Analysis: An Essay on the Organization of Experience (1974).

What are Goffman's frames? In his own words:

When the individual in our Western society recognizes a particular event, he tends, whatever else he does, to imply in this response (and in effect employ) one or more frameworks or schemata of interpretation of a kind that can be called primary. I say primary because application of such a framework or perspective is seen by those who apply it as not depending on or harking back to some prior or 'original' interpretation; indeed a primary framework is one that is seen as rendering what would otherwise be a meaningless aspect of the scene into something that is meaningful. (Goffman 1974: 21)

Goffman distinguishes between natural and social frameworks. Natural frameworks 'identify occurrences seen as undirected, unoriented, unanimated, unguided, purely physical'. (Ibid.: 22) Social frameworks, on the other hand,

provide background understanding for events that incorporate the will, aim, and controlling effort of an intelligence. [...] Motive and intent are involved, and their imputation helps select which of the various social frameworks of understandings is to be applied. (Ibid.: 24)

There are different frames one can apply to a single event/entity, as in our two reconstructed examples with a square ball and the Notre-Dame Gargoyles, but 'we tend to perceive events in terms of primary frameworks, and the type of framework we employ provides a way of describing the event to which it is applied'. (Ibid.: 24)

For a contextualized illustration, let us go back to the smoking fish advertisement (Figure 1). The authors (Birdsell and Groarke) first admit that 'visual images can, of course, be vague and ambiguous. But this alone does 
not distinguish them from words and sentences, which can also be vague and ambiguous'. (Birdsell, Groarke 1996: 2) Than they qualify this poster as 'an amalgam of the verbal and the visual' (ibid.), which, again, sounds quite acceptable. But then they conclude: 'Here the argument that you should be wary of cigarettes because they can hook you and endanger your health is forwarded by means of visual images ...' (Ibid.: 3) Which is obviously not the case. Without the verbal part, 'don't you get hooked!', the poster could be understood (framed) as a joke, as a cartoon, where, for example, smoking is presented as such an ubiquitous activity that even anglers use cigarettes to catch fish. Only when we add the verbal part, 'don't you get hooked!'- where 'hooked' activates a (this time semantic) frame of (semantic) knowledge relating to this specific concept (Fillmore 1977: $76-138$ ), ${ }^{2}$ which includes 'get addicted', and is, at the same time, coupled with a visual representation of a hook with a cigarette on it-is the appropriate (intended) frame set: the poster is now understood as an anti-smoking ad, belonging to an anti-smoking campaign.

\section{Mental spaces}

Equally problematic and ambiguous is the UvA poster Leo Groarke is using in his 'Logic, Art and Arguing' (1996: 112):

2 Probably the most widely known slogan describing the basic feature of frame semantics is due to Ch. Fillmore: 'Meanings are relativized to scenes.' And an often cited example by Fillmore (1997) demonstrating the above slogan is the difference in meaning between the following two sentences:

(1) I spent three hours on land this afternoon.

(2) I spent three hours on the ground this afternoon.

The 'background' scene refered to in (1) would be a sea voyage while (2) refers to an interruption of an air travel. 


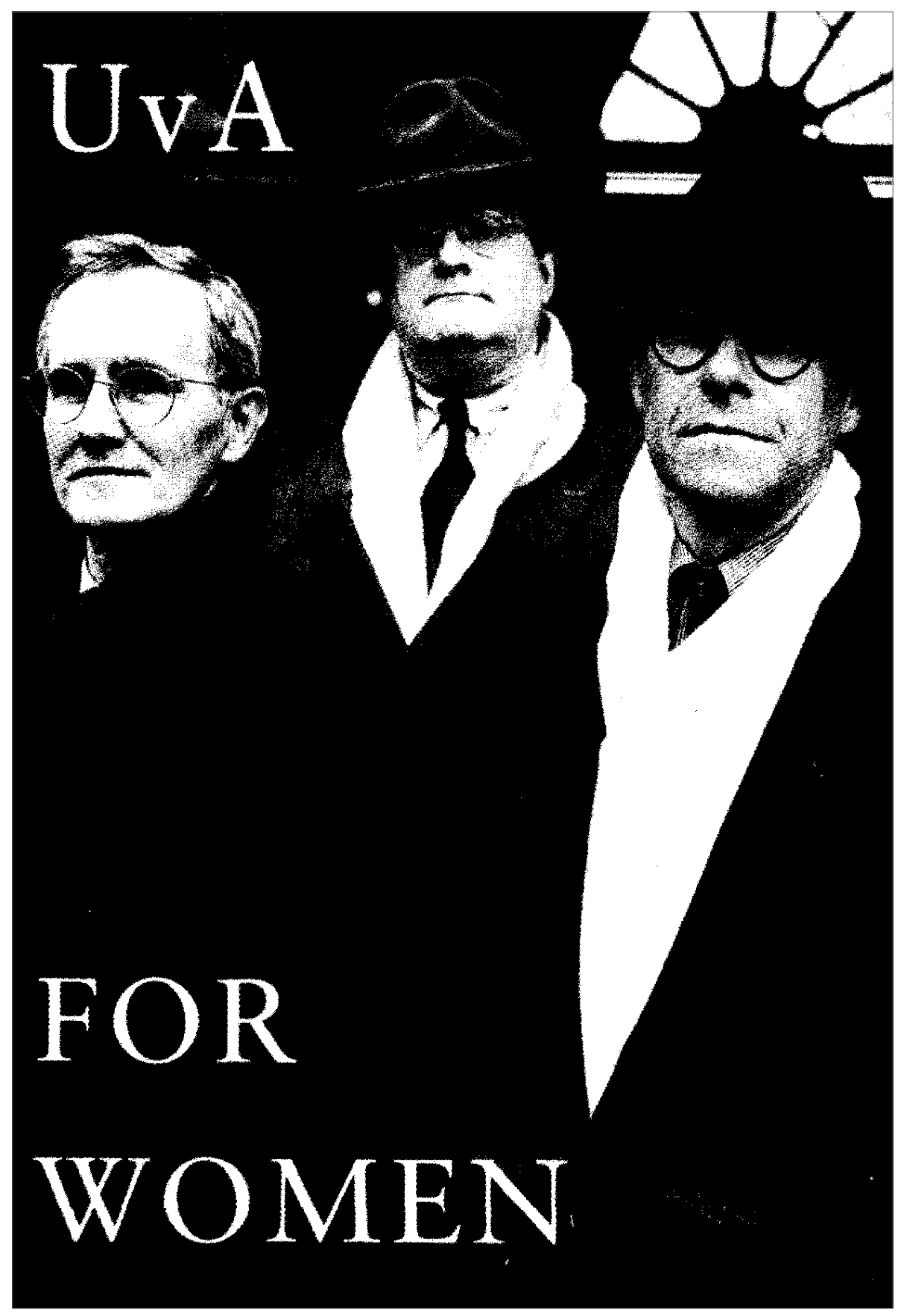

Figure 5. UvA chief administrators. 
Groarke's argument goes as follows:

The black and white photograph [...] presents the university's three chief administrators in front of the official entrance to the university. Especially in poster size, the photograph makes a stark impression, placing all this confident maleness in front of (visually blocking) the university's main entrance. According to the committee, which commissioned the poster, it is a 'statement' which effectively makes the point that 'we want more women at our university' and 'still have a long way to go in this regard. (Groarke 1996 ibid.)

But, if we are not acquainted with the committee's 'statement' that they want more women at their university (as, I guess, an 'average' Amsterdamer is not), and we just, walking the streets of Amsterdam, bump into this poster with three corpulent males, 'stating' 'UvA for Women', it is not at all clear how the poster was intended to be framed (by its authors). Is it (simply) a bad joke? Should it be taken ironically, maybe cynically, as a meta-statement from somebody who knows and objects the fact that UvA is all male? There is even a (at least implicitly) sexist interpretation that all these males at UvA need more women.

In other words, because of the insufficiently unambiguous framing it is not at all clear that we (the observers) can (and even should) reconstruct the argument(ation) in question the way Groarke does:

The poster thus presents the argument:

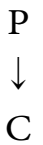

where the premise $\mathrm{P}$ is the (visual) statement that 'The University of Amsterdam's three chief administrators are all men' and $\mathrm{C}$ is the conclusion that 'The University needs more women' (Groarke 1996: 111).

Even if we take $\mathrm{P}$ as rather unambiguous (which it is not; for one thing, the fact that the University of Amsterdam's three chief administrators are all men is not a matter of general knowledge), the arrow, leading to $\mathrm{C}$, can in no way be so linear, unidirectional, or monotonic (if you want) as to lead directly and exclusively to $C$, interpreted as 'The University 
needs more women'. C could have had many other interpretations (and P many other formulations, for that matter), for example: 'UvA doesn't need women!', 'UvA is a sexist institution', 'UvA needs some women to change appearances'.

Much more appropriate representation of how we can read the UvA poster, and how we should interpret it, could be formulated in terms of mental spaces (nowadays more popularly called blending theory). Like this:

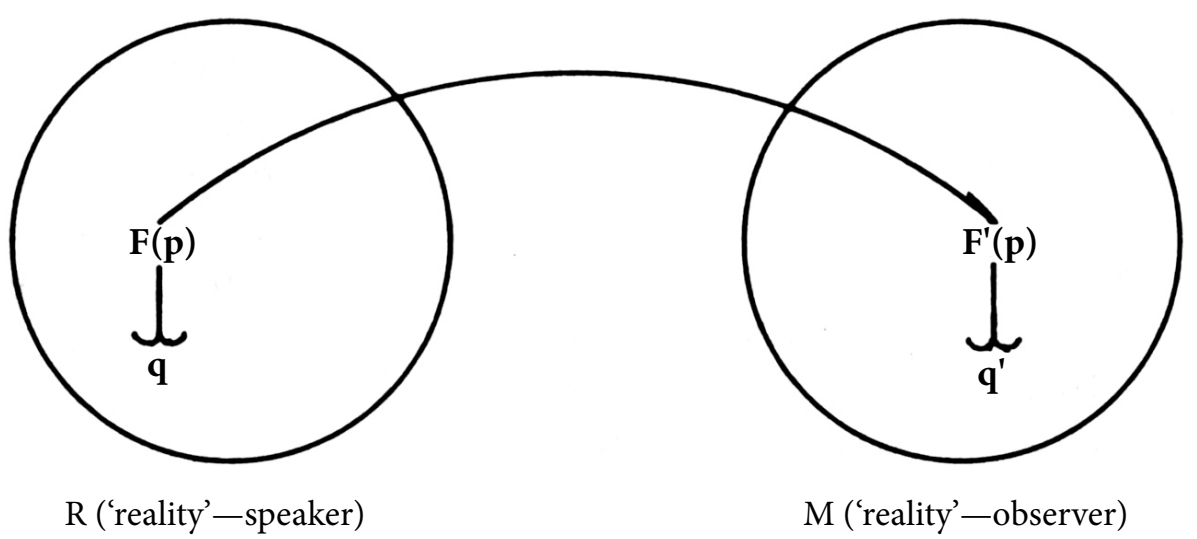

Figure 6. Construction of meaning in mental spaces.

Figure 6 should be read (interpreted) as follows. R stands for the 'reality' of the speaker (speaker's mental space), $M$ for the 'reality' of the observer (observer's mental space). $p$ represents the poster in question, $F(p)$ its (intended) premise, and $q$ its (intended) conclusion in R. In M, on the other hand, $p$ still represents the same poster in question (hence the long arrow connecting the two spaces), but $F^{\prime}(p)$, the observer's premise, and $q$ ', the observer's conclusion, may be quite different from speaker's premise and speaker's conclusion (depending on the context (time and place of encountering the poster), observers' experience, their social and cultural background, education, gender, and many other, even bio-neurological and cognitive factors). On top of that, $\mathrm{M}$ spaces may be multiplied in relation to $\mathrm{R}$ space, precisely because of different observers' different (social, cultural, etc.) background, education, gender, and many other factors. 


\section{Polyphony}

A bit different mechanism seems to be at work in Marlboro advertisements Asimakis Tseronis used at the Brač Argumentation Conference in 2012. Actually, these were not advertisements but 'subvertisements', produced by a group called Adbusters (a name that is rather indicative as to what they are doing to advertisements).

Chronologically, the original Marlboro advertisements come first, of course. The background is always the American (Wild?) West, represented in warm, yellowish and brownish colors, and in the foreground there is always one or several cowboys. They may be smoking or not, but a pack of Marlboro cigarettes together with the company's logo is always highly visible and sets the frame (= we are talking cigarettes advertisement here, not, for example, westerns, or horse breeding).

What do Adbusters do to these original ads? They can't use the company's logo and packs of cigarettes, of course, so they use the standardized Marlboro background (warm, yellowish and brownish colors in the background, several cowboys in the foreground) to activate the appropriate frame with the observers (= this is (about) Marlboro). And the text within this familiar 'Marlboro country', implicitly and indirectly, alludes to the missing packs of cigarettes.

Like in Figure 7:

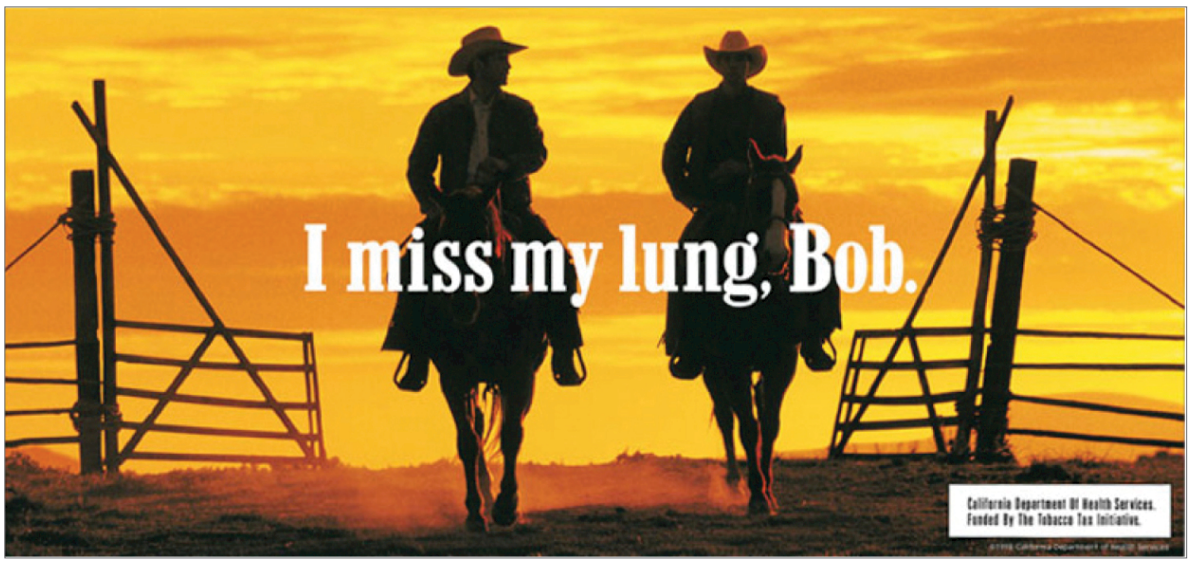

Figure 7 .

Maybe even more efficient is the following parody. On the original advertisement we see cowboys on horses in a winter landscape, with Marlboro 
packs in the lower right corner (for obvious reasons, we can't reproduce the photo). On the 'busted' version, we just see the horses in an empty graveyard, covered with snow, while the tombstones symbolically replace packs of cigarettes.

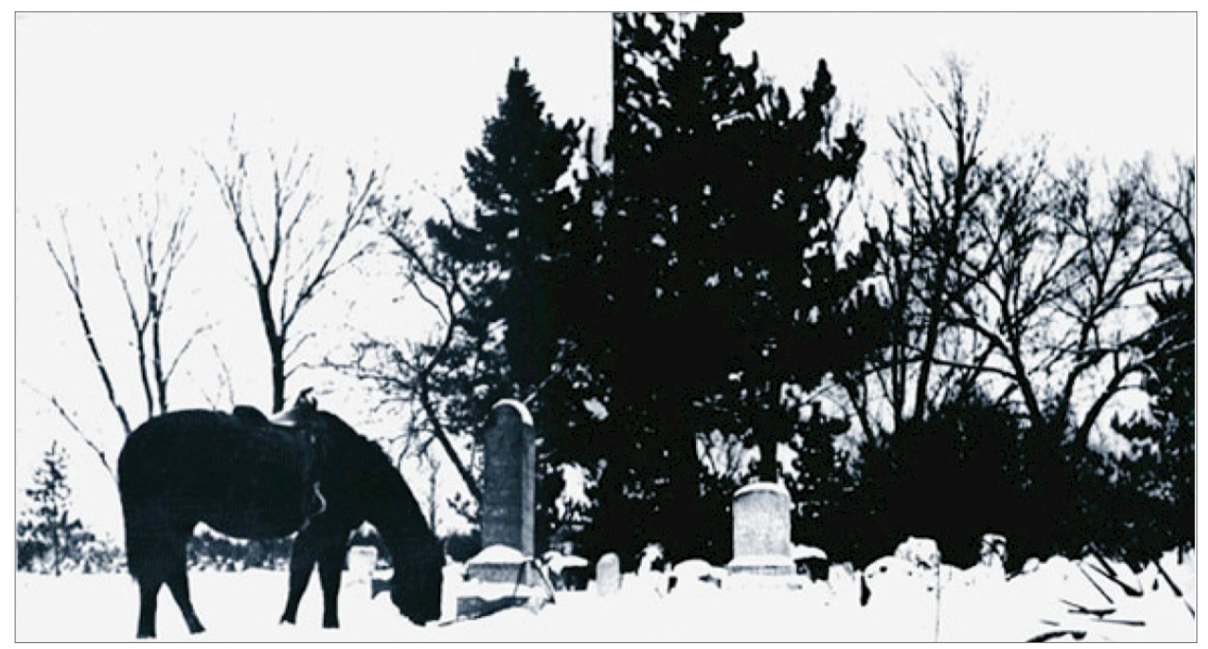

Figure 8.

What is the mechanism at work here? It appears that a kind of 'gestalt' (warm, yellowish/brownish colors in the background, cowboys in the foreground ...) sets the frame (= Marlboro advertisements), while the text or the setting in the photo activates a (kind of) polyphonic reading: we can only make sense of and understand the busted advertisements if we connect them to the original advertisements, i.e. we can only understand them on the background of the original ads, i.e. as a kind of meta-ads.

When I am mentioning polyphony, I am referring to Bakhtin, of course, but even more explicitly to Ducrot's theory of polyphony, informed by Bakhtin, but much more elaborated. You may recall that Ducrot (2009: $32-44$ ) is distinguishing between a producer, a locutor and several enunciators/utterers or uttering positions. A producer is the person/organization ... that is the 'material' author of a given piece of text (or visual). In our case, the producer(s) would be the Adbusters (and their collaborators), the people who produced the anti-ads in question, those who had the idea, set the scenery, took the photo, developed it, and so on ... 
A locutor is the entity (person, organizationa ...) that is (symbolically) responsible for the message of the ad. In our case the message could be reconstructed as something like: 'Smoking kills'. But this (meta)message is obviously only possible because there is an interplay of (at least two) enunciators or uttering positions within the locutor; the first one declaring that smoking is cool/attractive/adult (the original Marlboro ads) ..., and the second one subverting, criticizing such a position (the Adbuster ads). And the criticism as the main theme of the Adbuster ads prevails as the main message.

\section{Rhizome and superdiversity in visual argumentation - a commentary}

At this point, it may be worth briefly mentioning that in dealing with visuals, with construction of meaning and interpretation in visuals, we are necessarily dealing with the so-called rhizomatic structure and rhizomatic reading.

Rhizome is a (philosophical) concept developed in 1980 by two French philosophers, Gilles Deleuze and Félix Guattari (2005), and defined as theoretical approach that

ceaselessly establishes connections between (different) semiotic chains, organizations of power, and circumstances relative to the arts, sciences, and social struggles. A semiotic chain is like a tuber agglomerating very diverse acts, not only linguistic, but also perceptive, mimetic, gestural and cognitive ...' (Deleuze, Guattari 2005: 28)

The concept was borrowed from botany and dendrology, where rhizome is a modified subterranean stem of a plant that is usually found underground, often sending out roots and shoots from its node. The rhizome also retains the ability to allow new shoots to grow upwards. If a rhizome is separated into pieces, each piece may be able to give rise to a new plant. 


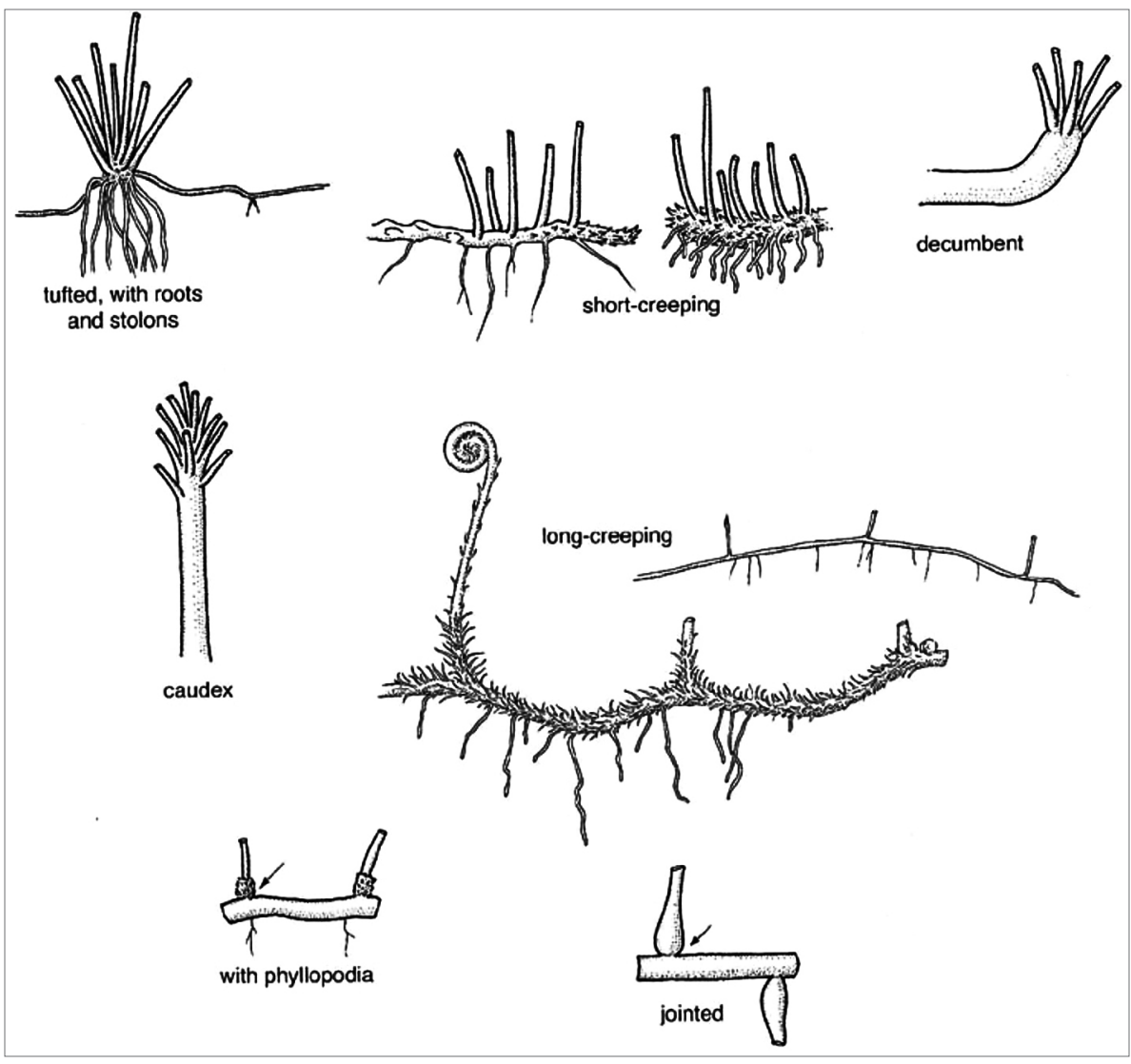

Figure 9. Rhizome, plant.

Or, in a more abstract and generalized form: 


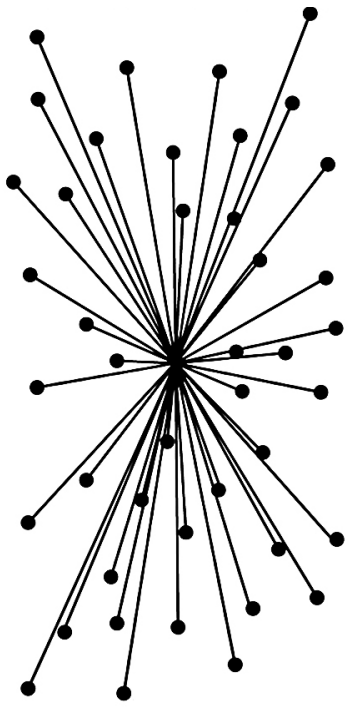

Centralized

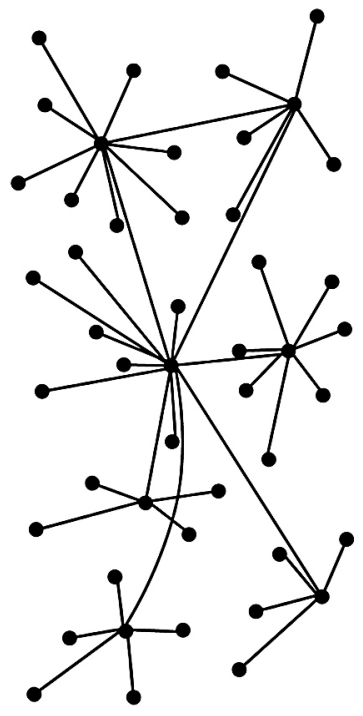

Decentralized

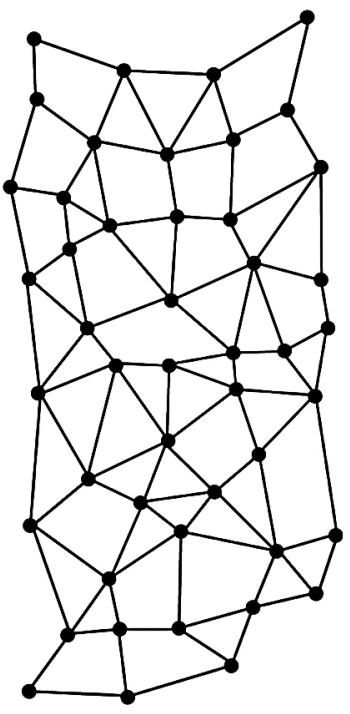

Distributed

Figure io. Rhizome, abstract.

Rhizome and rhizomatic structures become conceptually especially interesting if coupled and integrated with a (rather) new sociological concept that is rapidly gaining importance, the concept of superdiversity. Superdiversity is a concept coined by sociologist Steven Vertovec, and he describes it as:

[...] a dynamic interplay of variables among an increased number of new, small and scattered, multiple-origin, transnationally connected, socio-economically differentiated and legally stratified immigrants who have arrived over the last decade (Vertovec 2007: 1025).

And what could be the significance of this new concept, referring to immigrants (among others), for the analysis and interpretation of visuals? Exactly the possibility that increasingly different ethnic, cultural, educational, and ideological background of potential readers/interpreters (not necessarily immigrants, of course) in a more and more globalized, multiethnic and multicultural word, may imply even more different access points and interpretational paths in reading and interpreting visuals. In other words, the allegedly unidirectional and unproblematic arrow connecting $\mathrm{P}$ and $\mathrm{C}$ in Leo Groarke's interpretation of the UvA poster may not just be 
multiplied in different ways, pointing in different directions, but may (and should) also change its shape, from straight to wavy or curved or even broken (indicating that the conclusion is not linear and uni-dimensional, but had to make many detours, stops, as well as several repeated (and reconstructed) starts; which makes it conceptually very close to enchrony, the concept we will introduce later in this chapter), depending on how complex the meaning and possibilities of its interpretation may be. There are many useful arrows in stock already, like:

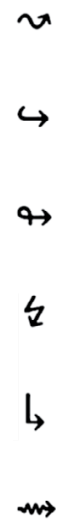

Which also implies that possible C's in this case (and many others, ambiguous or/and biased) may come not just in different forms and formulations, but also with different content and different versions and values attributed to this content.

This is the reason why the theory of visual argumentation would benefit from concentrating more on different possible entry and exit points in representation of visuals and interpretation of hypothetical visual arguments.

The reasoning is the seeing. Is it?

This is the reason why visual argumentation should concentrate more on different possible entry and exit points in data representation and interpretation of hypothetical visual arguments. As a kind of a case study-exposing possible caveats as well as cul-de-sacs of visual argumentation-we will concentrate on Leo Groarke's proposal of reconstructing visual arguments as presented and conceptualized in his 2013 article 'The Elements of Argument: Six Steps to a Thick Theory', published in the e-book What do we know about the world?: Rhetorical and Argumentative perspectives.

Here is the photo Groarke is taking as a starting point: 


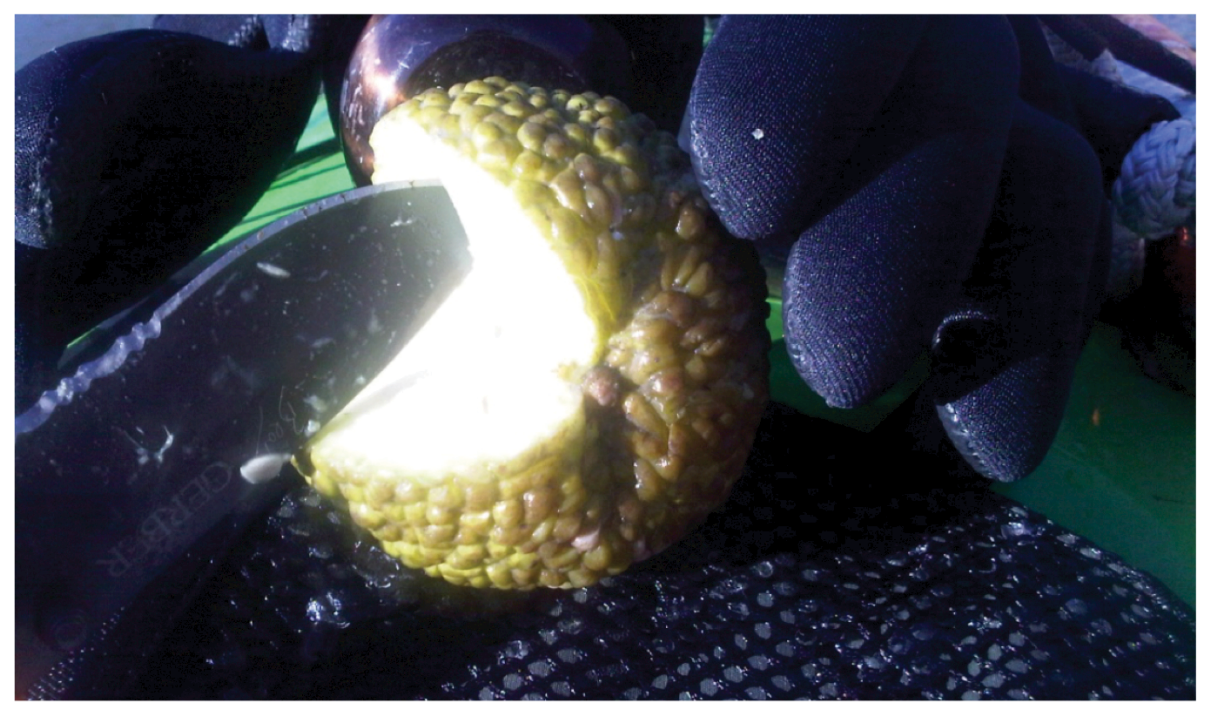

Figure II. Fruit found on the Detroit River I.

If we just take the photo in Figure 11 per se, as it is (as we see it prima facie), without or before any verbal explanation, and not knowing anything about possible context(s), the photo could be framed in many ways. As, for example:

(1) introducing/showing a peculiarly looking fruit;

(2) preparing a snack (or some other kind of meal);

(3) showing/presenting a new knife;

(4) showing/presenting an efficient/robust/... knife;

(5) showing the protective gloves, or how do protective gloves look like/how we use them;

(6) warning that one should wear protective gloves when using a knife (demonstrating safety procedures), etc.

But Groarke does disambiguate the photo rather quickly with the following explanation (all emphases throughout the text that will follow are mine):

Consider a debate spurred by an unusual fruit I discovered during a kayak ride on the Detroit River. When my description ('nothing I recognize; a bumpy, yellow skin') initiated a debate 
and competing hypotheses on the identity of the fruit, I went back and took the photographs reproduced below. On the basis of these photographs, the fruit was quickly identified as breadfruit.

So the frame in question is the first one mentioned: introducing/showing a peculiarly looking fruit. And here is how Groarke reconstructs the argument (actually the process of arriving from argument(s) to conclusion) in question:

The argument that established this conclusion compared my photographs to similar photographs found in encyclopaedia accounts of breadfruit. One might summarize the reasoning as: 'The fruit is breadfruit, for these photographs are like standard photographs of breadfruit.' But this is just a verbal paraphrase. The actual reasoning - what convinces one of the conclusion-is the seeing of the sets of photographs in question. Using a variant of standard diagram techniques for argument analysis, we might map the structure of the argument as:

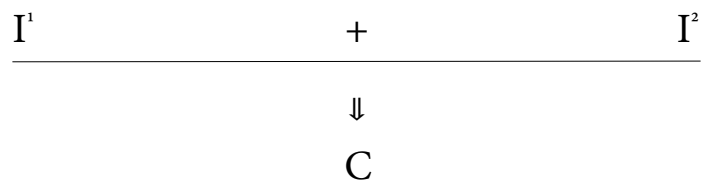

where $\mathrm{C}$ is the conclusion that the fruit is a piece of breadfruit, $\mathrm{I}^{1}$ is the set of photographs I took, and $\mathrm{I}^{2}$ is the iconic photographs of breadfruit to which they were compared.

\section{Comparing the visuals as argumentation}

But should (and does) the reasoning really consist just of 'the seeing of the sets of photographs in question'? Is just seeing and visually comparing photographs from different sources really enough for a reasoned, justified conclusion (in question)? And last but not least, let us not neglect Groarke's remark that 'on the basis of these photographs, the fruit was quickly identified as breadfruit'. Is the velocity of (visual?) reasoning to be considered a necessary and sufficient criterion for good argumentation?

In order to answer these questions, we will be replicating Groarke's procedure. Here are some photos of breadfruit found in different encyclopaedias: 


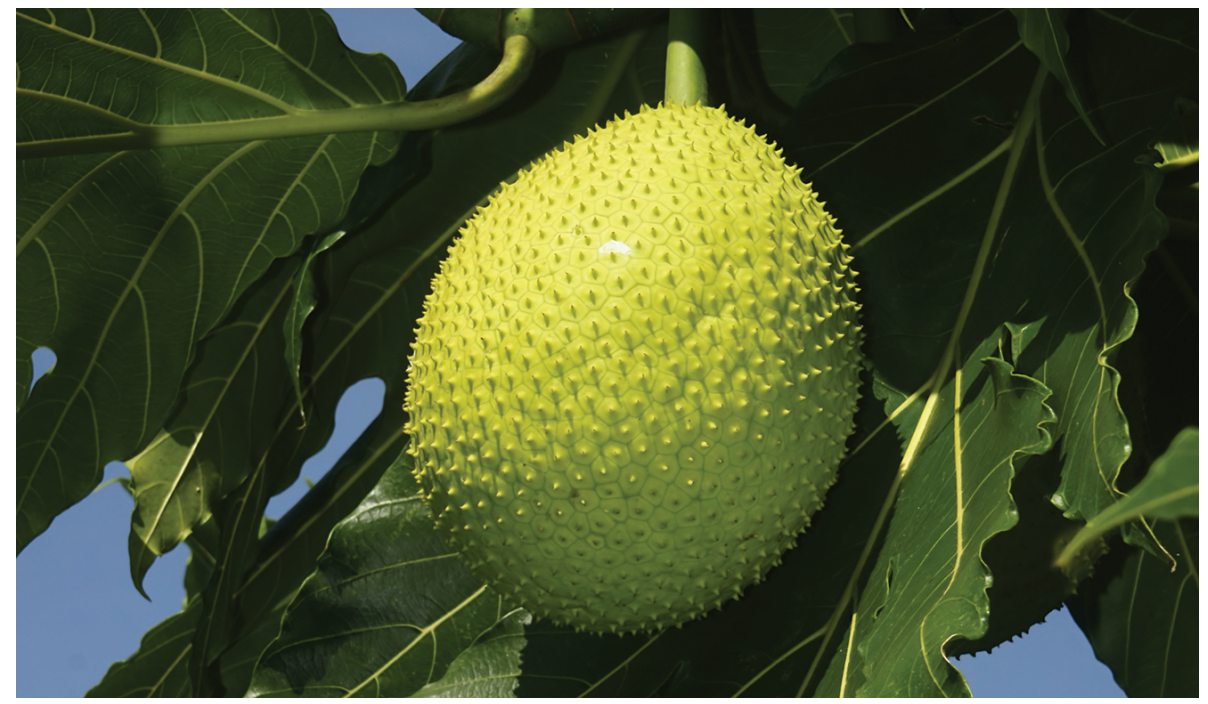

Figure I2 Breadfruit at Tortuguero (Wikipedia, https://en.wikipedia.org/wiki/ Breadfruit).

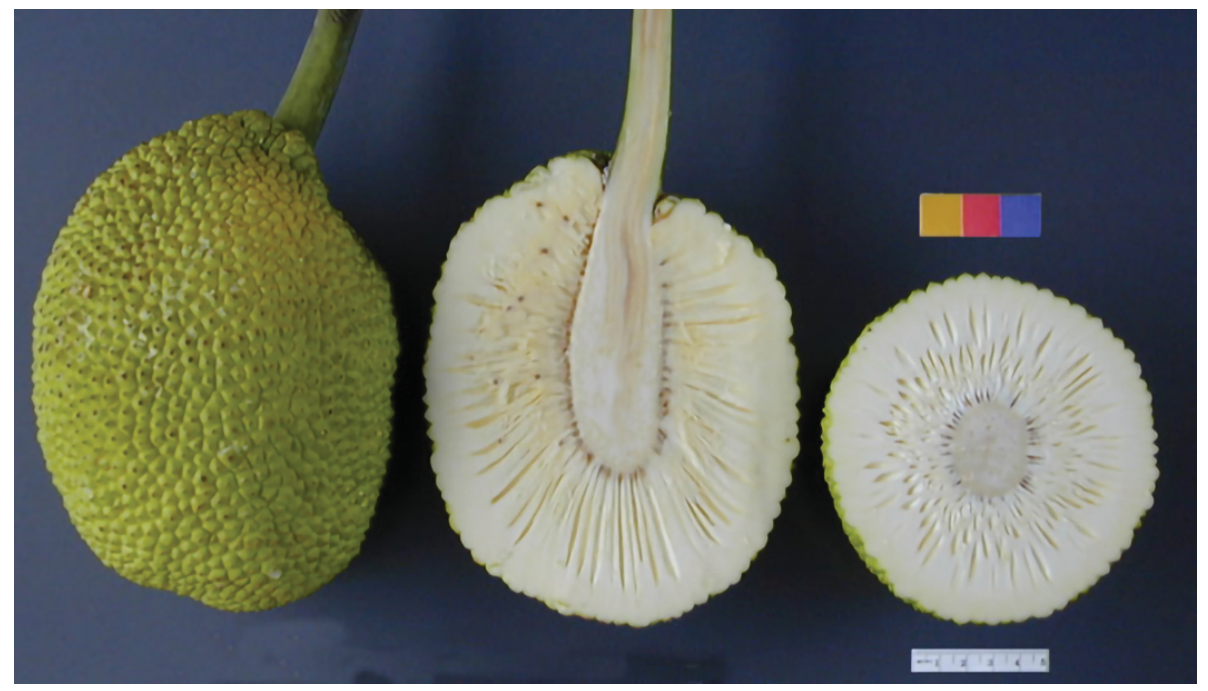

Figure 13. The fruit of the breadfruit tree-whole, sliced lengthwise and in cross-section (Wikipedia, https://en.wikipedia.org/wiki/Breadfruit). 


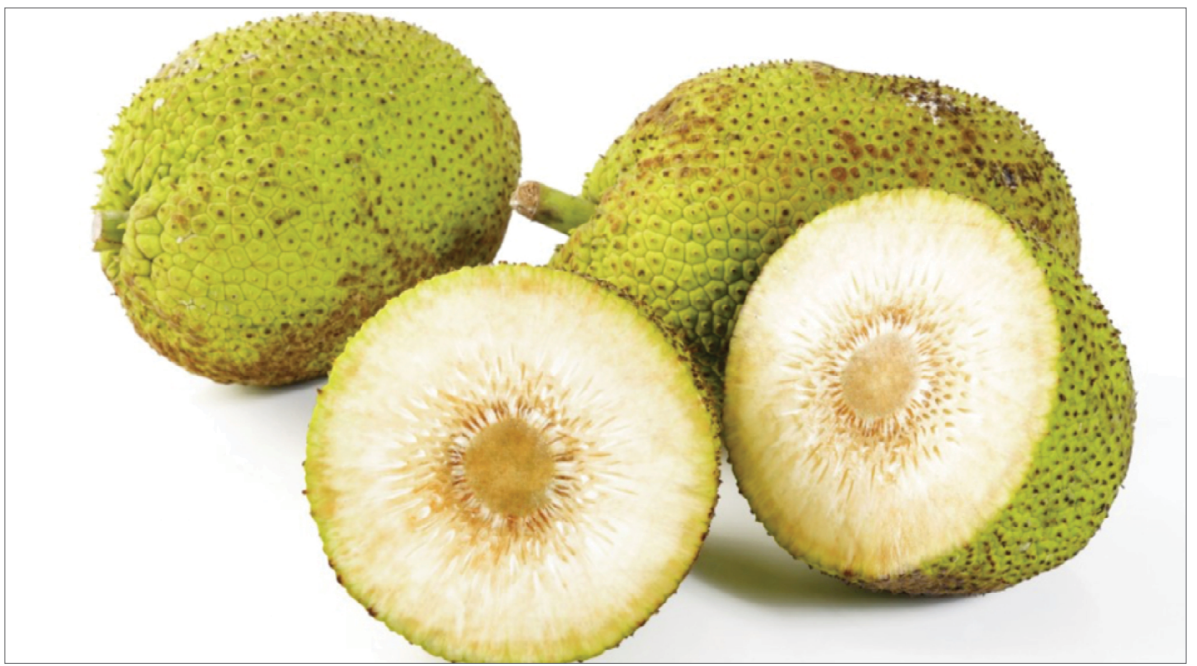

Figure i4. Breadfruit (Healthy Benefits, http://healthybenefits.info/ the-health-benefits-of-consuming-bread-fruit $\% \mathrm{E}_{2} \% 80 \% 8 \mathrm{~F} /$ ).

And here, again, are Groarke's two photos (from the point of view of perception, processing and meaning construction, it is important for the ('argumentative') viewer that they are incorporated between new photos (of breadfruit), and not just referred to by numbers (e.g. Figure 11)): the one we have already seen:

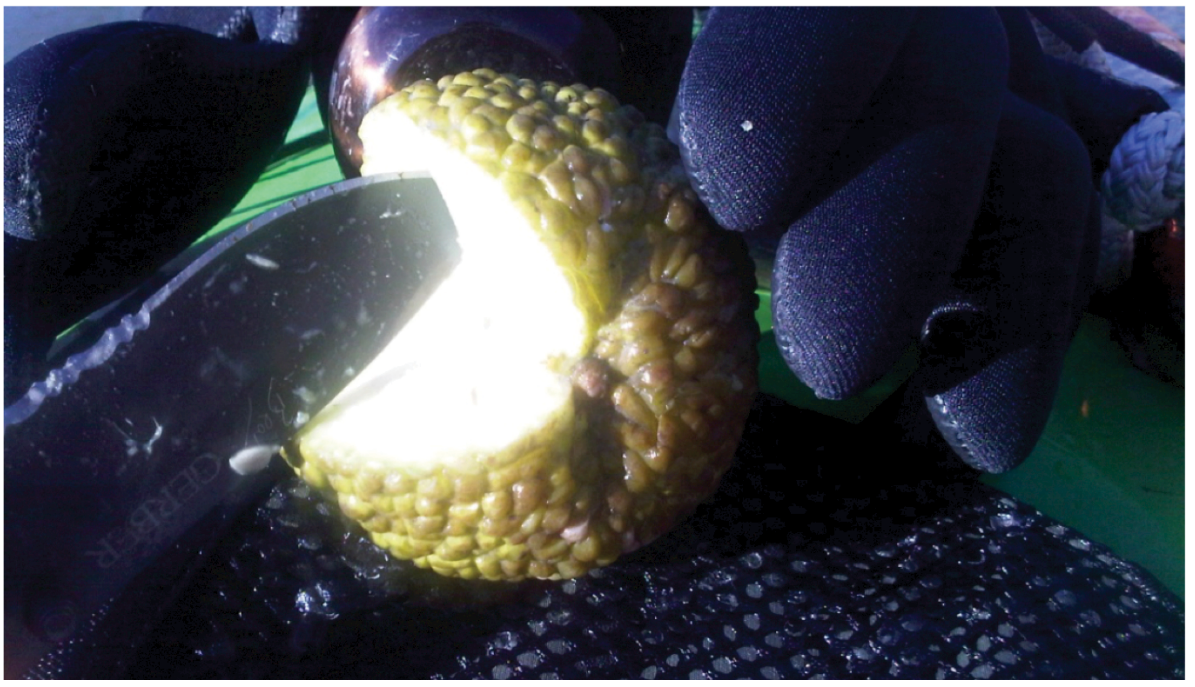

Figure II. Fruit found on the Detroit River I. 
and the one we haven't seen yet:

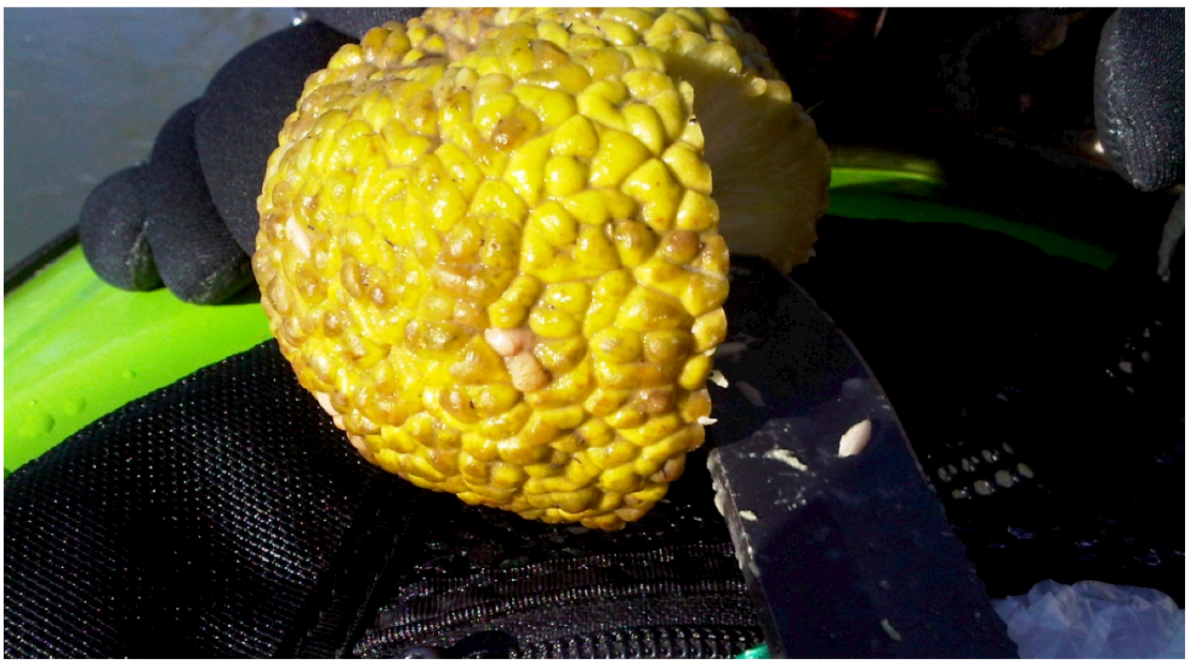

Figure 15. Fruit found on the Detroit River II.

Please inspect these photos carefully. Is there really such a resemblance between the two represented fruits that we can quickly identify the fruit from the Detroit River as breadfruit? To put it in Groarke's words, I don't see that resemblance.

Breadfruit, as we have seen, has a kind of knobbly skin with spines or hard hairs, patterned with irregular, 4- to 6-sided face, while in the center there is a cylindrical core. On the other hand, the skin of the fruit found in the Detroit River seems smooth, without spines or hairs, covered with smooth irregular bumps, no 4- to 6-sided face, and there seems to be no cylindrical core in the centre (though that may be due to the lightning, the angle or some other disturbing factor).

\section{Introducing the necessity of the verbal}

In such a case (where some items/entities look alike, but don't quite the same), just 'seeing' is not enough, and it is wise if not necessary to consult other reliable sources, like verbal description.

Why verbal descriptions? Because in such a case there is not much else one can consult. On the other hand, language is still the only communicative 'medium' that is (rather) linear, straightforward, and unambiguous enough; in combination with pertinent visuals almost error-proof. And 
if, when consulting encyclopaedias or other relevant sources, we don't just check the photos, but the text as well, we find the following description of breadfruit (please, pay special attention to emphases in italics):

Breadfruit (Artocarpus altilis) is one of the highest-yielding food plants, with a single tree producing up to 200 or more fruits per season. In the South Pacific, the trees yield 50 to 150 fruits per year. In southern India, normal production is 150 to 200 fruits annually. Productivity varies between wet and dry areas. In the Caribbean, a conservative estimate is 25 fruits per tree. Studies in Barbados indicate a reasonable potential of 6.7 to 13.4 tons per acre (16-32 tons/ha).

$[\ldots]$

Breadfruit, an equatorial lowland species, grows best below elevations of 650 metres $(2,130 \mathrm{ft})$, but is found at elevations of 1,550 metres $(5,090 \mathrm{ft})$. Its preferred rainfall is $1,500-3,000$ millimetres (59118 in) per year.

$[\ldots]$

Breadfruit is a staple food in many tropical regions. The trees were propagated far outside their native range by Polynesian voyagers who transported root cuttings and air-layered plants over long ocean distances. (From Wikipedia: http://en.wikipedia.org/wiki/ Breadfruit)

If we sum up, breadfruit is a tropical plant, usually found (and used) in tropical areas. It is, therefore, not very probable to find it in Ontario, in the Detroit River, though it is not completely impossible, of course, that a specimen of a breadfruit found its way into the Detroit River from one of the local Caribbean restaurants or stores.

But if relevant sources were indeed amply consulted (i.e. browsed through), and the point of departure in investigating the nature of the found fruit was not based on some kind of preconceived idea or a hunch that the Detroit River fruit looked very much like breadfruit, a neutral, objective and interested investigator should have easily found the following photos as well: 


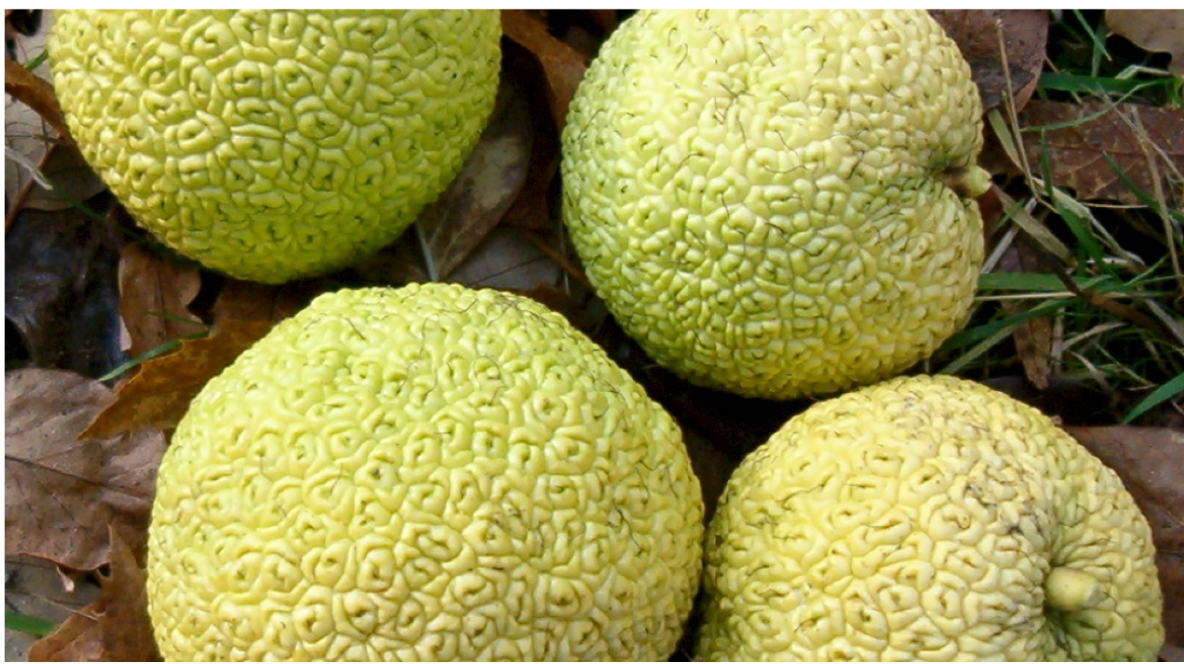

Figure i6. Maclura pomifera (Wikimedia Commons, https://commons.wikimedia.org/ wiki/File:Maclura_pomifera_Inermis_BotGardBlnıosFruits.jpg).

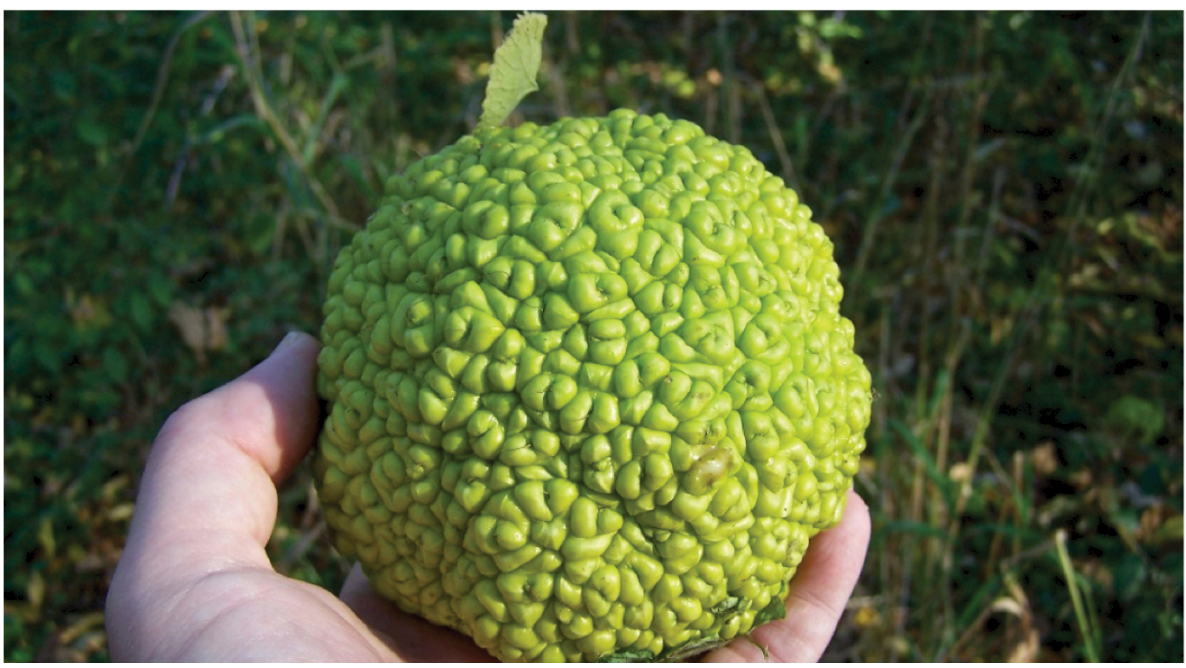

Figure 17. Maclura pomifera (Plants for a Future, http://www.pfaf.org/user/Plant. aspx?LatinName=Maclura+pomifera). 


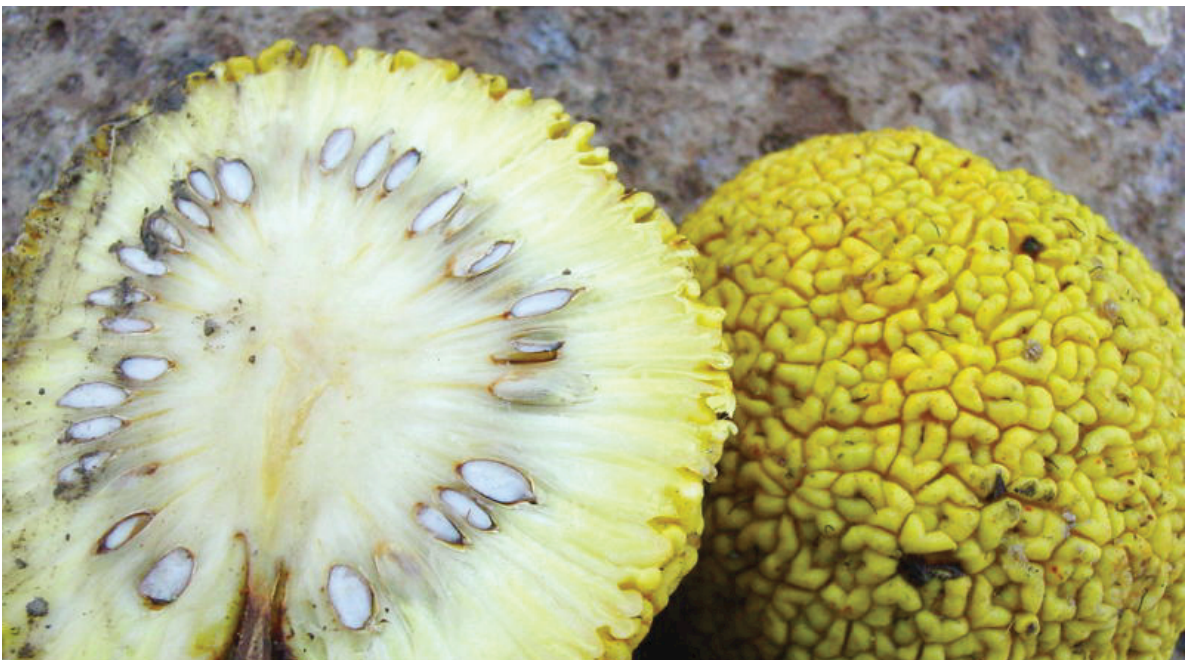

Figure i8. Maclura pomifera (Acta Plantarum, http://www.actaplantarum.org/acta/ galleriaı.php?aid=463).

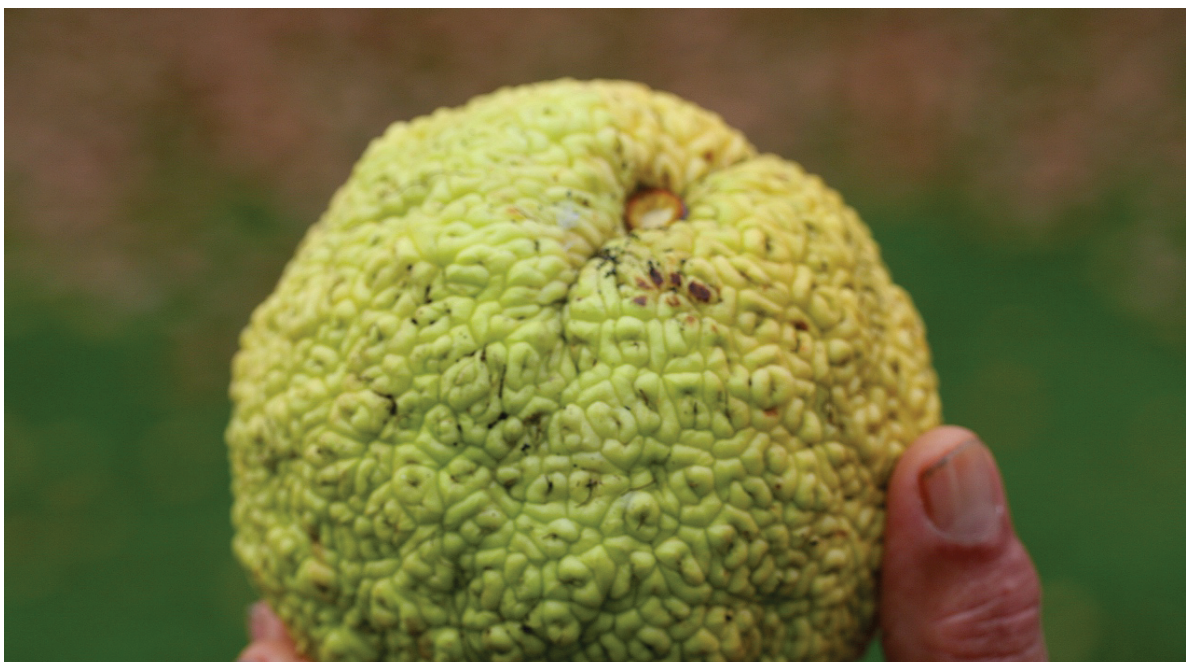

Figure 19. Maclura pomifera (Wikimedia Commons, https://commons.wikimedia.org/ wiki/File:Maclura_pomifera_FrJPG.jpg).

And once more, here are the two photos of a fruit found in the Detroit River: 


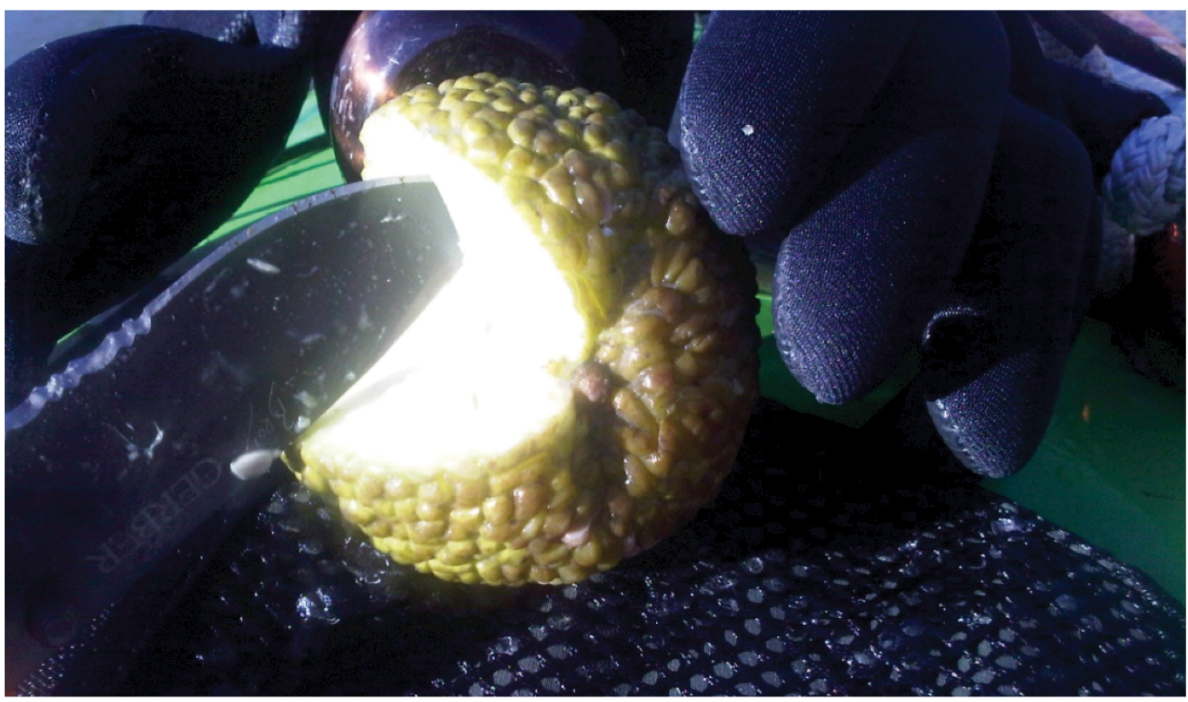

Figure II. Fruit found on the Detroit River I.

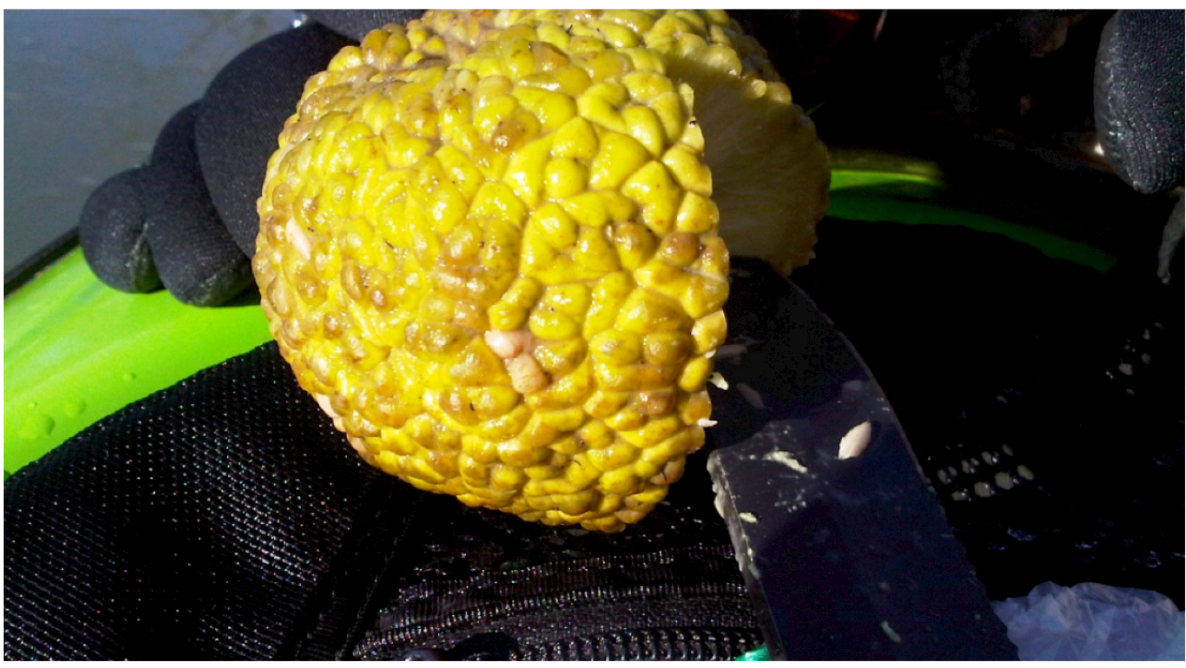

Figure 15. Fruit found on the Detroit River II.

A close comparative observation between encyclopedic photos of this second fruit and the photos of breadfruit reveals that this second fruit looks much more like the fruit found in the Detroit River: its skin seems smooth, without spines or hairs, and it is covered with smooth irregular bumps, not 4- to 6-sided face as in the bread fruit. 
And if we consult the verbal part of the encyclopaedia, connected to this fruit, we find the following (once more, please, pay attention to emphases in italics):

Macula pomifera, commonly called Osage orange, hedge apple, horse apple, bois d'arc, bodark, or bodock is a small deciduous tree or large shrub, typically growing to $8-15$ meters $(26.49 \mathrm{ft})$ tall. It is dioecious, with male and female flowers on different plants. The fruit, a multiple fruit, is roughly spherical, but bumpy, and 7.6-15 centimetres (3-6 in) in diameter. It is filled with sticky white latex. In fall, its color turns a bright yellow-green.

$[\ldots]$

Osage orange occurred historically in the Red River drainage of Oklahoma, Texas and Arkansas and in the Blackland Prairies, Post Oak Savannas, and Chisos Mountains of Texas. It has been widely naturalized in the United States and Ontario. (Wikipedia: http://en.wikipedia.org/wiki/Maclura_pomifera)

As you can see for yourself, the verbal description of Macula pomifera actually fits the Detroit River fruit much more accurately than the description of breadfruit. And since we learn that the Osage orange 'has been widely naturalized in the United States and Ontario' it is much more probable that it fell in the water someplace along the Ontario river than that it found its way into the river from one of the Caribbean facilities in Ontario.

\section{Thousands of words and a single picture}

What can we learn from this? Above all that sayings like: 'A picture tells a thousands words' should be indeed taken seriously. But, to be (absolutely) sure which of these thousands words refer to that particular picture we have in front of us in these particular circumstances, we have to cut down (on) those words considerably. On the other hand, without any words at all, we can hardly identify the exact meaning of the picture

In other words, there seem to be no pure visual arguments (as there are, probably, very few purely verbal arguments; if any at all), and instead of visual argumentation (or purely verbal argumentation, for that matter) we should (always) talk about multimodal argumentation and multimodal meaning (combining, in our case, at least visual and verbal, but other semiotic modes are usually involved as well, such as gesture and gaze). But 
multimodal meaning and multimodal argumentation require different (expanded, at least) analytical framework, let us simply call it multimodal analysis. And in relation to that, I would like to emphasize a few points.

In cases where just 'seeing' is not enough, and we have to consult verbal (or other) sources (and incorporate other types of signs, like gestures, gazes ...), we should be talking of enchronic analysis (Enfield 2009). What is enchronic analysis?

Enchronic analysis is concerned with relations between data from neighbouring moments, adjacent units of behaviour in locally coherent communicative sequences. (Enfield 2009: 10)

Enchronic analysis is therefore looking at sequences of social interaction in which the moves that constitute social actions occur as responses to other such moves, and in turn these give rise to further moves. The Detroit River fruit is exactly a case in point: from observation of the photos of the fruit taken on the river, we have to move to the observation of the photos in encyclopaedias. And to get more complete and accurate information we have to switch from photos to text, and incorporate the textual information as well. And to fine-tune our findings (understanding), we have to switch to yet other photos (if necessary), and from them to yet another text(s) (if necessary), and finally compare all these again with the initial photo (of the fruit taken on the river).

If, when consulting encyclopaedias, we don't just check the photos, but the text as well, and then go and (re)check other available texts and photos, and compare them with the initial photo(s), the final result we arrive at should be described as composite meaning, resulting in composite utterances, conceptualized as: '[...] a communicative move that incorporates multiple signs of multiple types'. (Enfield ibid.: 15)

Here is a visual example of a composite sign (with composite meaning), Enfield is using himself: 


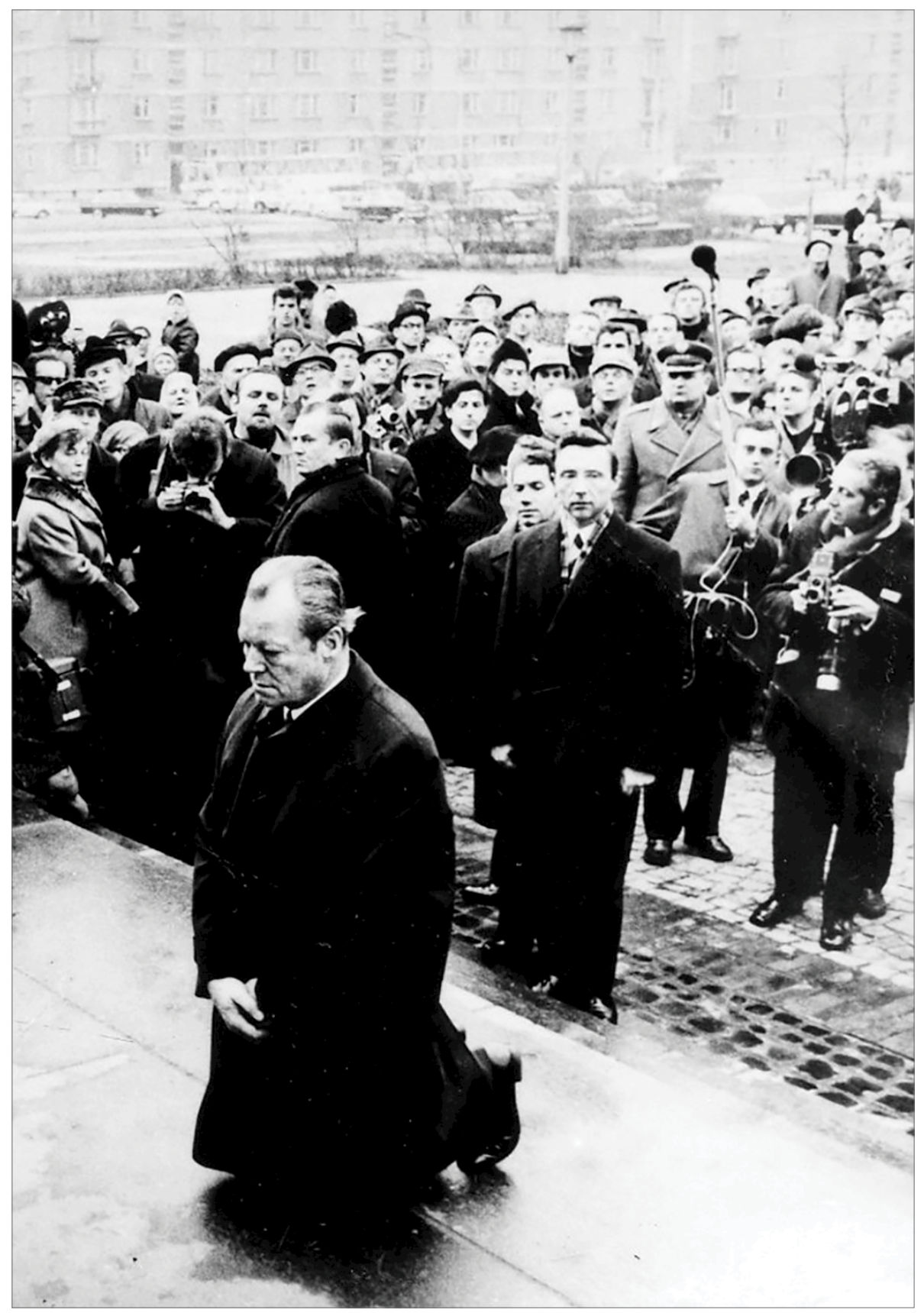

Figure 20. Willy Brandt in Warsaw Ghetto (published in Enfield 2009: 3). 
And this is his analysis (Ibid.: 3-4):

While the kneeling posture may have an intrinsic, ethological basis for interpretation, this particular token of the behaviour has had a deeply enriched meaning for many who have seen it, because it was performed by this particular man, at this time and place. The man is Willy Brandt, chancellor of West Germany. Once you know this, the act already begins to take on enriched meaning. It is not just a man kneeling, but a man whose actions will be taken to stand for those of a nation's people. It is 7 December 1970, a state visit to Warsaw, Poland. These new layers of information should yet further enrich your interpretation. To add another layer: the occasion is a commemoration of Jewish victims of the Warsaw Ghetto uprising of 1943. [...] The body posture [...] is a composite sign in so far as its meaning is partly a function of its co-occurrence with other signs: in particular, the role being played by its producer, given the circumstances of its time and place of production. The behaviour derives its meaning as much from its position on these coordinates as from its intrinsic significance.

\section{In place of conclusion}

We are dealing with several layers of meaning here, resulting in complex amalgam of signs as a process and product of a sequence of meaning-making moves. First, there is a kneeling posture as such, with its prototypical meaning. Then there is the presence of Willy Brandt, at that time the chancellor of Germany, with a variety of different meanings being attached to him or his function. The chancellor of Germany taking this kneeling position creates the third (amalgam) layer of meaning. The fourth layer of meaning is provided by the information that this act of kneeling was part of Brandt's state visit to Warsaw, and the fifth layer is provided by the information that Brandt's kneeling act was part of the commemoration of Jewish victims of the Warsaw Ghetto.

Speaking of the photo as such, these five layers of meaning form an amalgam of signs. But even more layers of meaning may be added, depending on the background knowledge of the observer and interpreter, as well as the context in which the photo is interpreted.

In view of all that has been said, let us return to the fruit found in Detroit River. If after checking and re-checking different photos, different 
texts, and the strange fruit that was found in Detroit River, we finally point (and probably gaze) at it, declaring: 'This fruit is not a bread fruit!', we have produced a composite utterance, enchronically embracing several, at least seven, layers of meaning (1) checking the photos of the Detroit River fruit, (2) checking the photos of breadfruit in different encyclopaedias, (3) checking the text that comments on these photos, (4) checking the Detroit River fruit again, (5) looking for photos of similar fruits, (6) checking the text that comments on these fruits, (7) rechecking the Detroit River fruit again), belonging to three types of signs (conventional signs: words/text; non-conventional signs: photos, gesture, gaze; symbolic indexicals: demonstrative pronoun 'this', linking the conventional and non-conventional signs).

Put in other words and more explicitly: reasoning is not and cannot be just seeing, and just seeing is not and cannot be reasoning. Consequently, there is no 'pure' visual, but only multimodal argumentation: ${ }^{3}$ at least verbal and probably other codes should be taken into consideration in order to reach sufficient, satisfying and complete meaning interpretation. To gain analytic credibility and interpretive force, scholars working on visual argumentation should consider incorporating into their framework all these intermediate gradual steps, as well as all these mutually dependent concepts.

3 A large body of literature has already been published on multimodality. An excellent introductory study is the book by Gunther Kress, Multimodality: A social semiotic approach to contemporary communication (London: Routledge, 2010). 



\section{Perception, inference, and understanding in visual argumentation (and beyond) ${ }^{\mathrm{I}}$}

In the previous chapter, I was concentrating on some theoretical concepts VA was (in my view) lacking (and still is), but should be incorporated in their conceptual framework in order to better explain how visuals really function, that is, how they catch the viewers' attention, how the viewers break them down, and how they reconstruct and infer their meaning.

I'll be returning to some of these concepts at the very end, when (tentatively) introducing the 'perceptual-cognitive filtering grid' (a purely technical working name), a version of pragmatic-semantic interface, indispensable (but usually implicit) in every meaning construction and interpretation.

My conclusion in the previous chapter, after analyzing Groarke's famous Detroit River fruit paper in detail, was that

If after checking and re-checking different photos, different texts, and the strange fruit that was found in Detroit River, we finally point (and probably gaze) at it, declaring: 'This fruit is (not) a bread fruit!', we have produced a composite utterance, (enchronically) embracing several (at least) seven layers of meaning, belonging to three types of signs (conventional signs: words/text; non-conventional signs: photos, gesture, gaze; symbolic indexicals: demonstrative pronoun 'this'). (Žagar ibid.: 852)

1 First version of this chapter was published in Steve Oswald and Didier Maillat, eds., Argumentation and Inference, vol. II. Studies in Logic and Argumentation, vol. 77. (London: College Publications, 2018), 439-469. 
Or put differently and more explicitly: in case of visuals and VA, reasoning is not and cannot be just seeing, and just seeing is not and cannot be reasoning, as Groarke hastily claims in his paper 'The Elements of Argument: Six Steps to a Thick theory ' (Groarke 2013:34-36). Consequently, there can be no 'pure' visual, but only multimodal, argumentation: at least verbal and most probably other codes should be taken into consideration when analyzing an alleged visual, in order to reach sufficient, satisfying, complete, and as less biased meaning interpretation as possible.

\section{'Pure' and 'infected' visuals, eye tracking and pilot questionnaire}

In the present chapter, I want to upgrade the theoretical (conclusions) from the previous chapter, and support them with empirical research and data.

The first step to achieve this was a short stay at the Max Planck Institute for Empirical Aesthetics in Frankfurt, ${ }^{2}$ where (with some help from more experienced colleagues in empirical methodology) I devised a preliminary proposal/pilot study to be tested experimentally and exploratory at the eye-tracking lab at the Institute for Specialized and Intercultural Communication (University of Warsaw).

The overarching research question of this pilot study was: When confronted with visuals, 'pure' (no verbal elements) or 'infected' (visuals combined with (a few) verbal elements)), could reasoning (i.e., constructing meaning through inferences) really consist only of seeing the visuals? More precisely: when confronted with 'infected' visuals, would (and could) people really disregard the few verbal elements present and just concentrate on the visual? And when confronted with 'pure visuals', would they be looking for (expected, usual, possible, hypothetical ...) verbal (or other) cues in order to make sense (construct the meaning) of the visual?

To shed some more light on this question, an eye tracking experiment was to be conducted, involving 10 participants and 10 visuals (mostly visual advertisements (posters) and comics well known from the VA literature that contain a few verbal elements). The experiment would be of the so called 'between subjects design', consisting of 2 rounds, a pre-test and a post-test.

A pre-test would try to establish how experimental subjects (in their own view and in their own words) see, perceive, process, and interpret

2 The workshop in Frankfurt was part of COST Action IS1404, E-READ, Evolution of Reading in the Age of Digitisation. 
visual materials. Whether they look for other (non-visual) cues in order to help them interpret what they see, and construct (some) meaning.

The same test would be administered to them after 2 rounds of eye-tracking, while during these two rounds the experimental subjects would be asked what they have seen (what the visual was about, what was its 'message'; in their view, of course) after each visual.

Round 1:

Participants 1-5 see visuals $1-5$ from which all verbal elements were eliminated.

Participants 6-10 see visuals 1-5 as they are, with verbal elements.

Round 2 (reverse of round 1 ):

Participants 1-5 see visuals 6-10 as they are, with verbal elements. Participants 6-10 see visuals 6-10 from which verbal elements were eliminated.

o hypothesis: participants would process 'pure' visuals and 'infected' visuals in the same way.

1 hypothesis: participants would look for potential verbal (or other non-visual) elements in order to help them interpret the visuals.

Unfortunately, for the lack of funds, the experiment had to be postponed in the last minute, so I had to find a more or less suitable replacement. I opted for an experimental survey study, involving a pilot questionnaire.

This pilot questionnaire, titled A Short Questionnaire on Understanding the Visuals (Drawings, Pictures, Photographs ...) comprised three wellknown visuals from Leo Groarke's work on VA, namely: 
(1) The smoking fish (where all the text was removed from the picture):

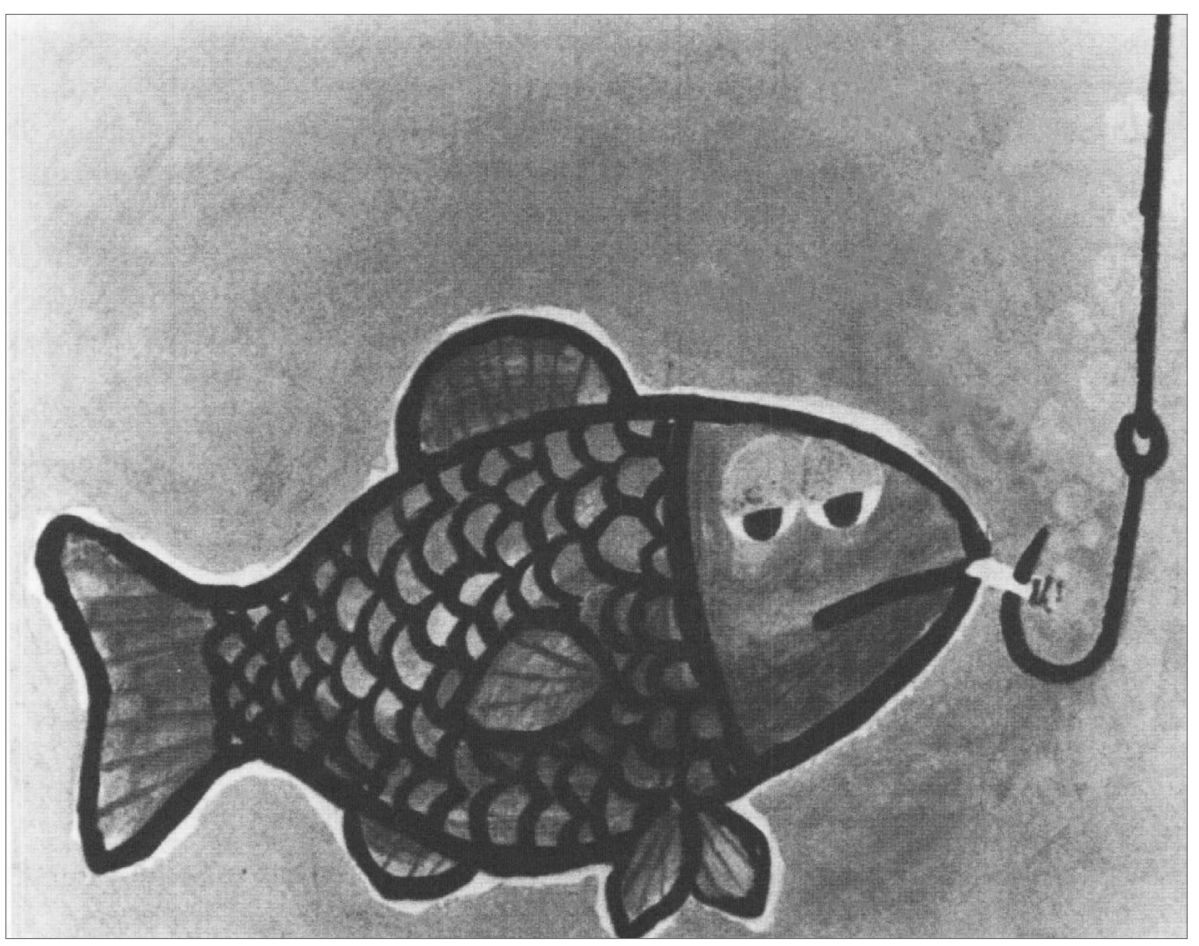


(2) The poster 'UvA for Women' (see pp. 78-79 for details):

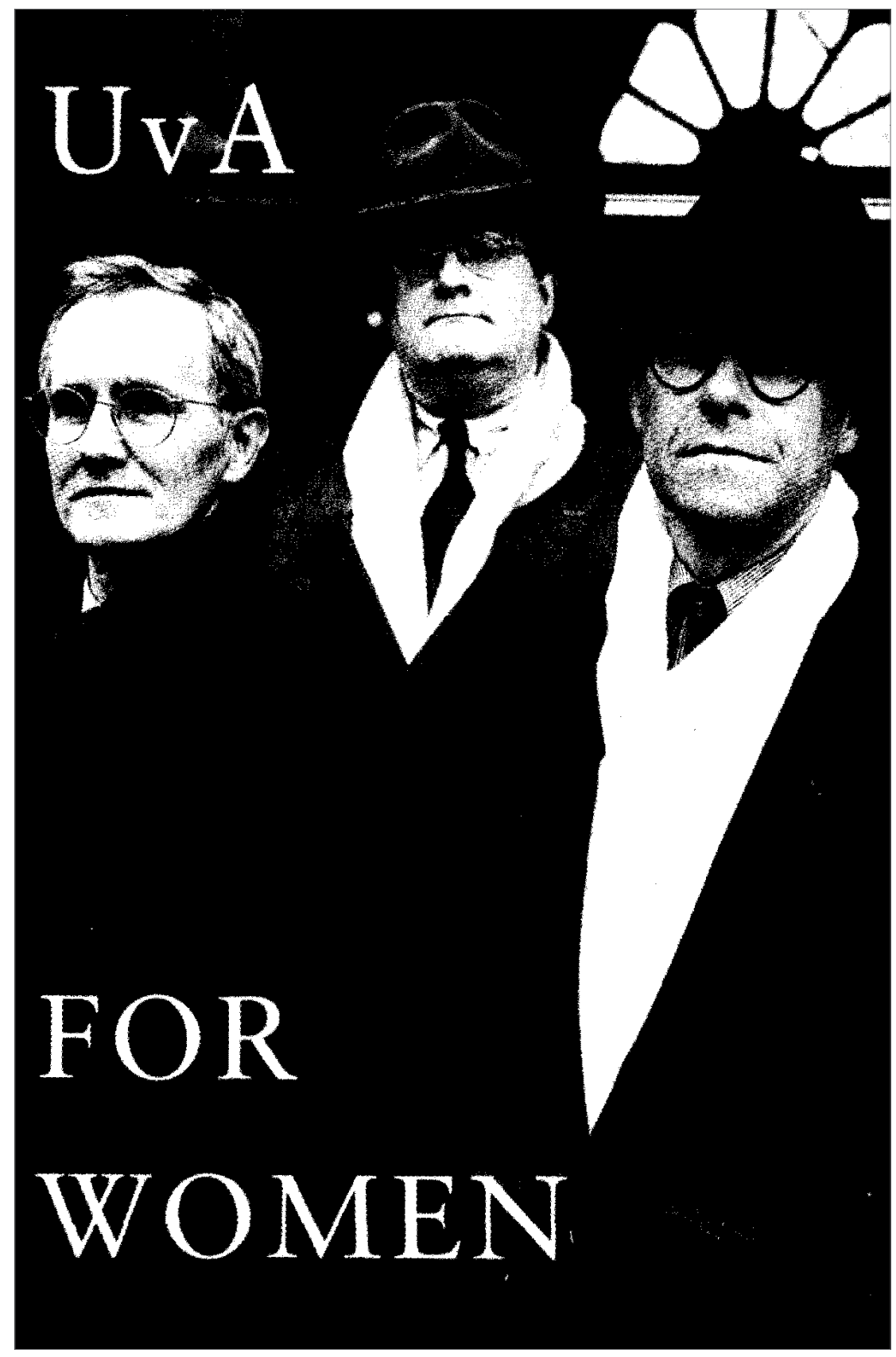


(3) Jacques-Louis David's painting La Mort de Marat (Marat's Death):

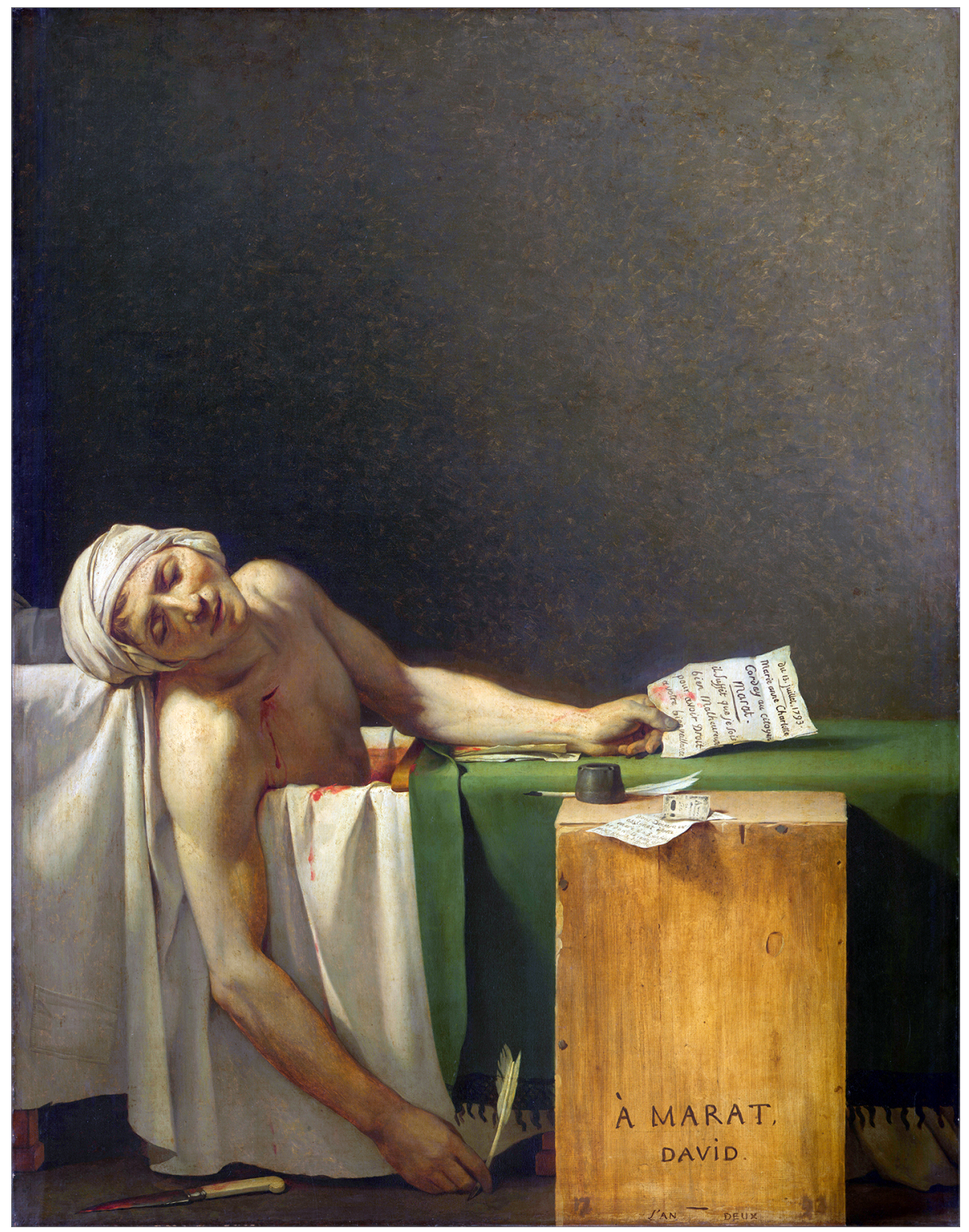




\section{Calibrating the questionnaire: not too much and not too little}

Each visual was preceded with a necessary but short introduction-necessary for historically or chronologically framing the visual (but not explaining the context) - , while following each visual there were two questions, constructed in as neutral way as possible, at the same time trying to avoid a very actual possibility in this kind of surveys that respondents wouldn't understand what the goal (the intention) of these questions was. Here they are.

In the case of the smoking fish:

Introduction: The drawing below dates back to the seventies of the previous century. Please, take a good look at it, and then answer the two questions below.

Question 1: What do you see on the drawing (how would you describe the 'content' or 'what is going on' in the drawing in the most correct and objective way)?

Question 2: In your opinion, what could be the goal/purpose/meaning of the drawing? In other words, how would you interpret it (e.g., advertisement against smoking/cigarettes, advertisement in favour of smoking/cigarettes, advertisement in anglers' bulletin, joke, caricature, other). Please, give reasons for your opinion.

In the case of UvA for Women:

Introduction: The photograph below represents a poster that was to be found around Amsterdam some time ago, probably especially in the vicinity of the University of Amsterdam. The text on the poster reads: 'University of Amsterdam - for Women'. Please, take a good look at it, and then answer the two questions below.

Question 1: What do you see on the poster (how would you describe the 'content' or 'what is going on' in the poster in the most correct and objective way)?

Question 2: In your opinion, what could be the goal/purpose/meaning of the poster? In other words, how would you interpret it (e.g. advertisement for the university, call for enrollment, call for employment, joke, parody, other). Please, give reasons for your opinion. 
In the case of David's Marat:

The painting below was created in 1793 by Jacques-Louis David, and bears the title La Mort de Marat (Marat's Death). Please, take a good look at it, and then answer the two questions below.

Question 1: What do you see on the painting (how would you describe the 'content' or 'what is going on' in the poster in the most correct and objective way)?

Question 2: Does the painting remind you of anything or recall any historical (or other) reminiscences? If yes, please explain which one(s), and why.

This questionnaire was distributed/administered to three different age groups, with different educational background, all European, with Slovenian citizenship. I planned a fourth one, a group of refugees living in Slovenia (mostly from Syria, Iraq and Afghanistan, some of them from North Africa), but the refugee coordinator refused to participate because of ethical reasons. The survey took place between $29^{\text {th }}$ May and $8^{\text {th }}$ June 2017.

Here are some of the characteristics of these groups:

Group 1: STUDENTS (number: 26; age: 20-24; sex: 25 female, 1 male; education: completed high school, currently and year students of Educational Studies at the University of Primorska, Slovenia).

Group 2: RESEARCHERS (number: 7/30; age: 28-68; sex: 6 female, 1 male; education: $\mathrm{PhD}$ in Philosophy, Sociology, Psychology, Education Sciences, two PhD candidates, all working at the Educational Research Institute, Slovenia).

Group 3: SENIORS (number: 3/12; age: 69-86; sex: 2 female, 1 male; education: high school to university education, all attendants of the University of the Third Age, Slovenia).

Obviously, from the methodological point of view and strictly statistically speaking, samples vary too much and cannot be compared in an orderly quantitative fashion. But at this point, I was interested in qualitative data, and as a pilot study, even such disparate groups are acceptable.

What follows are the findings of our survey. 


\section{About the smoking fish}

\section{The claims}

First, let us have a look at Groarke's and Birdsell's argument from 1996, and my criticism from the previous chapter:

The authors (Birdsell and Groarke) first admit that 'visual images can, of course, be vague and ambiguous. But this alone does not distinguish them from words and sentences, which can also be vague and ambiguous' (Birdsell, Groarke 1996: 2). And I agree with that. Than they qualify this poster as 'an amalgam of the verbal and the visual' (ibid.), which, again, sounds quite acceptable. But then they conclude: 'Here the argument that you should be wary of cigarettes because they can hook you and endanger your health is forwarded by means of visual images ...' (ibid.: 3). Which is obviously not the case. Without the verbal part, 'don't you get hooked!', the poster could be understood (framed) as a joke, as a cartoon, where, for example, smoking is presented as such a ubiquitous activity that even anglers use cigarettes to catch fish. Only when we add the verbal part, 'don't you get hooked!'where 'hooked' activates a (this time semantic) frame of (semantic) knowledge relating to this specific concept, which includes 'get addicted', and is, at the same time, coupled with a visual representation of a hook with a cigarette on it-is the appropriate (intended) frame set: the poster is now undoubtedly understood as an anti-smoking add, belonging to an anti-smoking campaign.

And what does our pilot study show.

\section{The results}

Group 1: 9 students out of $26(34,6 \%)$ thought that the drawing 'could have been/might have been/probably was/likely was' an anti-smoking ad (but none of them straightforwardly answered that the ad was an anti-smoking ad).

There were another three answers $(12,8 \%)$ that the ad was probably against smoking, but two of them argued further that anti-smoking intention was just an intermediate stage, while the main point of the ad was that by smoking, we are polluting the environment. One of the respondents $(3,8 \%)$ opted for an anti-smoking ad because 'the hook pulls the cigarette out of the fish's mouth, thus preventing it to smoke'. 
Interestingly, three students $(12,8 \%)$ thought that the drawing was a representation of society in the seventies. One of them commented that 'the society realized that smoking was bad, but has already surrendered to destiny', the other one that the drawing 'represents people dissatisfied with the system'.

What is even more interesting is the fact that most of the respondents substantiated their claims not with the maggot on the hook in the fish's mouth, but by the expression on the fish's 'face'. Here are some qualifiers they used for the expression of the fish's face in relation with the maggot on the hook (and further, social situation at large):

- $\quad$ sad expression

- $\quad$ indifferent eyes

- $\quad$ bored and apathetic fish

- $\quad$ bored and indifferent gaze

- dead face

- $\quad$ sad gaze

- $\quad$ angry gaze

- unsatisfied expression

- $\quad$ boredom and discontent

- $\quad$ not in good mood

- reluctant and angry

- $\quad$ without emotions

- sad eyes.

This shifting focus from the (1) maggot on the hook to the (2) 'facial expression' of the fish, while (3) keeping in mind the info from the instructions that the drawing is from the seventies is a perfect proof that the decision about the meaning of the drawing was reached through enchronic analysis, something I argued for in previous chapter on purely theoretical grounds. Just a reminder what enchronic analysis is:

Enchronic analysis is concerned with relations between data from neighbouring moments, adjacent units of behaviour in locally coherent communicative sequences (Enfield 2009: 10). 
And what about the other answers from Group 1? Two of the respondents $(7,7 \%)$ thought it was (a kind of) a joke, meaning/implying that smoking is so widespread nowadays that even fish started to smoke.

Another two thought the drawing was an ad in an anglers' newsletter, its purpose being to alert the readers against the pollution of waters.

One of the respondents $(3,8 \%)$ thought it was a joke at the expense of non-smokers, another one that it was a teaser, a challenge to non-smokers (pleading in favour of cigarettes). Another one thought the drawing was a protest from the vegetarian viewpoint (emphasizing the feelings of a fish when it gets caught), somebody took it as a kind of allegory (in her own words): you can get hooked or you cannot (the choice is yours).

The remaining three $(11,5 \%)$ couldn't decide about the meaning of the message.

Group 2 had much less to say about the appearance of the fish, for most of them it looked 'sad and bored'.

As for the message, three of them $(42,8 \%)$ answered it could have been an anti-smoking ad, two of them $(28,8 \%)$ emphasized it could be either a funny ad, a joke, or an anti-smoking ad, while one of them $(14,3 \%)$ was reminded of the Rat Park Experiment, and one of the respondents thought the drawing looked like an illustration from a child book.

From the Group 3, we got the following three answers: (1) advertisement of the tobacco industry, (2) could be anything, and (3) I really don't know (33,3\% each).

\section{The discussion}

The conclusion we can draw from all these answers is pretty obvious, I think: Birdsell's and Groarke's claim that the argument that you should be wary of cigarettes because they can hook you and endanger your health is forwarded by means of visual images, is clearly refuted. Unless there is a clear verbal supplement, 'don't you get hooked', the interpretator's inference about the (intended) meaning of the drawing (let alone its possible argumentativity, which may not be inferred at all), obviously depends on their historical, social, cultural and/or individual background, on the specifics of their education and/or their values (to name just a few parameters) - as will become more and more clear with the following examples. 


\section{About UVA for women}

\section{The claims}

First, here is Groarke's argument(ation) from Informal Logic (1996: 112), and my counter-argument from the previous chapter.

Groarke's argument goes as follows:

The black and white photograph [...] presents the university's three chief administrators in front of the official entrance to the university. Especially in poster size, the photograph makes a stark impression, placing all this confident maleness in front of (visually blocking) the university's main entrance. According to the committee, which commissioned the poster, it is a 'statement', which effectively makes the point that 'we want more women at our university' and 'still have a long way to go in this regard'.

And this was my objection:

But, if we are not acquainted with the committee's 'statement' that they want more women at their university (as, I guess, an 'average' Amsterdamer is not), and we just, walking the streets of Amsterdam, bump into this poster with three corpulent males, 'stating' 'UvA for Women', it is not at all clear how the poster was intended to be framed (by its authors). Is it (simply) a bad joke? Like, these corpulent males looking down on women and explicitly mocking them (with an implicitly inverted message like 'We don't need any women at UvA!'). Should it be taken ironically, maybe cynically, as a meta-statement from somebody who knows and objects the fact that UvA is all male? There is even a (at least implicitly) sexist interpretation that all these males at UvA need more women (but not necessarily for teaching and research ...).

In other words, because of the insufficiently unambiguous framing it is not at all clear that we (the observers) can (and even should) reconstruct the argument(ation) in question the way Groarke does:

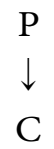

where the premise $\mathrm{P}$ is the (visual) statement that 'The University of Amsterdam's three chief administrators are all men' and C is the conclusion 
that 'The University needs more women' (Groarke ibid.: 111). Even if we take $\mathrm{P}$ as rather unambiguous (which it is not; for one thing, the fact that the University of Amsterdam's three chief administrators are all men is not a matter of general knowledge; also, it is far from obvious that the three men in the photo are University's administrators), the arrow leading to $\mathrm{C}$ is in no way - at least it couldn't have and it shouldn't have been-so linear, unidirectional, or monotonic (if you want) as to lead exclusively and directly to $C$, interpreted as 'The University needs more women'. C could easily have had many other interpretations (and $\mathrm{P}$ many other formulations than the one chosen by Groarke, for that matter), for example: 'UvA doesn't need women!', 'UvA is a sexist institution', 'UvA needs some women to change appearances'.

\section{The results}

Here is what my survey showed.

When describing the photo (question a), all three groups formulated what they saw in the photo in very similar, almost identical words: three well dressed middle-aged white males with spectacles, standing together, looking seriously.

As for question $b$, asking about the purpose, the objective of the poster, the answers were very far from Groarke's claim.

\section{Group 1}

Most of the students, $12(46,1 \%)$, thought the poster was a joke or a parody, two of them $(7,7 \%)$ qualified this joke as irony, one $(3,8 \%)$ of them as a sexist joke, and another one as some kind of advertisement for some kind of a band.

One of the respondents took it as a provocation (from the part of feminists), another one as making fools of women as well as of the university.

One respondent understood the poster as a criticism of the system (being unfair to women), another one as means of discouraging women to enrol.

Two of the respondents answered that the message was not clear, but maybe the purpose of the poster was to get attention of women (in one way or another).

Only two students answered that the poster may represent an advertisement for the university (asking women students to enroll), while a third one added the following explanation: 'call for enrollment addressed 
to women, so that they could have the same education as the men on the photo.'

The remaining $3(11,5 \%)$ couldn't decide.

\section{Group 2}

Two of the respondents $(28,6 \%)$ saw the poster as a parody (one of them as originating from students, the other as emphasizing the contradiction: more and more women at universities, while most of the leading positions are still in the hands of men).

One of the respondents (14,3\%) saw the poster as sexist, one of them as protest (against inequality), and another one as an effort to promote equality through contradiction.

One of the respondents saw the poster as failed advertisement for the university (failed because it was, according to the respondent, conveying the message that at UvA men work also for women).

Only one respondent saw the poster as calling more women to enrol, but added, 'especially in the fields where traditional patterns are dominant'.

\section{Group 3}

Out of only three answers, one of them 33,3) saw the poster as a joke, the other one as pointing to the problems (in the society), and the third one couldn't tell.

\section{The discussion}

It is quite obvious from the answers that the poster does not present the argument:

\section{P \\ C}

where the premise $\mathrm{P}$ is the (visual) statement that 'The University of Amsterdam's three chief administrators are all men' and $\mathrm{C}$ is the conclusion that 'The University needs more women' (Groarke 1996: 111). P and C could have been, even should have been, formulated quite differently, in many different ways and versions, and the possibilities of starting from different starting points should have been considered in interpretation (as rhizome theory (Deleuze, Guattari 2005) and superdiversity theory (Vertovec 2007; Blommaert, Rampton 2011) convincingly show), while the arrow 
connecting $\mathrm{P}$ and $\mathrm{C}$ should not be straightforward, but bent, curved or broken in different ways and on different places, indicating different non-linear ways to reach the conclusion.

\section{About Marat'a death}

\section{The claims}

Leo Groarke's interpretation of Jacques-Louis David' painting La Mort de Marat (IF 18/2-3, 1996) was often praised (but without giving any concrete arguments for this praise) as 'arguing convincingly' for the argumentative potential or argumentativity of David's painting presumably representing Marat as a dying Christ. Leo Groarke himself speaks more cautiously of 'the way in which argumentative analysis can illuminate a work of visual art' (119); according to him, it is 'the interpretation, not the work of art itself'.

But, how does Groarke proceed?

After a series of quotes and references from art history (which is an important fact for his argumentation as well as for my counter-argumentation), Groarke first comes to his (intermediate) claim:

We might easily understand the message of David's painting as the argument: 'Marat was a great martyr. You should, therefore, strive to be like him (and support the revolution).' There is something to this analysis, but a fully satisfactory account of Marat must better recognize the painting's visual and political context [sic!], which are evident in the number of details. Above all else, it is important to recognize that its style and composition compare Marat to Christ [sic!]. This is in keeping with hymns and rumours of the day [sic!], which celebrated this comparison (Marat's heart was, for example, treated as a relic and claimed to resemble Christ's [sic!]). (Groarke ibid.: 120)

If we sum up Groarke's analysis so far, in order to recognize the presumed resemblance between (the depiction of) dying Christ and (the depiction of) dying Marat, the observer is supposed to know about:

- painting's visual and political context

- style and composition

- $\quad$ hymns and rumours (of those days = Marat's days $=$ days of French revolution) 
- Catholic doctrine/mythology about the importance of people's hearts (especially heroes and martyrs).

But then, to justify his claim even more firmly, Leo Groarke gives this quote from his brother Louis Groarke's paper 'David's Marat: Beautiful Falsity or False Beauty ${ }^{34}$ that goes even deeper into detail and finesse of art history [sic!]:

David likewise presents us with a homage to a revolutionary Christ. The treatment of the figure recalls traditional religious iconography. The idealized nude body is like a Renaissance Christ. The recumbent pose with the extended, trailing arms recalls, in detail, depictions of the Dispositions of Christ (cf. Giroet, ${ }^{[s]}$ Caravaggio, Montagnea, ${ }^{[6]}$ Pontormo, Fiorentino, van der Wyden, etc.). The gaping wound with the stream of blood parallels the wound in the Saviour's side. The knife, smeared with blood, is the instrument of his passion, comparable to the lance and thorns and nails emphasized in many paintings of Christ's passion. Even the note clutched in his languishing hand might be compared to the notice nailed to the cross above the Saviours's head ...

When reading all this erudite and detailed thoughts and comparisons, we should be aware that Louis Groarke specializes in ethics, aesthetics and political history, this is (one of the reasons) why he was drawn to and fascinated by David's picture, and why he was able to see and discern all those details. But, could just anybody do it? Could an 'average' person from the street do it? Could a person with just an average education, without special interest in art history, do it? Could a(ny) person from another (non-Western) culture do it? Could a(ny) person belonging to another religious tradition than Christianity do it? I have serious doubts about that and my survey confirms them.

But after this quote and several other details coming (again) from art history, Leo Groarke proposes a diagram of the extended argument supposedly contained in and presented by David's painting. In short, the argument goes like this:

$\mathrm{P}_{1}=$ Marat was a man of great dignity and composure;

4 The exact reference of the paper, marked as 'forthcoming', is unfortunately missing.

5 Supposedly Anne-Louis Girodet de Roussy-Trioson (1767-1824).

6 Supposedly Andrea Mantegna (1431-1506). 
$\mathrm{P}_{2}=$ Marat's assassin herself recognized his reputation as a benefactor of the unfortunate;

$\mathrm{P}_{3}=$ Marat gave his last penny to the poor;

$\mathrm{C}_{1}=$ Marat was, like Christ, a great moral martyr;

$\mathrm{MC}=$ You must strive to emulate Marat in support of the revolution.

After giving a series of detailed, but disputed, historical facts, Groarke rejects all the above premises $\left(\mathrm{P}_{1}, \mathrm{P}_{2}, \mathrm{P}_{3}\right)$, as well as the claims $\left(\mathrm{C}_{1}, \mathrm{MC}\right)$, and concludes:

These criticisms of the argument in Marat cannot undermine the fact that it displays a magnificent ability to paint. But one artificially ignores the meaning of the painting if one does not recognize that David was a social commentator as well as a painter when he created Marat. It is not insignificant that he wielded tremendous influence and contributed to out-of-control executions by propounding faulty arguments that glorified Marat. One might best compare his masterpiece to a rhetorically powerful verbal argument, which is nonetheless founded on false premises and invites a faulty inference. (Groarke ibid.: 122)

Not just everybody can follow this chain of reasoning (and those who can would certainly not agree on all the points Groarke is making), not everybody can recognize David's painting of Marat as a powerful argument, based on a series of (disputed) social, cultural, political and religious details (that have different evaluations, depending on class, religious preference and many other socio-cultural factors).

A prototypical consumer of Groarke's reasoning, of his detailed 'argument' about Marat resembling Christ, could only be constructed as a well-educated western male/female, educated in the humanities and especially in the art history, with (rather) good social and economic standing, profound interest in history, culture and religion, and strong inclination for (visual) arts.

But this hypothetical construct represents a very thin segment of mostly 'Western' population. Most of the younger or elderly people (even if Westerners), don't qualify. Neither do 'average' people, 'everyday' people, 'people from the street'. Probably not even most of the professionals from natural sciences and technology, unless they've had good, probably 'classical' education, and share special interest in arts. 
And we could go on, but my bottom line is this: a presumably visual argument that needs more than 3 pages of technically sophisticated, but $d u$ bious explanations in 10 paragraphs (but no visuals, even if they are available!) to persuade/convince a rather thin layer of population of itself being a visual argument, can hardly be called a visual argument.

Here are my arguments to support the above claim from my survey.

\section{The results and the discussion}

First (question a), what the students saw in the painting (all emphases are mine):

'I see a man, leaning on the chair, not showing any signs of life. We could conclude from what the picture is showing that he was writing a letter and committed suicide.'

'I see a person who committed suicide.'

'A man lies on the table/chair in a motionless position, in his hand he holds a letter he has just written, he is dressed inadequately, as a matter of fact just in blankets/sheets.'

'A man is sitting at the table. He has a turban on his head, so he could be of Muslim religion.'

'I see a man who leans on something. I suppose he committed suicide, because there is a knife on the floor.'

'I see a gentleman who dies while writing a love letter.'

'I see $a$ young boy, who has just finished writing a letter. From what I see in the painting, I conclude that he is suffering from some illness, and is writing about how he feels to somebody.'

'I see a man who was killed in a bathtub.'

It is pretty clear from these answers, I think, that the respondents (except, maybe, for the last one), despite the fact that they were told who was depicted, and when the painting was created, didn't have a clue about what was going on in the painting, let alone of any argumentative potential imputed to the painting by Groarke.

Now let us have a look at the following answers on question a: 
'There is a woman in the painting, with a scarf on her head... I conclude that she has maybe died.'

'There is a women in the picture that holds a letter in one hand, while she is gazing in another direction with a sad expression on her face..'

'I see a woman in the picture, lying in the bathtub. She was probably writing a farewell letter.'

'I see a woman who, with a last bit of energy, wrote a farewell letter.'

'I see a woman who wrote a letter. She is lying on the counter, she has a headdress on her head and wears a robe.'

I don't think any commentary is needed, but nevertheless: if people think Marat was a woman, then it is safe to conclude that they don't know at all who Marat was, and that they know even less what his role in the French revolution was. Which undermines a good part of Groarke's argument(s) if not all of it.

Let us have a look at the remaining part of the answers, answering the question b).

19 respondents (out of 26 ), $73 \%$, answered that the painting didn't remind them of anything, that seeing it doesn't recall any memories whatsoever. The other seven answers were the following:

'It reminds me of French revolution.' (The same person who under a) answered: 'I see a man who was killed in a bathtub.')

'It reminds me of high school where we learned about this painting.' (Under a that person answered that the man on the painting committed suicide)

'Maybe the end of some historical era, signing the contract with death.'

'Reminds me of assassinations that occurred through history.'

'Reminds me of war, because at that time women wrote letters to their husbands who went to war.'

'The painting reminds me of suicide.'

'The painting casts un ugly feeling.' 
Hence, absolutely nothing that could substantiate Groarke's claims. As for mine, it is pretty obvious from the answers that the level and the quality of education greatly affect possible interpretations.

\section{Group 2}

First a few answers to question a:

'I see a dead man in a bathtub.'

'What I know of French revolution.'

'I see a man who committed suicide (?). The light on the right indicates the departure toward light, which symbolizes belief in the afterlife.'

'I see a dying man who has written a farewell letter.'

'Dying Marat writing his last message.'

Despite the fact that most of the members of Group 2 hold a $\mathrm{PhD}$ in humanities or social sciences, the answers don't seem very encouraging (in any sense, the quality of education included). What about answers to question $b$ ?

'It reminds me of events after the French revolution ... The person depicted may be fictitious or real historical personality ... The inclination of the head and the expression on the face give the impression of martyrdom.'

'It reminds me of the death of Jesus. I don't know, maybe because of the way he died. Similarly wrapped head, the knife wound on the body, tranquility at the transition to the other side, belief in the afterlife.'

'Reminds me of the crucifixion of Christ, because of the position of the body.'

'French revolution, violence, terror, Napoleon, Bastille.'

'I think of Robert Capa: faking reality to get a good picture/photo.'

'Reminds me of French revolution, dynamics of struggles for power.'

'It makes me think, how hard it is if a man is alone in the last moments of his life. Older you are, more you are aware of it.' 
If, for a moment, we neglect the fact that the doctor of philosophy thinks Marat might have been a 'fictitious or real historical personality' (ignorance that speak in favour of my point of view), we finally get two answers, relating the painting of dying/dead Marat to the dying/dead Christ.

But the first respondent in question is reminded of the death of Jesus because the way Marat died. And her first argument is 'similarly wrapped head'. But while Jesus was on the cross, when he was taken of, and while in his mother's hand, his head was not wrapped. He was only wrapped for the burial.

Also, Jesus is usually described as expressing suffering, not tranquility.

The other respondent mentioning Jesus is reminded of the crucifixion of Christ, 'because of the position of the body'. That is, Marat's body. But Marat's body is not in the crucifixion position, it is in the pieta position.

In short, the only two persons reminded of Jesus by David's painting of Marat, are actually reminded of different attributes of Jesus, even of different versions of Jesus, which are historically not attested or were transformed in the (enchronic) process of inference. They somehow recognize the similarity between some depictions of Christ and David's depiction of Marat, but they are far from attributing any arguments or claims to the latter.

Group 3

Rather interesting were the answers of the $3^{\text {rd }}$ group. Already under a, not b, two respondents (out of three) started to literally quote what Wikipedia was saying about David's painting, while under b, they were quoting the same source about who David was and what was his role in the French revolution and later.

(The $3^{\text {rd }}$ respondent wrote: 'If a revolutionary dies while soaking in a bathtub this is not a heroic death worthy of a revolutionary.')

It therefore is obvious that the third group was not addressed by David's painting in any way, even more, they didn't have a clue what the painting was about at all. And since the questionnaire mentioned the name of the painter and the title of the painting, they obviously thought that copying the relevant entry from Wikipedia would be the best solution ...

\section{In place of conclusion: A perceptual-cognitive grid}

This small research (which is to be continued and upgraded) persuasively shows that direct - linear, uniform and 'objective' - argumentative impact 
of (more or less pure) visuals on different audiences is rather small. In other words, different audiences (different by age, education, cultural and social background ...) infer differently (or different 'things) and via these inferences come to different conclusions (if any at all).

That is why I would like to tentatively propose a basic sketch, a scheme, some may call it a model (in the making), I'll call it a grid, of how (and why) interpretations of visuals (but not just visuals, verbal arguments operate in similar way) function, what may trigger the inferences leading to these interpretations (and why), what these interpretations depend on (i.e. what are the necessary and/or sufficient conditions for such interpretations to unfold), and what may be their restrictions and limitations.

I will be using and combining the concepts mentioned in the previous chapter, but in time other concepts may show themselves useful and be(come) incorporated into the developing mechanics of the grid.

We will take a look at two perspectives, let us call them an 'objective' and a 'subjective' one (which are only technical, working terms).

\section{Objective (diachronic) view}

Step 1

'Reality'

The most obvious, natural, neutral and general background (note that all these adjectives should really be placed between quotation marks, 
because they are quite ambivalent, meaning different things to different people and in different situations) is, of course, reality. Well, it seems to be. And since there is really no reality as such-per se or an Sich-we can talk about (but only reality as it is 'for us'), we should put at least this one between quotation marks.

What I understand as 'reality' here is undefined, undiscerned and indistinct 'reality', things (material or immaterial) that are 'out there', that may be 'out there', that allow us to be, to do things, to think and act, but are not, or not yet, part of our 'social "reality"' (or 'subjective "reality"'; but subjective always depends on the social, even if this dependence seems minimal), that is, we have not given them any form of (intentional) conceptualization, and are not conscious to us as possible signs (i.e., something we can manipulate mentally and/or verbally).

That is the reason the space above is blank, empty (white), even without a frame. It could have also been full (black), symbolizing everything or nothing, a step before the first basic/primitive conceptualization.

Step 2

'Reality'

Social 'reality'

Second step narrows the perspective (in the direction of foregrounding), imposing a kind of a frame on the previously (still) undefined and undiscerned 'reality', thus forming our social 'reality'. This social 'reality' frame is a fuzzy frame, a frame that changes all the time, a frame that is 
being (enchronically) constructed and re-constructed all the time, thus becoming wider (expanding) at some point in time, comprising more elements, while at some other point in time it may become narrower (shrinking), comprising less elements.

And the term 'social' in this case/usage, embraces physical, intellectual, emotional, cultural, economic, demographic ... everything we (can) see, notice, and are aware of (but do not necessarily understand or conceptualize it yet!) at our individual hermeneutical horizon (as part of our necessary social perspective). Even nature is part of this framed social 'reality', in the sense and in the degree it enters our social experience. If it doesn't (a very rare experience), it is still part of our social 'reality' (by being, more or less, absent from it). And as such, social 'reality' is still pretty undifferentiated and unconceptualized.

\section{Step 3}

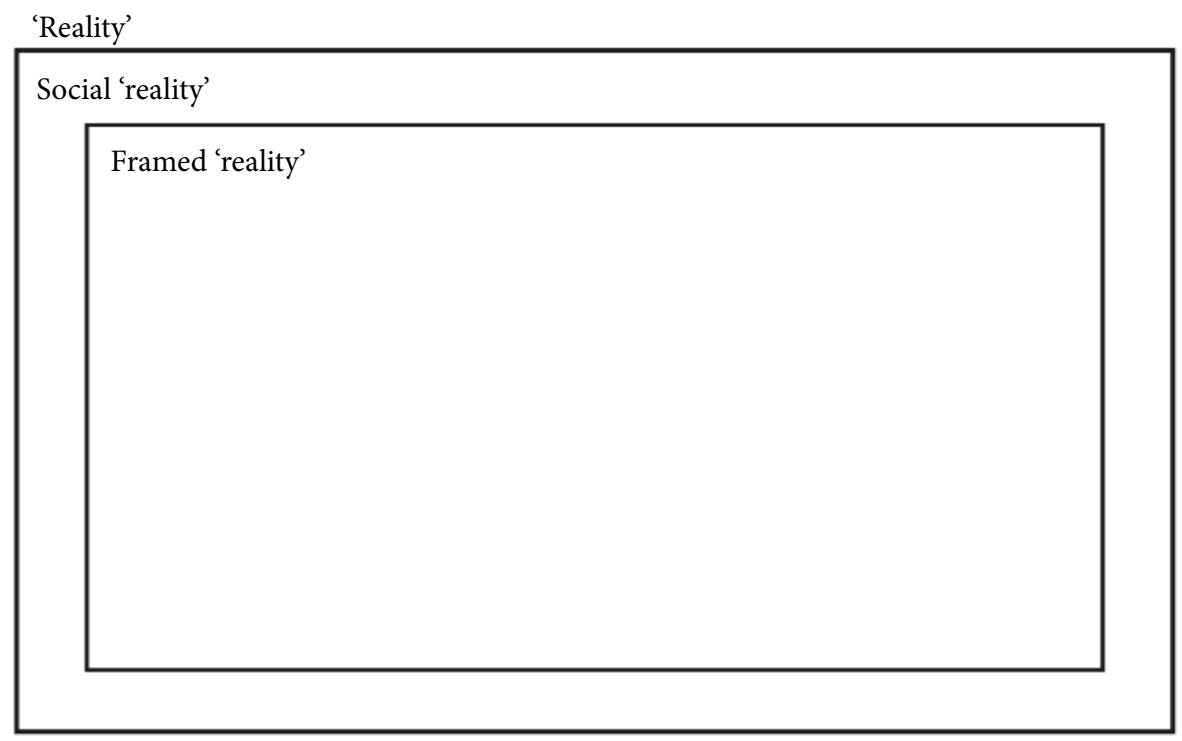

With framed 'reality' (in the sense of Goffman as well as Fillmore and Lakoff), we are narrowing the perspective even more, actually much more. Framed 'reality' isolates and concentrates on specific aspects, fragments, usually situations from the largely undefined social 'reality', in order to achieve (more) certainty, definiteness, in order to disambiguate and de-bias what may (still) be undefined and uncertain in the social 'reality' at large, 
thus giving it (at least) basic conceptualization and allowing further necessary cognitive processing.

Framing certain 'reality' or situation often implies predicting possible actors, topics, as well as possible (verbal) exchanges, scripts or scenarios. In other words, framing certain reality implies choosing or determining the possible semantic networks, verbal and conversational exchanges, and consequently possible lexical choices as well as boundaries.

Step 4

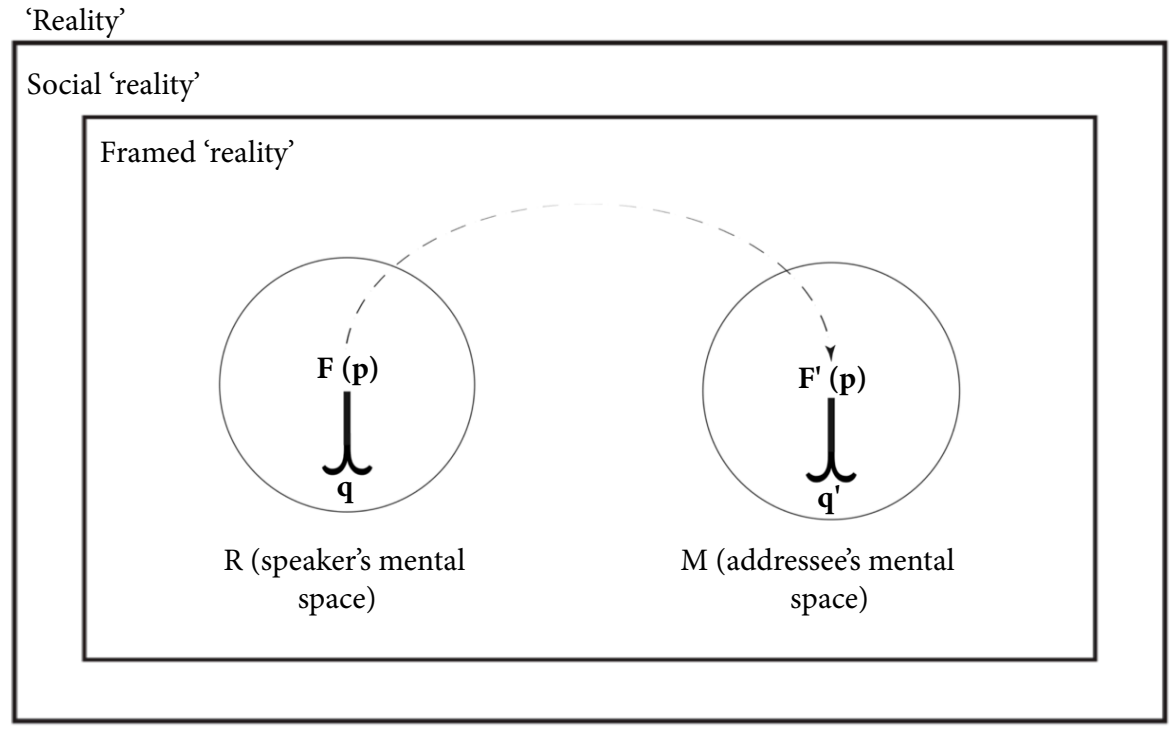

If we narrow the perspective even further towards the foreground (as we always do in everyday life), we come to mental spaces (Fauconnier, 1984). Mental spaces are fleeting, ephemeral constructions, relating to a certain framed 'reality', and triggered by a specific, very often singular elements, such as verbal (visual) expressions, which can assume a (specific) role in an activated semantic frame, polysemy chain, polyphony construction or something else.

For the explanation and illustration of the above table, let us try to apply it to the UvA poster.

$\mathrm{R}$ stands for the 'reality' of the speaker (speaker's mental space), and $M$ for the 'reality' of the observer (observer's mental space). $p$ represents the poster in question, $F(p)$ its (intended) premise, and $q$ its (intended) conclusion in $\mathrm{R}$. 
In $M$, on the other hand, $p$ still represents the same poster in question (hence the long dotted arrow connecting the two spaces), but $F^{\prime}(p)$, the observer's premise, and $q$ ', the observer's conclusion, may be quite different from speaker's premise and speaker's conclusion (depending on the observer's experience, social and cultural background, education, gender, and many other demographic, even bio-neurological and cognitive factors).

On top of that, $\mathrm{M}$ spaces may be multiplied in relation to $\mathrm{R}$ space-depending on the number of people, taking part in the conversation/event-, precisely because of observers' different (social, cultural, etc.) background, education, gender, and many other factors we have already mentioned, addressee's imminent intentions (based on the addressee's processing of the concrete situation) being one of the strongest factors.

This could be a (simple and simplified) model of a filtering grid, involved in a possible reconstruction of a diachronic, objective perspective on interpretation and meaning construction. But from the synchronic, subjective perspective things may look somehow different.

\section{Subjective (synchronic) view}

Of course there is still a generic, undefined 'reality' in the deep background. But in the immediate foreground, there are always just mental spaces, the elements that trigger the imminent construction of meaning interpretation of the problem at hand. And this construction (and re-construction) of respective ephemeral mental spaces in the subjective perspective, always already implies the framed chunks of 'reality' in the background (which again depend on the hermeneutical horizon of the social 'reality' the framed 'reality' relies upon). The synchronic view could be schematically represented in perspective, something like this: 


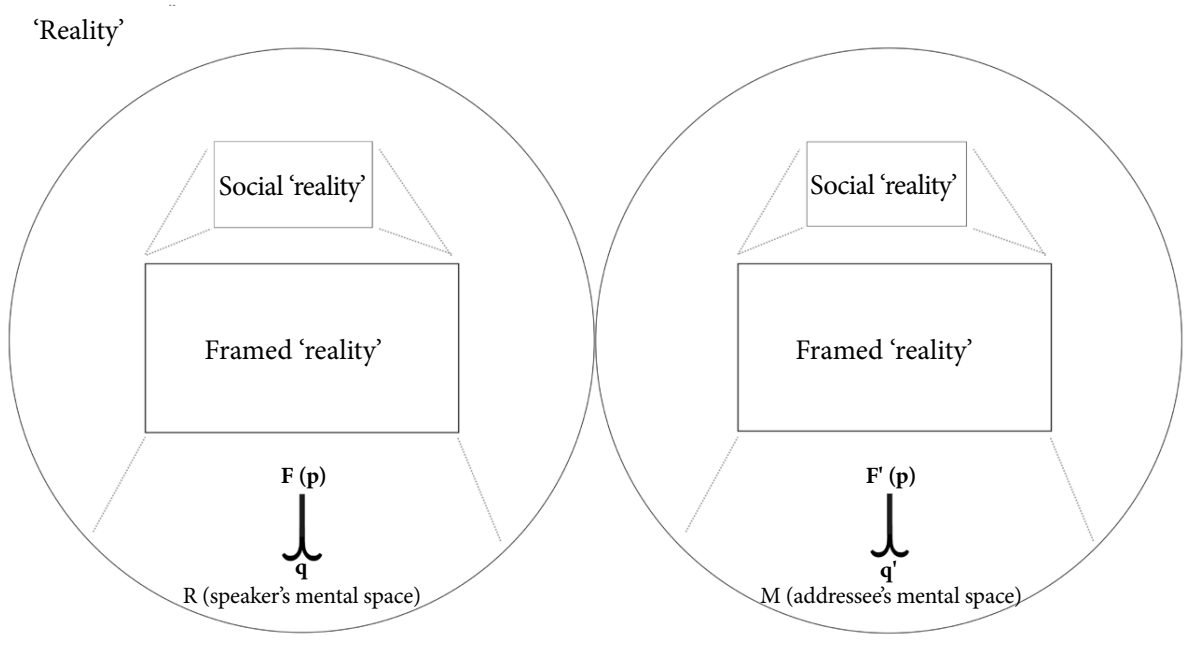

\section{Enchronic view}

Enchronic view embraces both, synchronic and diachronic perspective. Since it is concerned with relations between data from neighbouring moments, enchronic analysis is therefore looking at sequences of social interaction in which the moves that constitute social actions occur as responses to other such moves and in turn these give rise to other such moves.

Enchronic analysis is therefore constantly moving from synchronic to diachronic, thus constructing a new perspective, relative to and relevant for the particular moment in time, its representation and (re)construction of a particular mental space. 



\section{Summary}

This book is divided into two parts, Argumentation in Critical Discourse Analysis and Questions and Doubts about Visual Argumantation, each part containing two chapters.

1

In the first chapter, Topoi in Critical Discourse Analysis, I am concerned with how topoi are used (and misused) in the Discourse-Historical Approach.

The Discourse-Historical Approach (DHA), pioneered by Ruth Wodak (see Wodak, de Cillia, Reisigl, Liebhart 1999; Wodak, van Dijk 20oo; Wodak, Chilton 2005; Wodak, Meyer 2006; Wodak 2009), is one of the major branches of critical discourse analysis (CDA). In its own (programmatic) view, it embraces at least three interconnected aspects:

(1) 'Text or discourse immanent critique' aims at discovering internal or discourse-internal structures.

(2) The 'socio-diagnostic critique' is concerned with the demystifying exposure of the possibly persuasive or 'manipulative' character of discursive practices.

(3) Prognostic critique contributes to the transformation and improvement of communication. (Wodak 2006: 65)

CDA, in Wodak's view, 
is not concerned with evaluating what is 'right' or 'wrong'. CDA ... should try to make choices at each point in the research itself, and should make these choices transparent. ${ }^{1}$ It should also justify theoretically why certain interpretations of discursive events seem more valid than others.

One of the methodical ways for critical discourse analysts to minimize the risk of being biased is to follow the principle of triangulation. Thus, one of the most salient distinguishing features of the DHA is its endeavour to work with different approaches, multi-methodically and on the basis of a variety of empirical data as well as background information. (Wodak ibid.)

One of the approaches DHA is using in its principle of triangulation is argumentation theory, more specifically the theory of topoi. In the first chapter, I am concerned with the following questions: how and in what way are topoi and, consequentially, argumentation theory, used in DHA as one of the most influential schools of CDA? Other approaches (e.g., Fairclough 1995, 2000, 2003, or van Leeuwen 2004, 2008; van Leeuwen, Kress 2006) do not use topoi at all. Does such a use actually minimize the risk of being biased, and, consequentially, does such a use of topoi in fact implement the principle of triangulation?

Judging from the works we analysed in the first chapter, there are no rules or criteria how to use topoi or how to detect topoi in the discourse/ text; the only methodological precept seems to be, 'anything goes'! If so, why does CDA need triangulation? And what happened to the principle stipulating that CDA 'should try to make choices at each point in the research itself, and should make these choices transparent?'

We have seen identical and similar bundles of topoi for different purposes or occasions; we have seen different bundles of topoi for identical and similar purposes or occasions; we have seen different bundles of topoi for different occasion; and we have seen pretty exotic bundles of topoi for pretty particular and singular purposes. Which leads us to a key question: can anything be or become a topos within DHA? And, consequentially, what actually, that is, historically, is a topos?

If a topos is supposed to connect an argument with a conclusion, as all the relevant DHA publications claim, one would expect that at least a minimal reconstruction would follow, namely, what is the argument in the quoted fragment? What is the conclusion in the quoted fragment? How is 
the detected topos connecting the two, and what is the argumentative analysis of the quoted fragment? Unfortunately, all these elements are missing; the definition and the quoted fragment are all that there is of the supposed argumentative analysis.

And this is the basic pattern of functioning for most of the DHA works. At the beginning, there would be a list of topoi and a short description for each of them: first, a conditional paraphrase of a particular topos would be given, followed by a short discourse fragment (usually from the media) illustrating this conditional paraphrase (Discourse and Discrimination, 7580), but without any explicit reconstruction of possible arguments, conclusions, or topoi connecting the two in the chosen fragment. After this short 'theoretical' introduction, different topoi would just be referred to by names throughout the book, as if everything has already been explained in these few introductory pages.

It is quite surprising that none of the quoted DHA works even mention the origins of topoi, their extensive treatment in many works and the main authors of these works, namely Aristotle and Cicero. Even the definition, borrowed from Kienpointner (mostly on a copy-paste basis), does not stem from their work either: it is a hybrid product, with strong input from Stephen Toulmin's work The Uses of Argument, published in 1958. All this is even more surprising because today it is almost a commonplace that for Aristotle a topos is a place to look for arguments (which is true), a heading or department where a number of rhetoric arguments can be easily found (which is true as well), and that those arguments are ready for use-which is a rather big misunderstanding. According to Aristotle, topoi are supposed to be of two kinds: general or common topoi, appropriate for use everywhere and anywhere, regardless of situation, and specific topoi, in their applicability limited mostly to the three genres of oratory (judicial, deliberative, and epideictic).

With the Romans, topoi became loci, and Cicero literally defines them as 'the home of all proofs' (De or. 2.166.2), 'pigeonholes in which arguments are stored' (Part. Or. 5.7-10), or simply 'storehouses of arguments' (Part. Or. 109.5-6). Also, their number was reduced from 300 in Topics or 29 in Rhetoric to up to 19 (depending on how we count them).

Although Cicero's list correlates pretty much, though not completely, with Aristotle's list from the Rhetoric B 23, there is a difference in use: Cicero's list is considered to be a list of concepts that may trigger an associative process rather than a collection of implicit rules and precepts reducible 
to rules, as the topoi in Aristotle's Topics are. In other words, Cicero's loci mostly function as subject matter indicators and loci communes.

Which brings us a bit closer to how topoi might be used in DHA. In the works analysed in the first chapter, the authors never construct or reconstruct arguments from the discourse fragments they analyse-despite the fact that they are repeatedly defining topoi as warrants connecting arguments with conclusions; they just hint at them with short glosses. And since there is no reconstruction of arguments from concrete discourse fragments under analysis, hinting at certain topoi, referring to them or simply just mentioning them, can only serve the purpose of 'putting the audience in a favourable frame of mind'. 'Favourable frame of mind' in our case-the use of topoi in DHA-would mean directing a reader's attention to a 'commonly known or discussed' topic, without explicitly phrasing or reconstructing possible arguments and conclusions. Thus, the reader can never really know what exactly the author had in mind and what exactly he/she wanted to say (in terms of (possible) arguments and (possible) conclusions).

In Traité de l'argumentation: La nouvelle rhétorique, published in 1958 by Ch. Perelman and L. Olbrechts-Tyteca, topoi are characterised by their extreme generality, which makes them usable in every situation. It is the degeneration of rhetoric and the lack of interest for the study of places that has led to these unexpected consequences where 'oratory developments', as Perelman ironically calls them, against fortune, sensuality, laziness, etc., which school exercises were repeating ad nauseam, became qualified as commonplaces (loci, topoi), despite their extremely particular character. By commonplaces, Perelman claims, we more and more understand what Giambattista Vico called 'oratory places', in order to distinguish them from the places treated in Aristotle's Topics. Nowadays, commonplaces are characterised by banality which does not exclude extreme specificity and particularity. These places are nothing more than Aristotelian commonplaces applied to particular subjects, concludes Perelman.

And this is exactly what seems to be happening to the DHA approach to topoi as well. Even more, the works quoted in the first part of the article give the impression that DHA is not using the Aristotelian or Ciceronian topoi, but the so-called 'literary topoi', conceptualized by Ernst Robert Curtius in his Europaeische Literatur und Lateinisches Mittelalter (1990: 62-105, English translation). What is a literary topos? In a nutshell, oral histories passed down from pre-historic societies contain literary aspects, characters, or settings which appear again and again in stories from ancient 
civilisations, religious texts, art, and even more modern stories. These recurrent and repetitive motifs or leitmotifs would be then labelled literary topoi.

The same year that Perelman and Olbrechts-Tyteca published their New Rhetoric, Stephen Toulmin published his Uses of Argument, probably the most detailed study of how topoi work. Actually, he does not use the terms topos or topoi, but the somewhat judicial term 'warrant'. The reason for that seems obvious: he is trying to cover different 'fields of argument', and not all fields of argument, according to him, use topoi as their argumentative principles or bases of their argumentation. According to Toulmin (1958/1995: 94-107), if we have an utterance of the form, 'If D then C'-where D stands for data or evidence, and C for claim or conclusionsuch a warrant would act as a bridge and authorize the step from D to C. But warrant may have a limited applicability, so Toulmin introduces qualifiers $Q$, indicating the strength conferred by the warrant, and conditions of rebuttal (or Reservation) $\mathrm{R}$, indicating circumstances in which the general authority of the warrant would have to be set aside. And finally, in case the warrant is challenged in any way, we need some backing B as well.

If the DHA analysis would proceed in this way, applying all these steps to concrete pieces of discourse each time it wants to find the underlying topoi-their lists of topoi in the background would become unimportant, useless, and obsolete. Text mining, to borrow an expression from computation al linguistics, would bring the text's or discourse's own topoi to the surface, not the prefabricated ones. And there is more: Toulmin's scheme allows for possi ble exceptions or rebuttals, indicating where, when, and why a certain to pos does not apply. Such a reconstruction can offer a much more complex account of a discourse (fragment) under investigation than enthymemes or static and rigid lists of topoi.

2

The second chapter, Fallacies: do we 'use' then or 'commit' them, is a follow up to the first chapter. In the first one, I was analysing the use of topoi in DHA, a branch of CDA, in the second one, I am looking at how fallacies are used by DHA. In view of this goal, I propose a rhetorical reading of Austin, an Austinian interpretation of Hamblin, and a hybrid AustinoHamblinian perspective on fallacies.

I am asking three questions: what are fallacies? Are there obvious and unambiguous fallacies in natural languages? Aren't we forced to commit 
and live (in) fallacies? And, is it methodologically acceptable to use prefabricated lists of fallacies (constructed by DHA) as an analytical tool in such a dynamical enterprise as (critical) discourse analysis?

J. L. Austin is usually considered to be the 'father' of speech act theory, and the 'inventor' of performativity. In a very general framework this is both true, but historically and epistemologically speaking there is a narrow and intricate correlation, as well as a deep rupture between the two theories.

Performativity came about as a result of Austin's deep dissatisfaction with classical philosophical (logical) division between statements/utterances that can be (and should be) either true or false (with no gradation in between), and only serve to describe the extra-linguistic reality.

Speech acts, on the other hand, came about as a result of Austin's dissatisfaction with his own performative/constative distinction, a distinction that placed on the one side the utterances with which we can do (perform) something (and are neither true nor false), and the utterances with which we can only describe what is already there (and can be either true or false). After a careful consideration of what could be the criteria of performativity in the first part of his lectures, in the second part Austin comes to a conclusion that not only performatives do something (with words), but that every utterance does something (with words). 'Something' implying: not just describing reality. But between the two poles of the lectures, the performative one and the speech acts one, there is an important (I call it rhetorical) transitional passage that is usually overlooked, and in my examination of fallacies, I concentrate on this passage.

For Austin, in this passage, truth and falsity don't have objective criteria, but depend on 'good reasons and good evidence' we have for stating something. And Austin's conclusion concurs with Hamblin's: it is easy to say what is true or false in logic, it is much more complicated and less evident in everyday life and in everyday language use.

Statements/utterances cannot just be either true or false, there is (or at least should be) a gradation between what is false and what is true, between o and 1 . What we say can be more or less true, true up to a (certain) point, or more precisely: true for certain intents and purposes.

What we say can therefore not only be more or less true, true up to a point, or true for certain intents and purposes, it can also be true only in some contexts, but not in others.

If we sum up all Austin's hedgings, we get the following: 
(1) What we say can only be more or less true (i.e., true up to a point);

(3) it can only be true for certain intents and purposes;

(4) it can only be true in some contexts, and

(5) its truth (or falsity) depends on knowledge at the time of utterance.

is a real rhetorical perspective on communication (truth, logic, and philosophy) that was very often overlooked, mostly at the expense of classificatory madness that started with J. R. Searle. What Austin is proposing is that-outside logic, in the real world, in everyday communication, where we don't go around with propositions in our pockets and truth tables in our hands-the truth or falsity of what we say be replaced by right or proper things to say, in these circumstances, to this audience, for these purposes and with these intentions.

I claim that Hamblin followed the same enterprise 15 years later with his Fallacies. These two ground breaking works follow the same pat tern, run parallel, and I show why.

(1) Real life, Hamblin claims, as opposed to the simple situations envisaged in logical theory, one cannot always answer in a simple manner whether something is true or false: we can speak of formal validity (which includes truth and falsity, and, consequently, fallacies) only in formal systems, but not in 'natural languages'. If we want any kind of formal validity in natural languages, which wouldn't involve only la langue (language) in de Saussure's conceptualization, but also his la parole (speech, (everyday) communication) - we need to bring it into relation with a formal language of a formal (logical) system. This 'bringing into relation' usually means: translating the very vast vocabulary (lexicon) of ordinary language, with its extremely ramified semantics and pragmatics, into a very limited vocabulary of logic with its even more limited semantics.

And we can do so, Hamblin argues, 'only at the expense of features essential to natural language.' (Hamblin ibid.: 213)

(2) Reference depending on knowledge at the time of utterance, claims Hamblin.

Which implies that there is no perennial and universal truth, and consequently, no perennial and universal truth-conditions or criteria. The truth is relative, but we shouldn't understand 'relative' as a trivial stereotype that everything changes and everything can be different. 'Relative' should be 
understood more in its etymological sense (relativus = having reference or relation to, from relatus $=$ to refer), as a thing (concept, thought) having a relation to or being in a relation to another thing (concept, thought). In this particular relation, the truth is seen as such and such; in some other relation, the truth may be seen differently.

There are therefore no universal arguments or universal criteria for what an argument should look like to be (seen as) an argument. An argument should be adopted and/or constructed relative to the (particular) circumstances and the (particular) audience, as well as to the purposes and intentions we, as arguers, have. Consequently, there can be no universal fallacies or universal criteria for what is a fallacy in everyday communication (persuasion and argumentation).

In this light, Hamblin's claim from the beginning of his book that there has never yet been $a$ book on fallacies becomes more understandable: Arthur Schopenhauer's Art of Controversy is, in his opinion, too short, Jeremy Bentham's Book of Fallacies is too specialized, the medieval treatises are mostly commentaries on Aristotle, and Aristotle's Sophistical Refutations are, in Hamblin's view, 'just the ninth book of his Topics' (Hamblin ibid.: 11).

So, the state of the art would be that nobody is particularly satisfied with this corner of logic, concludes Hamblin.

And, there may be a reason for that. Even if in almost every account from Aristotle onwards we can read that a fallacious argument is one that seems to be valid, but it is not, it is rather often argued that it is impossible to classify fallacies at all.

On the other hand, it seems that certain fallacies are unavoidable, which raises the question whether they are fallacies at all (and even much more important ones: How to classify fallacies? Are there any stable criteria for detecting fallacies? All the way to the obvious one: do fallacies exist at all?).

Hamblin, 200 years later, opens a new perspective on this problem: if some fallacies seem to be omnipresent and unavoidable, maybe we shouldn't treat them as fallacies: 'Fallacy of Secundum Quid [hasty generalization] is an ever-present and unavoidable possibility in practical situations, and any formal system that avoids it can do so only at the expense of features essential to natural language.' (Hamblin ibid.: 213) Ignoratio Elenchi [ignoring the issue, irrelevant conclusion] is another fallacy of this unavoidable kind. 
And begging the question [Petitio Principii, circular reasoning] fits in the same category; already J.S. Mill (in his System of Logic, 1843) claims that all valid reasoning commits this fallacy. While Cohen and Nagel's affirm:

There is a sense in which all science is circular, for all proof rests upon assumptions which are not derived from others but are justified by the set of consequences which are deduced from them ... But there is a difference between a circle consisting of a small number of propositions, from which we can escape by denying them all, or setting up their contradictories, and the circle of theoretical science and human observation, which is so wide that we cannot set up any alternative to it. (Cohen, Nagel 1934: 379, in Hamblin ibid.: 35)

A possible conclusion we could draw from this observation: on the micro level, we can fuss about small things, everyday conversation and everyday reasoning, and pass our time in inventing numerous fallacies, but when it comes to the macro level, to big things (the big picture), fallacies are not objectionable any more-because there is no alternative.

All these epistemological and methodological objections, ambiguities and caveats on one side, as well as the practical, empirical multiplications of fallacies and their overlapping on the other, make the study of fallacies a thriving enterprise, a field of its own and in its own right. But, can we use fallacies or even a 'theory of fallacies' (singular) as an analytical tool (as one of the analytical tools) in another theoretical enterprise, within another theory, like DHA is doing it?

Here is the passage that introduces fallacies in Discourse and

\section{Discrimination:}

If one wants to analyse the persuasive, manipulative, discursive legitimation of racist, ethnicist, nationalist, sexist and other forms of discrimination and the pseudo-argumentative backing and strengthening of negative, discriminatory prejudices, one encounters many violations of these ten rules. In rhetoric and argumentation theory, these violations are called 'fallacies' (among many others see Kienpointner 1996; van Eemeren, Grootendorst, Kruiger 1987: 78-94; van Eemeren and Grootendorst 1992; Lamham 1991: 77ff.; Ulrich 1992). (Reisigl, Wodak 2001: 71) 
The 'violations of these ten rules' refer to pragma-dialectical ten rules for critical discussion that Reisigl and Wodak introduce on the previous page. But these ten rules for 'rational arguing' as Reisigl and Wodak call them are not valid just for 'persuasive, manipulative, discursive legitimation of racist, ethnicist, sexist and other forms of discrimination', but for every form of discussion that aims at resolving the difference of opinion in a rational way by means of critical discussion. Racist, ethnicist, sexist and other forms of discrimination usually don't aim at resolving the difference of opinion in a rational way.

Besides that, 'violations of these ten rules' is the way fallacies are defined in pragma-dialectics, not in rhetoric and argumentation theory in general. In rhetoric and argumentation theory there are many different approaches to fallacies that don't even mention those ten rules of critical discussion, even theories that are unfamiliar with those ten rules or refuse to use them.

In pragma-dialectics, fallacies are conceived and analysed from the dialectical perspective: they are incorrect, unreasonable moves in a debate or in a discussion. In DHA, on the contrary, a list of 14 fallacies is constructed (at least in $D \& D: 71-74$ ), with a short description and an even shorter example of each one of them. On the following 200 pages occasional references would be made to this list, without any analysis or justification why the examples on these 200 pages (mostly taken from the press) would represent any of the 14 fallacies listed (on pages 71-74), and the ten rules for critical discussion are never mentioned again. This is the very same way DHA deals with topoi as I have shown in the first chapter.

3

The second part of the book is devoted to visual argumentation, more precisely to some methodological problems regarding the interpretation of visuals. In the first chapter, Is there anything like visual argumentation: A short exercise in methodological doubt, I am concerned with the very beginnings of visual argumentation back in 1996, the argumentative potential the first authors (Birdsell and Groarke) see in visuals, and the problem of framing in the first 'visual argument' to be analysed, the famous Smoking Fish.

If I sum up these first conceptualizations of visuals and their argumentative potential: visuals may have some argumentative or persuasive potential (there is a possibility of visual meaning, visuals can forward arguments, 
and arguments can be derived from visuals), but they are usually (always?) still coupled with the verbal, and can achieve these argumentative effects only (?) in combination with the verbal. And the pièce de resistance Birdsell and Groarke are offering to illustrate the claims above (i.e., the possibility of visual argumentation) is an anti-smoking poster (Smoking Fish with a caption 'Don't you get hooked!'), published by the U.S. Department of Health, Education and Welfare in 1976.

The authors (Birdsell and Groarke) first admit that 'visual images can, of course, be vague and ambiguous. But this alone does not distinguish them from words and sentences, which can also be vague and ambiguous'. (Birdsell, Groarke 1996: 2) Than they qualify the poster as 'an amalgam of the verbal and the visual' (ibid.), which, again, sounds quite acceptable. But then they conclude: 'Here the argument that you should be wary of cigarettes because they can hook you and endanger your health is forwarded by means of visual images ...' (Ibid.: 3 ) Which is obviously not the case. Without the verbal part, the caption 'don't you get hooked!', the poster could be understood (framed) as a joke, as a cartoon, where, for example, smoking is presented as such a ubiquitous activity that even anglers use cigarettes to catch fish. Only when we add the verbal part, 'don't you get hooked!'- where 'hooked' activates a semantic frame of knowledge relating to this specific concept (Fillmore 1977: 76-138), which includes 'get addicted', and is, at the same time, coupled with a visual representation of a hook with a cigarette on it-is the appropriate (intended) frame set: the poster can now, and only now, be unequivocally understood as an anti-smoking ad, belonging to an anti-smoking campaign.

This is the reason, I emphasize, why visual argumentation should concentrate more on different possible entry and exit points in data representation and interpretation of hypothetical visual arguments. As a kind of a case study-exposing possible caveats as well as cul-de-sacs of visual argumentation-I then concentrate on Leo Groarke's proposal of reconstructing visual arguments as presented and conceptualized in his 2013 article 'The Elements of Argument: Six Steps to a Thick Theory', published in the e-book What do we know about the world?: Rhetorical and Argumentative perspectives. The object of Groarke's analysis is a photo of a fruit found on the Detroit River that he identified as a breadfruit. What I am objecting to in this chapter is methodological approach Groarke is using in identifying the fruit: 
The argument that established this conclusion compared my photographs to similar photographs found in encyclopaedia accounts of breadfruit. One might summarize the reasoning as: 'The fruit is breadfruit, for these photographs are like standard photographs of breadfruit.' But this is just a verbal paraphrase. The actual reasoning - what convinces one of the conclusion-is the seeing of the sets of photographs in question. Using a variant of standard diagram techniques for argument analysis, we might map the structure of the argument as:

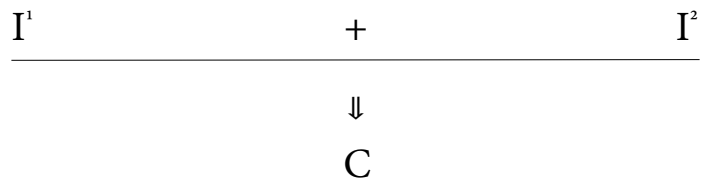

where $\mathrm{C}$ is the conclusion that the fruit is a piece of breadfruit, $\mathrm{I}^{1}$ is the set of photographs I took, and $\mathrm{I}^{2}$ is the iconic photographs of breadfruit to whi ch they were compared.'

But should (and does) the reasoning really consist just of 'the seeing of the sets of photographs in question'? Is just seeing and visually comparing photographs from different sources really enough for a reasoned, justified conclusion (in question)?

In order to answer these questions, I replicate Groarke's procedure and prove that his breadfruit is not really a breadfruit, but much less exotic fruit (Maclura pomifera).

What can we learn from this? Above all that sayings like: 'A picture tells a thousand words' should be indeed taken seriously. But, to be (absolutely) sure which of these thousand words refer to that particular picture, we have in front of us in these particular circumstances, we have to cut down (on) those words considerably. On the other hand, without any words at all, we can hardly identify the exact meaning of the picture.

In other words, there seem to be no pure visual arguments (as there are, probably, very few purely verbal arguments; if any at all), and instead of visual argumentation (or purely verbal argumentation, for that matter we should be talking about multimodal argumentation and multimodal meaning (combining, in our case, at least visual and verbal, but other semiotic modes are involved as well, such as gesture and gaze). But multimodal meaning and multimodal argumentation require different analytical 
framework, let us simply call it multimodal analysis. And in relation to that, I emphasize a few points.

In cases where just 'seeing' is not enough, and we have to consult verbal (or other) sources, and incorporate other types of signs, like gestures, gazes ..., we should be talking of enchronic analysis (Enfield 2009). What is enchronic analysis?

Enchronic analysis is concerned with relations between data from neighbouring moments, adjacent units of behaviour in locally coherent communicative sequences. (Enfield 2009: 10)

Enchronic analysis is therefore looking at sequences of social interaction in which the moves that constitute social actions occur as responses to other such moves, and in turn these give rise to further moves. The Detroit River fruit is exactly a case in point: from observation of the photos of the fruit taken on the river, we have to move to the observation of the photos in encyclopaedias. And to get more complete and accurate information, we have to switch from photos to text, and incorporate the textual information as well. And to fine-tune our findings (understanding), we have to switch to yet other photos (if necessary), and from them to yet another text(s) (if necessary), and finally compare all these again with the initial photo (of the fruit taken on the river).

If, when consulting encyclopaedias, we don't just check the photos, but the text as well, and then go and (re)check other available texts and photos, and compare them with the initial photo(s), the final result we arrive at should be described as composite meaning, resulting in composite utterances, conceptualized as: '[...] a communicative move that incorporates multi ple signs of multiple types'. (Enfield ibid.: 15)

4

The aim of the fourth chapter, Perception, Inference, and Understanding in Visual Argumentation, is to upgrade the theoretical (conclusions) from the previous chapter, and support them with empirical research and data. For the lack of funds, I opted for an experimental survey study, involving a pilot questionnaire.

This pilot questionnaire, titled A Short Questionnaire on Understanding the Visuals (Drawings, Pictures, Photographs ...) comprised three wellknown visuals from Leo Groarke's work on VA, namely: 
(1) The smoking fish (where all the text was removed from the picture);

(2) The poster 'UvA for Women' (exactly as it was presented in Groarke 1996: 112) and

(3) Jacques-Louis David's painting La Mort de Marat (Marat's Death).

Each visual was preceded with a necessary but short introductionnecessary for historically or chronologically framing the visual (but not explaining the context) - while following each visual there were two questions, constructed in as neutral way as possible, at the same time trying to avoid a very actual possibility in this kind of surveys that respondents wouldn't understand what the goal (the intention) of these questions was.

The questionnaire was distributed/administered to three different age groups, with different educational and professional background, all European, with Slovenian citizenship: Group 1: STUDENTS, Group 2: RESEARCHERS, Group 3: SENIORS.

There is no place in the summary to comment on all the answers the three groups gave about the visuals (in the chapter they are discussed in detail), but this small pilot research (which is to be continued and upgraded) convincingly showed that direct-linear, uniform and 'objective'-argumentative impact of 'pure' visuals on different audiences is rather small or none. In other words, different audiences (different by age, education, cultural and social background ...) infer differently (or different 'things) and via these inferences come to different conclusions (if any at all).

That is why, to conclude, I tentatively propose a basic scheme, a model (in the making), or a grid, of how (and why) interpretations of visuals (but not just visuals, verbal arguments operate in the same way) may function, what may trigger the inferences leading to specific interpretations (and why), what these interpretations depend on (i.e., what are the necessary and/or sufficient conditions for such interpretations to unfold), and what may be their restrictions and limitations. 


\section{References}

Aristotle. 1989. Topica. Translated by E. S. Forster. Cambridge, Massachusetts: Harvard University Press.

- - . 1991. Art of Rhetoric. Translated by J. H. Freese. Cambridge, Massachusetts: Harvard University Press.

Austin, John L. 1962/1980. How to Do Things with Words. Oxford: Oxford University Press

Blommaert, Jan. 2005. Discourse. Cambridge: Cambridge University Press.

Blommaert, Jan, and Rampton, Ben. 2011. "Language and Superdiversity." Diversities 13 (2), 1-21.

Cicero, Marcus T. 2003. Topica. Translated by T. Reinhardt. Oxford: Oxford University Press.

Curtius, Robert E. 1990. European Literature and the Latin Middle Ages. New Jersey: Princeton University Press.

Birdsell, David S., and Groarke, Leo. 1996. “Toward a Theory of Visual Argumentation." Argumentation and Advocacy 33 (1): 1-10.

Deleuze, Gilles, and Guattari, Félix. 1980/2005. A Thousand Plateaus. London, New York: Continuum.

Ducrot, Oswald. 1996/2009. Slovenian Lectures: Introduction into Argumentative Semantics. Ljubljana: Pedagoški inštitut. Digitalna knjižnica, Dissertationes 6. https://www.doi.org/10.32320/978-961-270-014-o 
Eemeren, Frans H., and Grootendorst, Rob. 1984. Speech Acts in Argumentative Discussion. Dordrecht: Foris.

- - - 1994. Argumentation, Communication, and Fallacies. London: Routledge.

- - -.2004. A Systematic Theory of Argumentation - The pragma-dialectical approach. Cambridge: Cambridge University Press.

- - -, ed. 2001. Crucial Concepts in Argumentation Theory. Amsterdam: Amsterdam University Press.

Enfield, Nick J. 2009. The Anatomy of Meaning. Cambridge, New York: Cambridge University Press.

Fairclough, Isabela, and Fairclough, Norman. 2011. "Practical reasoning in political discourse: The UK Government response to the economic crises in the 2008 Pre-Budget Report." Discourse \& Society 22 (3): 243-268.

Fairclough, Norman. 1995. Critical discourse analysis: the critical study of language. Harlow: Longman.

- - - 2000. Discourse and Social Change. Cambridge: Polity Press.

- - -. 2003. Analysing Discourse. Textual Analysis for Social Research. London/ New York: Routledge.

Fauconnier, Gilles. 1984. Espaces mentaux. Paris: Minuit.

Fillmore, Charles J. 1977a. “Topics in Lexical Semantics”. In Current Issues in Linguistic Theory, ed. R. W. Cole, 76-138. Bloomington: Indiana University Press.

- - - 1977b. "Scenes-and-frames semantics". In Linguistic Structures Processing, ed. A. Zampolli, 55-81. Amsterdam: North-Holland.

Galasinska, Aleksandra, and Krzyzanowski, Michal, eds. 2009. Discourse and Transformation in Central and Eastern Europe. Basingstoke: Palgrave Macmillan.

Goffman, Erving. 1974. Frame Analysis: An Essay on the Organization of Experience. London: Harper and Row.

Groarke, Leo. 1996. “Logic, Art and Arguing.” Informal Logic 18 (2, 3): 105-129. Hamblin, Charles L. 1970/2004. Fallacies. Newport: Vale Press.

- - -. 2013. "The Elements of Argument: Six Steps to a Thick, Theory”. In What Do We Know about the World? Rhetorical and Argumentative Perspectives, eds. Gabrijela Kišiček and Igor Ž. Žagar 25-43. Ljubljana: Pedagoški inštitut. Digitalna knjižnica, Digitalna knjižnica, Dissertationes 25. https:// www.doi.org/10.32320/978-961-270-171-O

Kienpointner, Manfred. 1992. Alltagslogik. Stuttgart, Bad Cannstatt: frommann-holzboog. 
Kleene, Stephen C. 2002. Mathematical Logic. $2^{\text {nd }}$ edition. Mineola: Dover.

Krzyzanowsky, Michal. 2009. „On the ,Europeanisation“ of Identity Constructions in Polish Political Discourse after 1989." In Discourse and Transformation in Central and Eastern Europe, eds. Aleksandra Galasinska and Michal Krzyzanowski, 95-113. Basingstoke: Palgrave Macmillan.

Perelman, Chaim, and Olbrechts-Tyteca, Lucie. 1983. Traité de l'argumentation. La nouvelle rhétorique. Bruxelles: Editions de l'Université de Bruxelles.

Peirce, Charles S. 1931-1958. Collected Writings. 1-8. Edited by Charles Hartshorne, Paul Weiss, Arthur W. Burks. Cambridge, Massachusetts: Harvard University Press.

Reisigl, Martin, and Wodak, Ruth. 2001. Discourse and Discrimination. Rhetoric of Racism and Antisemitism. London, New York: Routledge.

Richardson, John. E. 2004. (Mis)Representing Islam: the racism and rhetoric of British Broadsheet newspapers. Amsterdam: John Benjamins.

Richardson, John E., and Wodak, Ruth. 2008. The impact of visual racism: Visual arguments in political leaflets of Austrian and British far-right parties. Manuscript. Paper presented at the 2008 Venice Argumentation Conference.

- - -. 2009. “The Impact of Visual Racism: Visual Arguments in Political Leaflets of Austrian and British Far-Right Parties." Controversia: An international journal of debate and democratic renewal 6 (1).

Rubinelli, Sara. 2009. Ars Topica. The Classical Technique of Constructing Arguments from Aristotle to Cicero. Berlin: Springer.

Steele, Helen. 2006. Microhistory and macrohistory: different approaches to the analysis of history. http://www.guernicus.com/academics/pdf/macromicro.pdf

Tseronis, Asimakis. 2012. Refuting claims visually: the case of subvertisements. PPT presentation from Dani Iva Škarića conference. Postira, Brač, Croatia.

Toulmin, Stephen. 1995. The Uses of Argument. Cambridge: Cambridge University Press.

Walton, Douglas N. 1987. Informal Fallacies. Towards a Theory of Argument Criticism. Amsterdam: John Benjamins.

- - -. 1992a. “Types of Dialogue, Dialectical Shifts and Fallacies." In Argumentation Illuminated Eemeren, van F.H., Grootendorst, R., Blair, J.A. \& Willard, Ch.A.. Amsterdam: SicSat. 
- - - 1992b. The Place of Emotion in Argument. University Park, Pennsylvania: Pennsylvania State University Press.

- - 2007. Media Argumentation - Dialectic, Persuasion, and Rhetoric. Cambridge: Cambridge University Press.

van Leeuwen, Theo. 2004. Introducing Social Semiotics. London, New York: Routledge.

- - . 2008. Discourse and Practice. New Tools for Critical Discourse Analysis. Cambridge: Cambridge University Press.

van Leuween, Theo, and Kress, Günther. 2006. Reading Images. The Grammar of Visual Design. London, New York: Routledge.

Vertovec, Steven. 2007. "Super-diversity and its implications." Ethnic and Racial Studies 30 (6), 1024-1054.

Wittgenstein, Ludwig. 1953/1986. Philosophical Investigations. Translated by G. E. M. Anscombe. Oxford: Basil Blackwell.

Wodak, Ruth. 2009. The Discourse of Politics in Action. Basingstoke: Palgrave Macmillan.

Wodak, Ruth, de Cillia, Rudolf, Reisigl, Martin. and Liebhart, Karin. 1999. The Discursive Construction of National Identity. Edinburgh: Edinburgh University Press.

Wodak, Ruth. and van Dijk, Teun, eds. 200o. Racism at the Top. Klagenfurt: Drava.

Wodak, Ruth, and Chilton, Paul, eds. 2005. A New Agenda in (Critical) Discourse Analysis. Amsterdam, Philadelphia: John Benjamins.

Wodak, Ruth, and Meyer, Michael, eds. 2006. Methods of Critical Discourse Analysis. London: Sage.

Woods, John, and Walton, Douglas N. 1992. Fallacies. Dordrecht: Foris.

Žagar, Igor Ž. 2016. "Against Visual Argumentation: Multimodality as Composite Meaning and Composite Utterances". In Argumentation and Reasoned Action, Proceedings of the 1st European Conference on Argumentation, Lisbon 2015, eds. D. Mohammed and M. Lewinski, 829852. College Publications: London.

Fallacy Files. http://www.fallacyfiles.org/

Internet Encyclopedia of Philosophy. Fallacies. http://www.iep.utm.edu/ fallacy/

Nizkor Project. Fallacies. http://www.nizkor.org/features/fallacies/

Wikipedia. Fallacy. http://en.wikipedia.org/wiki/Fallacy

Wikipedia. List of fallacies. http://en.wikipedia.org/wiki/List_of_fallacies 


\section{Index}

A

Ad Baculum 53

Ad Consequentiam 53

Ad Hominem 52, 53, 65

Ad Ignorantiam 53

Ad Populum 52, 53

argumentation theory $14,33,55,56$,

69

argumentative analysis 19,115

argument schemes 15, 16, 17, 33

argumentum ad baculum 53, 57

argumentum ad exemplum 58,59

argumentum ad Hitlerum 53

argumentum ad hominem 57

argumentum ad populum 57

Aristotle 24, 25, 26, 27, 28, 29, 30, 31, 44,56

associative process 30

audience $16,30,31,41,42,43,64,65$, 66,72

Austin, John Langshaw 37, 38, 39, 40, 41,65
B

background knowledge 98

backing 34, 55

Bakhtin, Mikhail 81

Bentham, Jeremy 44

Billig, Michael 54

Birdsell, David S. 70, 75, 76, 109, 111

Blommaert, Jan 54, 55, 114

Brandt, Willy 97, 98

C

Caravaggio, Amerighi (Michelangelo Merisi) 116

Chilton, Paul 13, 54

Cicero 24, 30

Cillia, Rudolf 13, 14

claim 14, 19, 34, 35, 41, 44, 51, 52, 53, $59,62,111,113,115,116,118$

Cohen 44, 46

composite meaning 96

composite utterances 96 
conclusion 14, 15, 19, 20, 21, 22, 24, $34,36,38,39,45,46,50,53,64,65$, $78,79,85,87,98,101,111,112,114$, $115,121,125,126$

content-related 14, 15, 16 context-dependent reasoning 27 contexts 30, 40, 41 conventional signs 99,101 conviction 43,44 convince $16,42,43,118$ criteria $17,18,32,33,38,39,42,43$, $44,45,48,50,51,52,53,54,66$ critical discourse analysis 9, 11, 13, $14,18,33,37,54,55$

Curtius, Ernst Robert 32

D

data $14,32,34,48,49,58,62,85,96$, $102,108,110,127$

David, Jacques-Louis 45, 106, 108, $115,116,117,121$

David's Marat 108, 116

Deleuze, Gilles 82, 114

De Morgan 44

Dijk, Teun 13, 18, 21, 54

discourse $13,14,15,16,17,18,20,21$, $22,29,31,33,34,35,36,37,54,55,70$

discourse fragment 20, 29, 36

discourse-historical approach (DHA) $13,14,15,19,26,29,31,32,33,36,37$, $54,55,56,57$

doing 29, 38, 80

Ducrot, Oswald 81

E

Eemeren, Frans H. 56, 57

enchronic analysis 96, 110, 127

Enfield, Nick J. 96, 97, 110

enthymemetic 21
F

Fairclough, Norman 14, 54

fallacies 9, 37, 38, 41, 43, 44, 45, 46, $50,51,52,53,54,55,56,57,58,59$, $60,61,62,63,65$

false $38,39,40,41,43,51,53,58,62$, $65,66,117$

falsity 38, 39, 40, 41, 43

Fauconnier, Gilles 125

Fillmore, Charles 75, 76, 124

Fiorentino, Rosso 116

formal language 41

Fowler, Roger 54

frame $30,31,72,74,76,78,80,81,86$, $87,109,112,123,124,125,126$

frame analysis 74

framing 40, 72, 78, 107, 112, 125

G

Garssen 56

gaze $95,99,101,110$

gesture 95, 99, 101

Girodet de Roussy-Trioson, Anne-

Louis 116

Gödel, Kurt 46

Goffman, Erving 75, 124

Groarke, Leo 69, 70, 75, 76, 78, 84, $85,86,87,89,90,101,102,103,109$, $111,112,113,114,115,116,117,118,119$, 120

Groarke, Louis 116

Grootendorst, Rob 56, 57

Guattari, Félix 82, 114

$\mathrm{H}$

Halliday, Michael 54 
Hamblin, Charles Leonard 37, 39, 41, $42,43,44,45,46,50,58,59,60,61$, 65,66

Hitler, Adolf 22, 53

Hodge, Robert 54

Hume, David 45

I

ideas 15

Ignoratio Elenchi 45, 52, 53

induction 45

instructions 28

intentions $40,41,42,43,61,65,66$, 126

J

Joseph 44

K

Kienpointner, Manfred 14, 24, 34, 56,57

Kleene, Stephen Cole 46

knowledge $38,40,41,42,57,65,66$, 70, 76, 78, 98, 109, 113

Koselleck 23

Kress, Guenther 14, 54, 99

Kruiger 56

Krzyzanowski, Michal 14, 17, 18, 21, $22,23,26$

$\mathrm{L}$

Lamham 56

language 22, 38, 39, 41, 42, 45, 54, 55, 59,90

Leuween, Theo 14, 54

Liebhart, Karin 13, 14

loci communes 30

$\operatorname{logic} 39,41,42,44,50,53,66$
M

macrohistory 48, 49

Mantegna, Andrea 116

Marat, Jean-Paul 106, 108, 115, 116,

$117,119,120,121$

meaning 29, 53, 60, 69, 70, 74, 76, 79,

$82,85,89,95,96,98,99,101,102$,

103, 107, 110, 111, 117, 123, 126

mental spaces 76,125

Meuffels 56

Meyer, Michael 13

microhistory 48, 49

Mill, John Stuart 46

multimodal analysis 70, 96

multimodal argumentation 95, 96, 99

multimodal meaning 95, 96

$\mathrm{N}$

Nagel 44, 46

natural frameworks 75

natural language 41, 42, 45, 59

Nirvana fallacy 52, 53

non-conventional signs 99, 101

0

Olbrechts-Tyteca, Lucie 23, 31, 32, 33

ordinary language 42

P

Peirce, Charles S. 74

Pelinka 21

Perelman, Chaim 23, 31, 32, 33

performativity 37,38

persuasion 43

Petitio Principii 46, 52

Poisoning the Well Fallacy 51

polyphonic 81

polyphony $80,81,125$ 
polysemy 125

Pontormo, Jacopo 116

pragmatic 41, 101

pragmatics 42

predicate $26,28,29$

proposition 26,53

Q

qualifier 34

$\mathrm{R}$

Rampton, Ben 114

reality $38,42,57,79,120,123,124$, 125,126

rebuttal 34

reconstruction 19, 20, 21, 31, 36, 126

reference 2O, 21, 4O, 42, 55, 65, 116

Reisigl, Martin 13, 14, 19, 21, 23, 55, 56, 57

relative $42,43,82,127$

rhetorical analysis 70

rhizomatic 82,84

rhizome 82, 83, 84, 114

rhizome theory 114

Richardson, John E. 14, 15, 16, 21

Rubinelli, Sara 24, 27, 28, 30, 31

rules 28

S

saying 29, 38, 39, 41, 63, 121

Schopenhauer, Arthur 44

Searle, John Rogers 41

Secundum Quid 45, 49, 52, 53, 59, 61 semantic frames 75

semantics 42,76

smoking fish 75, 104, 107, 109

social frameworks 75

speech 24, 26, 29, 37, 38, 42, 54, 56

speech act theory 37
Stalin, Josif 22

statements 15, 37, 40, 42, 58, 65

Straw-man fallacy 49, 52, 61, 62, 65

subject matter $27,28,29,30$

superdiversity $82,84,114$

superdiversity theory 114

syllogistic 21

symbolic indexicals 99, 101

$\mathrm{T}$

text analysis 21,35

the fallacy of hasty generalization 57 ,

$58,59,62,64,65$

topoi $9,13,14,15,16,17,18,19,20,21$,

$22,23,24,25,26,27,28,29,30,31$,

$32,33,34,36,54,55,57,62,63$

topos of difference 20, 21, 63

topos of history 20, 21, 62

topos of urgency 62

Toulmin, Stephen 14, 24, 33, 34, 35,

36

true $24,37,38,39,40,41,43,46,51$,

$52,53,65,66$

truth $38,39,40,41,42,43,44,66$

truth-conditions 42,43

Tseronis, Asimakis 80

U

Ulrich 56

universal 18, 24, 28, 42, 43

utterances $37,38,39,40,96$

UvA for Women 78, 105, 107, 112

V

valid 13, 41, 43, 44, 46, 48, 56

validity 41, 42, 66

verbal $47,57,70,71,74,76,86,87,90$, 95, 96, 99, 102, 103, 109, 111, 117, 122, 125 
Vertovec, Steven 84, 114

Vico, Giambattista 31

visual 9, 21, 69, 70, 71, 74, 75, 76, 78, $81,82,85,87,95,96,99,101,102$, $103,107,109,111,112,114,115,117$, 118, 125

visual argument 69, 70, 118

visual argumentation (VA) 9, 21, 69, 70, 71, 74, 82, 85, 95, 99, 101, 102, 103

W

warrants 14, 15, 31, 33, 34, 35

Weiss, Paul 20

Wittgenstein, Ludwig 74

Wodak, Ruth 13, 14, 15, 16, 17, 19, 20, $21,22,23,32,35,54,55,56,57,58$, 59, 60, 61, 63, 64, 65

Wyden, Rogier 116

¿

Žagar, Igor Ž. 13, 17, 20, 55, 101 
Igor Ž. Žagar

Four Critical Essays on Argumentation

Znanstvena monografija/Scientific Monograph

Digitalna knjižnica/Digital Library

Uredniški odbor/Editorial Board: Igor Ž. Žagar (Educational Research Institute \& University of Primorska), Jonatan Vinkler (University of Primorska), Janja Žmavc (Educational Research Institute), Alenka Gril (Educational Research Institute), Marcello Potocco (University of Primorska)

Dissertationes (znanstvene monografije/Scientific Monographs), 40 (ISSN 1855-9638)

Glavni in odgovorni urednik/Editor in chief: Igor Ž. Žagar

Recenzenta/Reviewers: Janja Žmavc, Tomaž Grušovnik

Oblikovanje, prelom in digitalna objava/Graphic Design, Typesetting and Digitalization:

Jonatan Vinkler

Lektorica/Proofreading: Vesna Koželj

Izdal/Publisher: Pedagoški inštitut

Gerbičeva 62, SI-1000 Ljubljana

Ljubljana 2021

Za izdajatelja/For publisher: Igor Ž. Žagar

ISBN 978-961-270-336-3 (pdf)

http://www.pei.si/ISBN/978-961-270-336-3.pdf

ISBN 978-961-270-337-0 (html)

http://www.pei.si/ISBN/978-961-270-337-0/index.html

DOl: https://www.doi.org/10.32320/978-961-270-336-3

(c) 2021 Pedagoški inštitut/Educational Research Institute

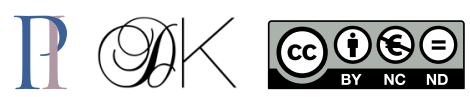





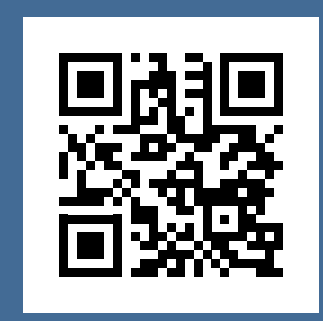

